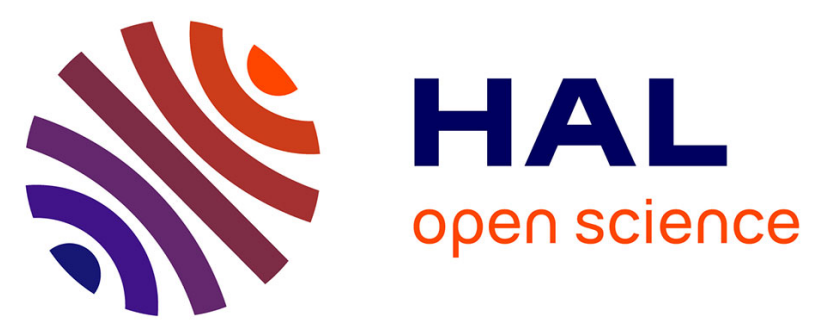

\title{
Atmospheric iodine, selenium and caesium depositions in France: II.Influence of forest canopies
}

Marine Roulier, Maïté Bueno, Frédéric Coppin, Manuel Nicolas, Yves Thiry, François Rigal, Isabelle Le Hécho, Florence Pannier

\section{To cite this version:}

Marine Roulier, Maïté Bueno, Frédéric Coppin, Manuel Nicolas, Yves Thiry, et al.. Atmospheric iodine, selenium and caesium depositions in France: II.Influence of forest canopies. Chemosphere, 2021, 273, pp.128952. 10.1016/j.chemosphere.2020.128952 . hal-03216018

\section{HAL Id: hal-03216018 \\ https://hal.science/hal-03216018}

Submitted on 30 Dec 2021

HAL is a multi-disciplinary open access archive for the deposit and dissemination of scientific research documents, whether they are published or not. The documents may come from teaching and research institutions in France or abroad, or from public or private research centers.
L'archive ouverte pluridisciplinaire $\mathbf{H A L}$, est destinée au dépôt et à la diffusion de documents scientifiques de niveau recherche, publiés ou non, émanant des établissements d'enseignement et de recherche français ou étrangers, des laboratoires publics ou privés.

\section{(ㅇ)(1) $\$$}

Distributed under a Creative Commons Attribution - NonCommercial - NoDerivatives| 4.0 


\section{Atmospheric iodine, selenium and caesium depositions in France: II. Influence of forest canopies}

Marine Roulier*a, b, Maïté Bueno ${ }^{\text {a }}$, Frédéric Coppin ${ }^{\mathrm{b}}$, Manuel Nicolas ${ }^{\mathrm{c}}$, Yves Thiry ${ }^{\mathrm{d}}$, François Rigal ${ }^{\text {as e }}$, Isabelle Le Hécho ${ }^{a}$ and Florence Pannier ${ }^{a}$.

*corresponding author

${ }^{a}$ CNRS/Univ. Pau \& Pays de 1'Adour/E2S UPPA, Institut des Sciences Analytiques et de Physico-Chimie pour 1'Environnement et les Matériaux, UMR 5254, Avenue du Président Angot, 64000 Pau, France (E-mail adresses : roulier.marine@univ-pau.fr; maite.bueno@univpau.fr; florence.pannier@univ-pau.fr; isabelle.lehecho@univ-pau.fr; francois.rigal@univpau.fr)

${ }^{\mathrm{b}}$ Institute of Radiological Protection and Nuclear Safety (IRSN), PSE-ENV/SRTE/LR2T, CE Cadarache, 13115 Saint Paul les Durance Cedex, France (E-mail adresses : frederic.coppin@irsn.fr)

${ }^{\mathrm{c}}$ Office National des Forêts (ONF), Direction forêts et risques naturels, Département recherche, développement, innovation, Boulevard de Constance, 77300 Fontainebleau, France (E-mail adress : manuel.nicolas@onf.fr)

${ }^{\mathrm{d}}$ Andra, Research and Development Division, Parc de la Croix Blanche, 1-7 rue Jean Monnet, 92298 Châtenay-Malabry Cedex, France (E-mail adress : yves.thiry@andra.fr)

e Azorean Biodiversity Group, cE3c - Centre for Ecology, Evolution and Environmental Changes, Angra do Heroísmo, Azores, Portugal 


\section{Graphical Abstract}

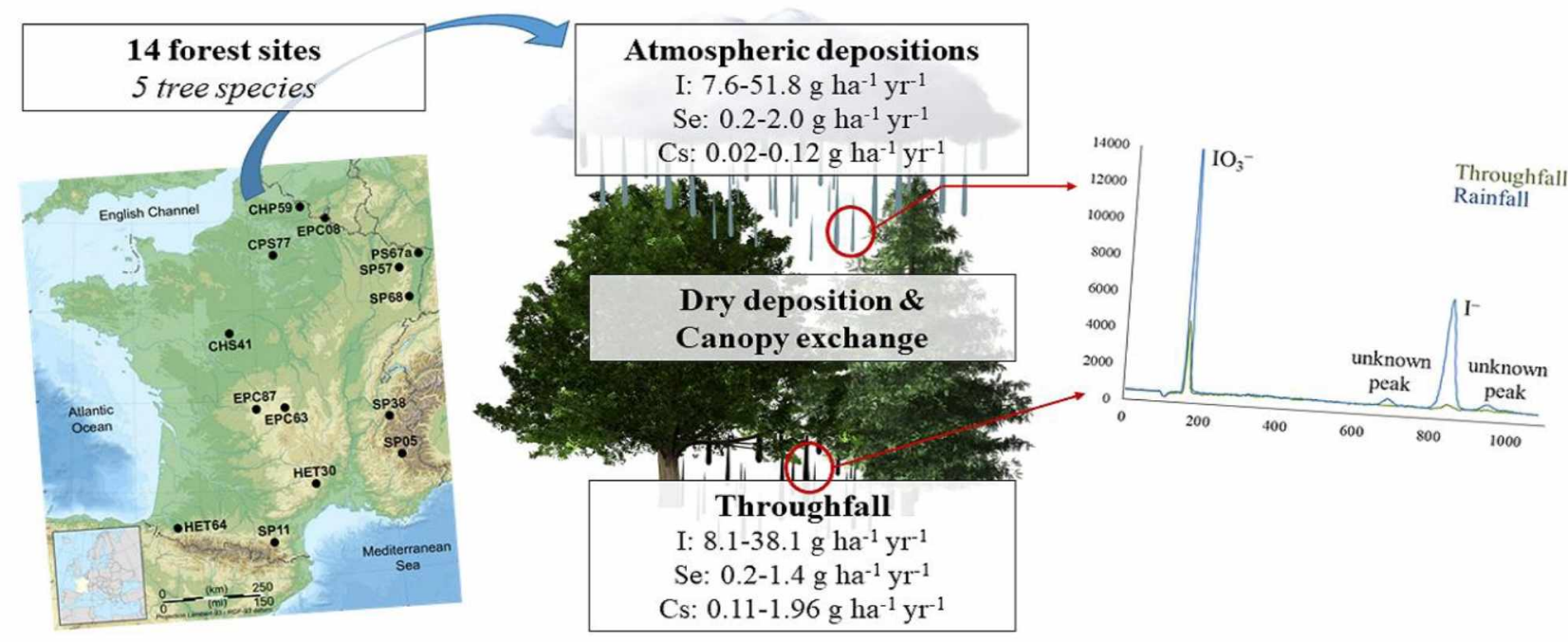

\section{Highlights:}

- Higher annual I, Se and Cs concentrations and fluxes in throughfall relative to rain

- Dry deposition contribution led to increased throughfall flux of I and Se

- Canopy budget model involved I and Se sorption by canopies

- Increase of annual flux of Cs in throughfall resulted mainly from canopy leaching

- Loss of inorganic I and Se species caused by forest canopy 


\begin{abstract}
Estimation of the canopy influence on atmospheric inputs of iodine (I), selenium (Se) and caesium (Cs) in terrestrial ecosystems is an essential condition for appropriate biogeochemical models. However, the processes involved in rain composition modifications after its passage through forest canopy have been barely studied for these elements. We monitored I, Se and $\mathrm{Cs}$ concentrations in both rainfall and throughfall of fourteen French forested sites throughout one year, and estimated dry deposition and canopy exchange fluxes for these elements, as well as speciation of I and Se. Comparison of rainfall and throughfall elemental composition highlighted an important impact of forest canopy on both (i) concentrations and fluxes of I, Se and Cs, and (ii) I and Se species. For the three elements, most of their throughfall concentrations were higher than corresponding rainfall. The increase of throughfall elemental fluxes was mostly due to dry deposition for I and Se although the canopy exchange model revealed some sorption within the canopy in most cases; for $\mathrm{Cs}$, foliage leaching was most influencing. Regarding speciation, iodine species in rainfall were highly modified by forest canopy with an important increase of unidentified I proportion in throughfall (on average 49 and $82 \%$ in rainfall and throughfall, respectively), possibly due to washoff of dry deposition and/or to transformation into organic forms. Similarly, while rainfall was composed of $26-54 \%$ of inorganic Se, inorganic species were undetectable in throughfall. This dataset represents key information to improve modelling of I, Se and Cs cycling within forest ecosystems.
\end{abstract}

Keywords: Iodine; Selenium; Caesium; Throughfall; Speciation; Forest tree species 


\section{Introduction}

Fluxes and speciation of atmospheric I, Se and Cs deposited in various terrestrial ecosystems are an essential baseline for understanding environmental conditions that control their persistence in soil and vegetation but their estimates still have large uncertainties. Forest ecosystems are particularly sensitive to atmospheric inputs because of, among others, the large interacting surface area of the forest canopy. The modification of the chemical composition of rain after its passage through the canopy (i.e. throughfall) results from various processes occurring in the phyllosphere: (i) direct absorption of elements and/or (ii) their release (leaching) by leaves or needles, (iii) accumulation then washoff of dry deposition (DD) and/or (iv) modification of physicochemical properties of rainfall leading to changes in element speciation (Lovett and Lindberg, 1984). Canopies could consequently influence the quantity and quality of water incoming to the forest floor. In order to evaluate canopy interaction with atmospheric inputs, the study of elemental compositions in both rainfall and throughfall is usually performed on major ions or nutrients (e.g. Adriaenssens et al., 2012; Staelens et al., 2008; Talkner et al., 2010). For example, it is generally assumed that the uptake or leaching of $\mathrm{Na}^{+}, \mathrm{Cl}^{-}$and $\mathrm{SO}_{4}{ }^{2-}$ by forest canopy is negligible (e.g. Adriaenssens et al., 2012; Lindberg et al. 1986; Talkner et al., 2010; Thimonier et al., 2008). Although enrichment of $\mathrm{Na}^{+}$in throughfall has been shown to be mainly due to the accumulation of dry deposition on the canopy, the main reason of this enrichment for $\mathrm{Cl}^{-}$and $\mathrm{SO}_{4}{ }^{2-}$ is still unclear. Indeed, some authors have shown that part of these ions in throughfall can originate from foliage leaching (e.g. Neary and Gizyn, 1994; Staelens et al. 2007); while $\mathrm{Cl}^{-}$and $\mathrm{SO}_{4}{ }^{2-}$ may also originate from dry deposition (e.g. Adriaenssens et al., 2012; Talkner et al., 2010). For potassium, many authors agreed on its canopy leaching (e.g. Adriaenssens et al., 2012; Berger et al., 2006; Pajuste et al., 2006; Talkner et al., 2010). In spite of their environmental interest, including the existence of their radionuclide analogues, the interaction of trace elements such as iodine and 
selenium with tree canopy have been barely studied. Indeed, to date, only five publications reported measurements of stable iodine in throughfall in U.K. (Neal et al., 2007), France (Roulier et al., 2018), Germany (Epp et al., 2020) and Japan (Takeda et al., 2016; Xu et al., 2016). Similarly, studies on Se canopy exchanges are scarce (Di Tullo, 2015; Tyler and Olsson, 2006). Due to the similarities in the chemistry (halogens and chalcogens) and atmospheric sources between $\mathrm{I}$ and $\mathrm{Cl}$, and, Se and $\mathrm{S}$, processes reported to act within the canopy for 1 and $\mathrm{S}$ may thus also affect fluxes and/or speciation of I and Se. More data are available for radiocaesium in rainfall and throughfall following Fukushima and Chernobyl accidents (e.g. Kato et al., 2017; Loffredo et al., 2015; Sombré et al., 1994; Yoschenko et al., 2018). As its chemical analogue potassium (e.g. Goor and Thiry, 2004; Varga et al., 2009), canopy leaching may thus act as the main process controlling Cs behaviour.

The persistence of iodine and selenium in terrestrial ecosystems depends on their incoming amounts but also on their speciation. In rain, the major inorganic iodine species are iodide $\left(\mathrm{I}^{-}\right)$and iodate $\left(\mathrm{IO}_{3}{ }^{-}\right)$, but iodine exists also as organic compounds (e.g. review of Fuge and Johnson, 2015). Similarly, selenium exists in several oxidation states, selenite $\left(\mathrm{SeO}_{3}{ }^{2-}\right)$ and selenate $\left(\mathrm{SeO}_{4}{ }^{2-}\right)$ being the major inorganic species detected in rainwaters (e.g. Alfthan et al., 1995; Cutter and Church, 1986; Floor et al., 2011; Robberecht et al., 1983; Suess et al., 2019). To date and to our knowledge, only $\mathrm{Xu}$ et al. (2016) provided information about iodine speciation in throughfall for a single Cedar site sampling; whereas Se speciation has never been surveyed in throughfall waters.

We reported in Part I. of this study the results of one year monitoring of $\mathrm{I}, \mathrm{Se}$ and $\mathrm{Cs}$ concentrations in rainfall at 27 forest sites all over France (Roulier et al., 2020). In this paper, Part II., 14 of these forest sites representative of various tree species (i.e. Oak, Beech, Spruce, Pine, Silver fir), and equipped for throughfall sampling, were monthly monitored in order to examine the interaction of iodine, selenium and caesium with tree canopies. Iodine and 
selenium speciation modification following canopy exchange was also investigated. The aim of this Part II. is to quantify atmospheric flux modifications induced by forest canopies for these trace species, and identify acting processes within the canopy leading to these changes.

\section{Material and methods}

\subsection{Study sites and sampling procedure}

The study sites and sampling procedure were already presented in Roulier et al., 2020. Briefly, sites are part of the French RENECOFOR network (i.e. National Network for the longterm Monitoring of Forest Ecosystem) managed by ONF (i.e. National Forest Board) (www.onf.fr/renecofor). They are representative of five temperate forest species: Oak (CHP: Pedunculate Oak; CHS: Sessile Oak; CPS: Pedunculate/Sessile Oak), Spruce (EPC), Beech (HET), Scots Pines (PS) and Silver Fir (SP); and four climates: oceanic, transition, continental and mountainous (Figure 1 and SI Table S1). Fourteen sites are equipped with weather stations to sample both rainfall and throughfall waters. Rainfall and throughfall were weekly collected from September 2016 to September 2017 with bulk collectors (including dry deposition). Stemflow being not collected at these sites, it was thus not considered in this study. Composite samples per 28 days period were analysed (weight pondered average sample from the 4 weekly

collected samples). The monthly basis composites were not acidified to prevent losses of I by volatilization and stored in the dark at $4^{\circ} \mathrm{C}$ after filtration at $0.45 \mu \mathrm{m}$ (cellulose nitrate membrane filters). Hereafter, the four seasons were defined as follows: September 2016 to November 2016 and September 2017 (Autumn), December 2016 to February 2017 (Winter), March 2017 to May 2017 (Spring), and June 2017 to August 2017 (Summer). 


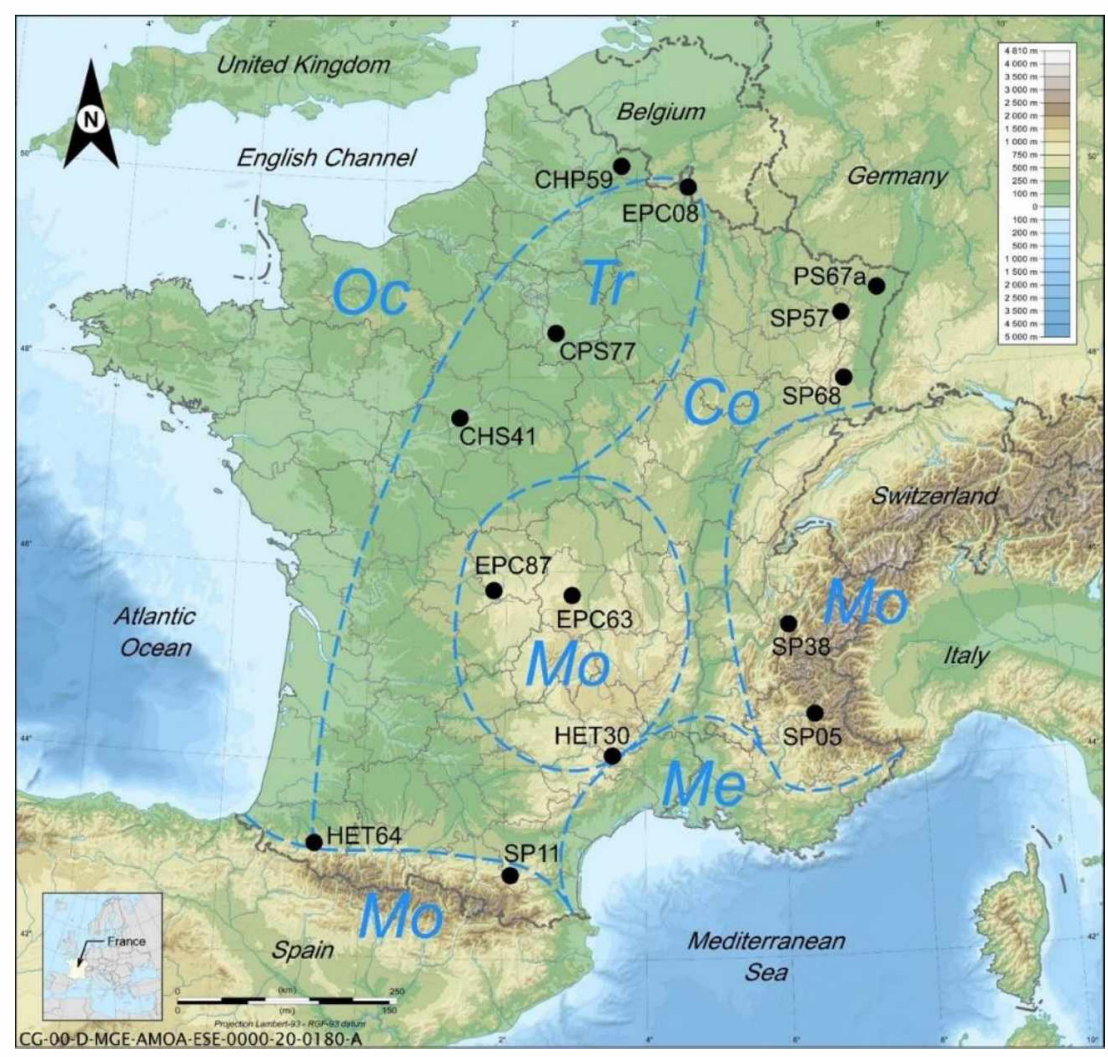

Figure 1. French climates and studied sites in the French RENECOFOR network $(n=14)$. Oc:

Oceanic; Tr: Transition; Co: Continental; Mo: Mountainous; Me: Mediterranean; $\mathrm{CHP}=$ Pedunculate Oak; CHS=Sessile Oak; CPS=Sessile/Ped. Oak; EPC=Spruce; HET $=$ Beech; PS=Scots Pine; $\mathrm{SP}=$ Silver fir. Base map: Eric Gaba (https://commons.wikimedia.org/w/index.php?curid=4899458).

\subsection{Chemical analyses of rainfall and throughfall waters}

The chemical analyses of waters for $\mathrm{pH}$, dissolved organic carbon (DOC) and concentrations of $\mathrm{Na}$ (used to estimate dry deposition), $\mathrm{K}$ (analogue of $\mathrm{Cs}$ ), I, Se and Cs were already detailed in Roulier et al. (2020). Briefly, Na and K were analyzed by ICP-AES with quantification limits of 0.01 and $0.05 \mathrm{mg} \mathrm{L}^{-1}$, respectively. Total soluble concentrations of I, Se and Cs were measured by inductively coupled plasma mass spectrometry (ICP-MS) (I and Cs: Agilent 7500ce; Se: Agilent 7900, Agilent Technologies, Japan). Quantification limits (I: $0.04 \mu \mathrm{g} \mathrm{L}{ }^{-1}$; Cs: $0.6 \mathrm{ng} \mathrm{L}^{-1}$, Se: $2 \mathrm{ng} \mathrm{L}^{-1}$ ) were obtained from external calibrations in ultrapure water with analytical precision $<5 \%$. An Agilent 1200 series HPLC pump was coupled to ICPMS (Agilent 7900) for speciation analyses of iodine (iodide $\mathrm{I}^{-}$and iodate $\mathrm{IO}_{3}{ }^{-}$) and selenium 
(selenite $\mathrm{SeO}_{3}{ }^{2-}$ and selenate $\mathrm{SeO}_{4}{ }^{2-}$ ). Chromatographic separation was carried out with a mobile phase of ammonium nitrate delivered at $1 \mathrm{~mL} \mathrm{~min}^{-1}$ flow rate (Agilent G3154-65001 column and G3154-65002 guard column, Agilent Technologies, Japan; 20 mmol L ${ }^{-1} \mathrm{NH}_{4} \mathrm{NO}_{3}$, $2.5 \% \mathrm{MeOH}, \mathrm{pH} 8.5)$. This method has quantification limits of $5\left(\mathrm{I}^{-\mathrm{IO}_{3}}{ }^{-}\right.$and $\left.\mathrm{Se}_{-} \mathrm{SeO}_{4}{ }^{2-}\right)$ and 10 $n g \mathrm{~L}^{-1}\left(\mathrm{I}^{-}\right.$and $\left.\mathrm{Se}_{-} \mathrm{SeO}_{3}{ }^{2-}\right)$. The unidentified fraction (denoted "other" iodine and selenium: $\mathrm{I}_{\mathrm{t} \text { ther }}$ and $\mathrm{Se}_{\text {other, }}$ respectively) was calculated as the difference between total and inorganic species concentrations (i.e. $\mathrm{I}_{\mathrm{other}}=\mathrm{I}-\left(\mathrm{I}^{-}+\mathrm{IO}_{3}{ }^{-}\right)$and $\left.\mathrm{Se}_{\text {other }}=\mathrm{Se}-\left(\mathrm{SeO}_{3}{ }^{2-}+\mathrm{SeO}_{4}{ }^{2-}\right)\right)$, and was always larger than zero.

\subsection{Calculation and data analysis}

\subsubsection{Methods for calculation}

According to Aussenac (1968), the amount of water reaching the forest floor (i.e. throughfall + stemflow) is generally less than the amount of water received in the field (i.e. rainfall). Several factors influence this interception, such as rainfall intensity, direct evaporation from crowns, foliage uptake and saturation capacity according to forest species, degree of tree defoliation and stand density (Ulrich et al., 1995). In our study, without stemflow collection, this interception was calculated as follow (Equation 1) with throughfall and rainfall water fluxes considered for the same time period (monthly or yearly basis):

$$
\text { Interception }(\%)=\left(1-\frac{\text { throughfall water flux }}{\text { rainfall water flux }}\right) \times 100
$$

To take into account the influence of sample volume on concentrations, the annual volume-weighted mean (AVWM) concentrations were calculated from elemental or species concentrations $\left(c_{i} ; \mu \mathrm{g} \mathrm{L}^{-1}\right)$ and the volume $\left(V_{i} ; \mathrm{mm}\right)$ of monthly basis composite samples for the analysed time period (13 periods of 28-days) as follow (Equation 2):

$$
\mathrm{AVWM}=\frac{\Sigma_{i}\left(c_{i} \times V_{i}\right)}{\sum_{i} V_{i}}
$$


Rainfall (RF) and throughfall (TF) annual elemental fluxes $\left(\mathrm{g} \mathrm{ha}^{-1} \mathrm{yr}^{-1}\right)$ were calculated as the sum of monthly elemental concentrations in waters multiplied by their corresponding monthly water fluxes (provided by ONF-RENECOFOR). The net throughfall flux (NTF; $\mathrm{g} \mathrm{ha}^{-1}$ $\mathrm{yr}^{-1}$ ) was calculated as the difference between throughfall and rainfall fluxes. Since rainfall was collected with bulk collectors, including thus dry deposition, the NTF could be underestimated.

\subsubsection{Concentration Ratios and Enrichment Factors}

In order to compare elemental composition in throughfall and rainfall, the concentration ratios of the considered element (i.e. $\mathrm{Na}, \mathrm{I}, \mathrm{Se}$ and $\mathrm{Cs}$ ) were determined from their AVWM concentrations (CR, Equation 3) as follow:

$$
\mathrm{CR}(\mathrm{i})=\frac{[\mathrm{i}]_{\text {throughfall }}}{[\mathrm{i}]_{\text {rainfall }}}
$$

Where: i: considered element; [i]: AVWM elemental concentration $\left(\mu \mathrm{g} \mathrm{L}^{-1}\right)$.

In order to determine elemental enrichment in throughfall compared to rainfall, the enrichment factors of considered element (i.e. $\mathrm{Na}$, I, Se and $\mathrm{Cs}$ ) were determined from their RF and TF annual fluxes (EF, Equation 4) as follow:

$$
\mathrm{EF}(\mathrm{i})=\frac{\mathrm{TF}(\mathrm{i})}{\mathrm{RF}(\mathrm{i})}
$$

Where: i: considered element; TF and RF: rainfall and throughfall elemental fluxes $\left(\mathrm{g} \mathrm{ha}^{-1} \mathrm{yr}^{-1}\right)$.

\subsubsection{Canopy budget model}

Interaction of the forest canopy with atmospheric inputs induces modification of the chemical composition of the rains under forest canopy (e.g. Adriaenssens et al., 2012; Gandois et al., 2010). In addition to wet deposition crossing the canopy, dry deposition (e.g. particles and adsorbed gases) could accumulate on the canopy and be further washed off. Moreover, an element can interact with the canopy (canopy exchange processes (CE)) including either 
absorption $(\mathrm{CE}<0)$ or leaching $(\mathrm{CE}>0)$ of the element by the canopy. In the present study, dry deposition washed off by throughfall $\left(\mathrm{DD}_{\mathrm{TF}}\right)$ and canopy exchange fluxes were calculated with the canopy budget model (Staelens et al., 2008; Talkner et al., 2010). This model simulates the interaction of ions with forest canopy based on throughfall and rainfall measurements with the aim to distinguish relative importance of $\mathrm{DD}_{\mathrm{TF}}$ and $\mathrm{CE}$ in their NTF fluxes (Equation 5).

$$
\mathrm{NTF}=\mathrm{TF}-\mathrm{RF}=\mathrm{DD}_{\mathrm{TF}}+\mathrm{CE}
$$

In the model, if element canopy exchange is assumed nil, the calculated $\mathrm{DD}_{\mathrm{TF}}$ equals NTF flux (Staelens et al., 2008). Direct measurement of dry deposition is quite impossible in forest ecosystems because of the complexity of the forest canopy area, hence their estimation is done through the "filtering approach" using sodium as an inert reference ion (Adriaenssens et al., 2012; Staelens et al., 2008; Ulrich, 1983). Indeed, as no interaction of Na with canopy (low uptake and leaching by tree) is supposed, its NTF is only due to dry deposition. In this approach, particles and aerosols containing sodium and considered elements are assumed to be deposited with the same efficiency onto the forest canopy. Therefore, the dry deposition of an element washed off by throughfall (DD $\mathrm{DF}_{\mathrm{T}}(\mathrm{i}) ; \mathrm{g} \mathrm{ha}^{-1} \mathrm{yr}^{-1}$ ) was calculated using Equation 6:

$$
\mathrm{DD}_{\mathrm{TF}}(\mathrm{i})=\mathrm{RF}(\mathrm{i}) \times \frac{\mathrm{NTF}(\mathrm{Na})}{\mathrm{RF}(\mathrm{Na})}
$$

Where: RF(i): rainfall element flux $\left(\mathrm{g} \mathrm{ha}^{-1} \mathrm{yr}^{-1}\right)$; $\mathrm{NTF}(\mathrm{Na})$ : net throughfall Na flux $\left(\mathrm{g} \mathrm{ha}^{-1} \mathrm{yr}^{-1}\right)$ and $\mathrm{RF}(\mathrm{Na})$ : rainfall $\mathrm{Na}$ flux $\left(\mathrm{g} \mathrm{ha}^{-1} \mathrm{yr}^{-1}\right)$. 


\subsubsection{Statistical analyses}

Prior to the statistical analyses, data normality was evaluated using Shapiro-Wilk test. When normality was fulfilled, relationships between pairs of continuous variables (i.e. water interception; rainfall and throughfall amounts; NTF of Na, I, Se and Cs; CR, DD and CE of I, Se and Cs) were tested with Pearson's correlations. When normality was not met, Spearman's correlations were performed. Given the small number of sites per tree species (Oak, $n=3$; Beech, $\mathrm{n}=2$; Spruce, $\mathrm{n}=3$; Scots Pines, $\mathrm{n}=1$; Silver Fir, $\mathrm{n}=5$ ), statistical analyses were restricted to the comparison between the two functional tree types namely deciduous (Oak and Beech; $n=5$ ) and coniferous (Spruce, Scots Pines and Silver Fir; $n=9$ ). Hence, comparison between functional tree types were performed using Two-Samples Wilcoxon tests. A KruskalWallis test was performed between NTF of Na and the climate type (the only oceanic site was grouped with transition sites: transition, $n=5$; continental, $n=3$; mountainous, $n=6$ ). Statistical analyses were performed using the R programming environment ( $\mathrm{R}$ Core Team, 2013, version 3.4.3). Simple linear regressions were performed using Excel software. 


\section{Results and discussion}

Detailed data of (a) annual water amount, annual $\mathrm{pH}$ mean, AVWM DOC, $\mathrm{Na}$ and $\mathrm{K}$ concentrations, (b) AVWM total I, Se and Cs concentrations, and I and Se species proportions in RF and TF, (c) monthly water amount and $\mathrm{I}, \mathrm{Se}, \mathrm{Cs}, \mathrm{Na}$ and $\mathrm{K}$ concentrations in RF and TF for the 14-studied sites are available in SI Tables S2 to Table S9.

\subsection{Impact of the canopy on rainfall water fluxes and their physicochemical properties}

On an annual basis, the throughfall amount represented between 44 and $86 \%$ of the rainfall amount (SI Figure S1), with no difference between functional tree types (Wilcoxon test, $p=0.364$ ). These results correspond to average values reported for temperate French forests (Aussenac, 1968; Gandois et al., 2010; Ulrich et al., 1995). For deciduous trees, the intensity of interception seemed not different according to seasons considering uncertainties (SI Figure S2). Only the beech HET64 site showed lower interception in spring-summer than autumn-winter seasons $\left(R^{2}=0.91\right.$ and 0.97 , slopes of regression lines $T F$ versus $R F=0.71 \pm 0.03$ and $0.59 \pm$ 0.02 , respectively).

Rainfall and throughfall $\mathrm{pH}$ values were mostly acidic, with mean annual values of 6.0 \pm 0.5 and $6.2 \pm 0.5$, respectively (SI Table S2). Dissolved organic carbon (DOC) concentrations in rainfall were very low (AVWM median $=0.40 \mathrm{mg} \mathrm{L}^{-1}$ ), while they were much higher in throughfall $\left(\mathrm{AVWM}\right.$ median $\left.=16 \mathrm{mg} \mathrm{L}^{-1}\right)$ in agreement with literature (Gandois et al., 2010; Karavoltsos et al., 2017). Indeed, dissolved organic carbon in throughfall comes from foliar or needles leaching and microbiological activities in the phyllosphere as well as from soluble organic deposits washed off from the canopy surface (Mellec et al., 2010; Michalzik et al., 2001). 


\subsection{Impact of canopies on content and/or speciation of iodine, selenium and caesium atmospheric inputs}

\subsubsection{Sodium: indicator of dry deposition accumulated on canopies}

Sodium was a major element in rainfall with AVWM concentrations ranging from 0.20 to $0.82 \mathrm{mg} \mathrm{L}^{-1}$ (SI Table S2; median $=0.34 \mathrm{mg} \mathrm{L}^{-1}$ ). In throughfall, AVWM Na concentrations were higher than in corresponding rainfall (range and median $=0.29-1.65$ and $1.08 \mathrm{mg} \mathrm{L}^{-1}$, respectively), with concentration ratios ranging from 1.2 to 4.5 (SI Table S2). Throughfall Na concentrations led to annual fluxes from $\sim 2.4$ to $15.5 \mathrm{~kg} \mathrm{ha}^{-1} \mathrm{yr}^{-1}$ (Table 1 ; median $=5.2 \mathrm{~kg} \mathrm{ha}$ ${ }^{1} \mathrm{yr}^{-1}$ ), generally superior to rainfall ones (Figure $2(a)$, EF(Na) mean $=1.78$ ) with the exception of sites HET30 and SP38 whose TF were not significantly different from RF. Sodium enrichments in throughfall obtained from annual fluxes were confirmed by comparison of monthly TF and RF fluxes (SI Figure S3 and Figure S4) that showed TF enrichment can occur throughout the year. Since sodium is considered to be hardly taken up and leached by trees, exchange of this element with canopy is assumed to be negligible, thus its net throughfall is expected to equal its dry deposition (Adriaenssens et al., 2012; Gandois et al., 2010; Staelens et al., 2008; Talkner et al., 2010). Therefore, sites with high $\mathrm{NTF}(\mathrm{Na})$ are especially influenced by dry deposition. Hence, for our study period, the sites EPC08, EPC63 and SP11 were highly impacted by dry deposition (Table 1) compared to the sites HET30, SP05, SP38 and SP68 with low dry deposition fluxes $\left(\mathrm{NTF}(\mathrm{Na})<1 \mathrm{~kg} \mathrm{ha}^{-1} \mathrm{yr}^{-1}\right)$. Although conifers are generally more efficient in trapping dry deposition than deciduous trees because of their aerodynamic properties and constant leaf area throughout the year (Bergkvist et al., 1989), in our study sodium enrichment (and thus the dry deposition flux) did not solely depend on functional tree types (Wilcoxon test, $p=0.699$ ). Furthermore, rainfall amount can impact dry deposition by their washing-off from canopy, but here no link between $\mathrm{NTF}(\mathrm{Na})$ and RF amount was found (Spearman's correlation, $p=0.492$ ). Moreover, $\mathrm{NTF}(\mathrm{Na})$ did not correlate neither with TF amount nor interception (Spearman's correlation, $p=0.952$ and 0.916 , respectively). The 
influence of marine aerosol input on sodium NTF was tested according to climate type and no link was found (Kruskal-Wallis test, $p=0.693$ ). However, these different dry deposition fluxes in the various sites could be explained by numerous other factors (e.g. canopy structure, tree density in the stand, surface wetness chemistry, local meteorology; Adriaenssens et al., 2012; Gandois et al., 2010), that could not be tested based on the current data set.
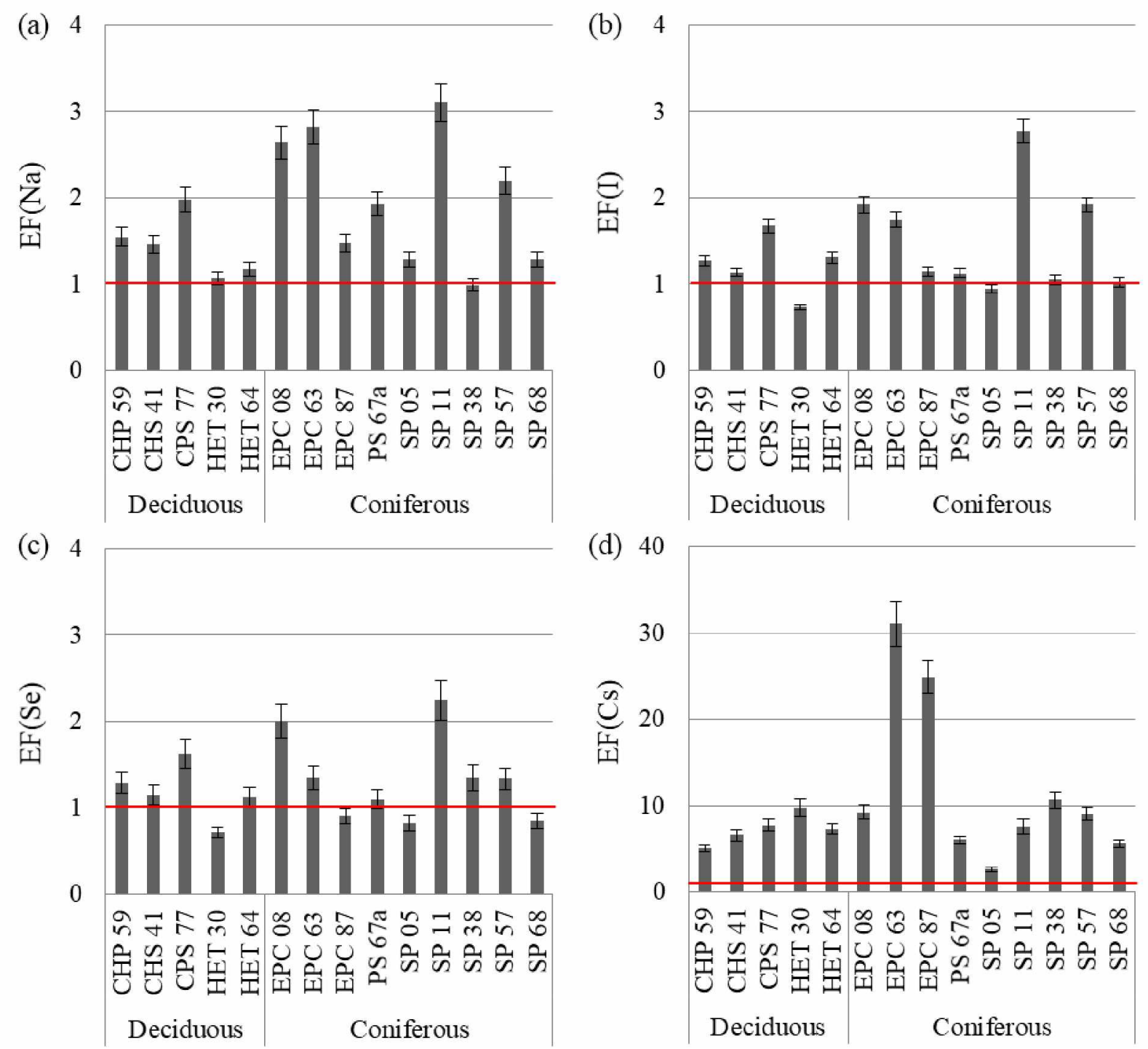

Figure 2. Enrichment Factors (EF) from rainfall and throughfall annual fluxes of (a) $\mathrm{Na}$, (b) I,

(c) Se and (d) Cs. Error bars based on error propagation of annual fluxes in rainfall and throughfall. Red lines correspond to EF equal to one. CHP: Pedunculate Oak; CHS: Sessile Oak; CPS: Pedunculate/Sessile Oak; HET: Beech; EPC: Spruce; PS: Scots Pines; SP: Silver Fir. 
Table 1. Annual values and associated error of rainfall (RF), throughfall (TF), net throughfall (NTF), dry deposition washed off by throughfall (DDTF) and canopy exchange (CE) fluxes of $\mathrm{Na}, \mathrm{I}, \mathrm{Se}$ and $\mathrm{Cs}$ on the fourteen studied sites.

\begin{tabular}{|c|c|c|c|c|c|}
\hline & & $\begin{array}{c}\mathrm{Na} \\
\left(\mathrm{kg} \mathrm{ha}^{-1} \mathrm{yr}^{-1}\right)\end{array}$ & $\begin{array}{c}\mathrm{I} \\
\left(\mathrm{g} \mathrm{ha}^{-1} \mathrm{yr}^{-1}\right)\end{array}$ & $\begin{array}{c}\mathrm{Se} \\
\left(\mathrm{g} \mathrm{ha}^{-1} \mathrm{yr}^{-1}\right)\end{array}$ & $\begin{array}{c}\mathrm{Cs} \\
\left(\mathrm{g} \mathrm{ha}^{-1} \mathrm{yr}^{-1}\right)\end{array}$ \\
\hline \multirow{5}{*}{$\begin{array}{c}\mathrm{CHP} \\
59\end{array}$} & $\mathrm{RF}$ & $3.6 \pm 0.2$ & $9.9 \pm 0.4$ & $0.34 \pm 0.02$ & $0.042 \pm 0.003$ \\
\hline & $\mathrm{TF}$ & $5.5 \pm 0.3$ & $12.7 \pm 0.4$ & $0.43 \pm 0.03$ & $0.21 \pm 0.01$ \\
\hline & $\mathrm{NTF}$ & $1.9 \pm 0.3$ & $2.7 \pm 0.5$ & $0.10 \pm 0.04$ & $0.17 \pm 0.01$ \\
\hline & $\mathrm{DD}_{\mathrm{TF}}$ & & $5.4 \pm 1.0$ & $0.18 \pm 0.03$ & $0.023 \pm 0.004$ \\
\hline & $\mathrm{CE}$ & & $-2.7 \pm 1.1$ & $-0.09 \pm 0.05$ & $0.15 \pm 0.01$ \\
\hline \multirow{5}{*}{$\begin{array}{c}\text { CHS } \\
41\end{array}$} & $\mathrm{RF}$ & $3.2 \pm 0.2$ & $10.2 \pm 0.4$ & $0.28 \pm 0.02$ & $0.031 \pm 0.002$ \\
\hline & $\mathrm{TF}$ & $4.7 \pm 0.2$ & $11.6 \pm 0.3$ & $0.32 \pm 0.02$ & $0.20 \pm 0.01$ \\
\hline & NTF & $1.5 \pm 0.3$ & $1.4 \pm 0.5$ & $0.04 \pm 0.03$ & $0.17 \pm 0.01$ \\
\hline & $\mathrm{DD}_{\mathrm{TF}}$ & & $4.7 \pm 1.0$ & $0.13 \pm 0.03$ & $0.014 \pm 0.003$ \\
\hline & $\mathrm{CE}$ & & $-3.4 \pm 1.1$ & $-0.09 \pm 0.04$ & $0.16 \pm 0.01$ \\
\hline \multirow{5}{*}{$\begin{array}{c}\text { CPS } \\
77\end{array}$} & $\mathrm{RF}$ & $2.1 \pm 0.1$ & $8.2 \pm 0.3$ & $0.25 \pm 0.02$ & $0.028 \pm 0.002$ \\
\hline & $\mathrm{TF}$ & $4.2 \pm 0.2$ & $13.8 \pm 0.3$ & $0.40 \pm 0.03$ & $0.21 \pm 0.01$ \\
\hline & NTF & $2.1 \pm 0.2$ & $5.5 \pm 0.5$ & $0.15 \pm 0.04$ & $0.19 \pm 0.01$ \\
\hline & $\mathrm{DD}_{\mathrm{TF}}$ & & $8.1 \pm 1.0$ & $0.24 \pm 0.03$ & $0.027 \pm 0.004$ \\
\hline & $\mathrm{CE}$ & & $-2.5 \pm 1.1$ & $-0.09 \pm 0.05$ & $0.16 \pm 0.01$ \\
\hline \multirow{5}{*}{$\begin{array}{c}\text { EPC } \\
08\end{array}$} & $\mathrm{RF}$ & $3.9 \pm 0.2$ & $12.5 \pm 0.5$ & $0.50 \pm 0.03$ & $0.048 \pm 0.004$ \\
\hline & $\mathrm{TF}$ & $10.3 \pm 0.5$ & $24.0 \pm 0.7$ & $1.01 \pm 0.08$ & $0.44 \pm 0.02$ \\
\hline & NTF & $6.4 \pm 0.5$ & $11.5 \pm 0.8$ & $0.50 \pm 0.08$ & $0.40 \pm 0.02$ \\
\hline & $\mathrm{DD}_{\mathrm{TF}}$ & & $20.5 \pm 2.2$ & $0.82 \pm 0.10$ & $0.08 \pm 0.01$ \\
\hline & $\mathrm{CE}$ & & $-9.0 \pm 2.3$ & $-0.32 \pm 0.13$ & $0.32 \pm 0.02$ \\
\hline \multirow{5}{*}{$\begin{array}{c}\mathrm{EPC} \\
63\end{array}$} & $\mathrm{RF}$ & $2.6 \pm 0.1$ & $9.9 \pm 0.4$ & $0.28 \pm 0.02$ & $0.063 \pm 0.004$ \\
\hline & $\mathrm{TF}$ & $7.4 \pm 0.4$ & $17.3 \pm 0.5$ & $0.38 \pm 0.03$ & $1.96 \pm 0.09$ \\
\hline & NTF & $4.7 \pm 0.4$ & $7.4 \pm 0.7$ & $0.10 \pm 0.03$ & $1.89 \pm 0.09$ \\
\hline & $\mathrm{DD}_{\mathrm{TF}}$ & & $18.0 \pm 1.9$ & $0.51 \pm 0.06$ & $0.11 \pm 0.01$ \\
\hline & $\mathrm{CE}$ & & $-10.6 \pm 2.0$ & $-0.41 \pm 0.07$ & $1.78 \pm 0.09$ \\
\hline \multirow{5}{*}{$\begin{array}{c}\text { EPC } \\
87\end{array}$} & $\mathrm{RF}$ & $6.4 \pm 0.3$ & $16.4 \pm 0.7$ & $0.46 \pm 0.03$ & $0.075 \pm 0.005$ \\
\hline & $\mathrm{TF}$ & $9.5 \pm 0.5$ & $18.8 \pm 0.5$ & $0.42 \pm 0.03$ & $1.87 \pm 0.08$ \\
\hline & $\mathrm{NTF}$ & $3.1 \pm 0.6$ & $2.4 \pm 0.8$ & $-0.04 \pm 0.04$ & $1.80 \pm 0.08$ \\
\hline & $\mathrm{DD}_{\mathrm{TF}}$ & & $7.8 \pm 1.5$ & $0.22 \pm 0.05$ & $0.04 \pm 0.01$ \\
\hline & $\mathrm{CE}$ & & $-5.4 \pm 1.8$ & $-0.26 \pm 0.06$ & $1.76 \pm 0.08$ \\
\hline \multirow{5}{*}{$\begin{array}{c}\text { HET } \\
30\end{array}$} & $\mathrm{RF}$ & $14.6 \pm 0.7$ & $51.8 \pm 1.5$ & $2.01 \pm 0.10$ & $0.12 \pm 0.01$ \\
\hline & $\mathrm{TF}$ & $15.5 \pm 0.8$ & $38.1 \pm 1.1$ & $1.45 \pm 0.10$ & $1.16 \pm 0.06$ \\
\hline & NTF & $0.9 \pm 1.1$ & $-13.7 \pm 1.9$ & $-0.57 \pm 0.14$ & $1.04 \pm 0.06$ \\
\hline & $\mathrm{DD}_{\mathrm{TF}}$ & & $3.2 \pm 3.8$ & $0.12 \pm 0.15$ & $0.01 \pm 0.01$ \\
\hline & $\mathrm{CE}$ & & $-16.9 \pm 4.2$ & $-0.69 \pm 0.20$ & $1.03 \pm 0.06$ \\
\hline
\end{tabular}




\begin{tabular}{|c|c|c|c|c|c|}
\hline \multirow{5}{*}{$\begin{array}{c}\text { HET } \\
64\end{array}$} & $\mathrm{RF}$ & $11.1 \pm 0.6$ & $27.1 \pm 1.1$ & $0.70 \pm 0.05$ & $0.045 \pm 0.003$ \\
\hline & $\mathrm{TF}$ & $13.1 \pm 0.7$ & $35.4 \pm 0.9$ & $0.78 \pm 0.06$ & $0.33 \pm 0.02$ \\
\hline & NTF & $1.9 \pm 0.9$ & $8.3 \pm 1.4$ & $0.08 \pm 0.08$ & $0.28 \pm 0.02$ \\
\hline & $\mathrm{DD}_{\mathrm{TF}}$ & & $4.7 \pm 2.1$ & $0.12 \pm 0.05$ & $0.008 \pm 0.004$ \\
\hline & $\mathrm{CE}$ & & $3.6 \pm 2.5$ & $-0.04 \pm 0.09$ & $0.28 \pm 0.02$ \\
\hline \multirow{5}{*}{ PS67a } & $\mathrm{RF}$ & $1.6 \pm 0.1$ & $7.6 \pm 0.3$ & $0.31 \pm 0.02$ & $0.043 \pm 0.002$ \\
\hline & $\mathrm{TF}$ & $3.1 \pm 0.2$ & $8.6 \pm 0.3$ & $0.34 \pm 0.02$ & $0.26 \pm 0.01$ \\
\hline & NTF & $1.5 \pm 0.2$ & $1.0 \pm 0.4$ & $0.03 \pm 0.03$ & $0.22 \pm 0.01$ \\
\hline & $\mathrm{DD}_{\mathrm{TF}}$ & & $7.1 \pm 0.9$ & $0.28 \pm 0.04$ & $0.04 \pm 0.01$ \\
\hline & $\mathrm{CE}$ & & $-6.1 \pm 1.0$ & $-0.25 \pm 0.05$ & $0.18 \pm 0.01$ \\
\hline \multirow{5}{*}{ SP 05} & $\mathrm{RF}$ & $2.0 \pm 0.1$ & $12.4 \pm 0.5$ & $0.24 \pm 0.02$ & $0.042 \pm 0.004$ \\
\hline & $\mathrm{TF}$ & $2.6 \pm 0.1$ & $11.5 \pm 0.3$ & $0.20 \pm 0.01$ & $0.11 \pm 0.01$ \\
\hline & NTF & $0.6 \pm 0.2$ & $-0.9 \pm 0.6$ & $-0.04 \pm 0.02$ & $0.07 \pm 0.01$ \\
\hline & $\mathrm{DD}_{\mathrm{TF}}$ & & $3.6 \pm 1.0$ & $0.07 \pm 0.02$ & $0.012 \pm 0.004$ \\
\hline & $\mathrm{CE}$ & & $-4.5 \pm 1.2$ & $-0.11 \pm 0.03$ & $0.06 \pm 0.01$ \\
\hline \multirow{5}{*}{ SP 11} & $\mathrm{RF}$ & $3.5 \pm 0.2$ & $11.7 \pm 0.5$ & $0.31 \pm 0.02$ & $0.022 \pm 0.002$ \\
\hline & $\mathrm{TF}$ & $10.8 \pm 0.5$ & $32.4 \pm 0.9$ & $0.70 \pm 0.05$ & $0.16 \pm 0.01$ \\
\hline & NTF & $7.3 \pm 0.6$ & $20.7 \pm 1.0$ & $0.39 \pm 0.06$ & $0.14 \pm 0.01$ \\
\hline & $\mathrm{DD}_{\mathrm{TF}}$ & & $24.6 \pm 2.5$ & $0.65 \pm 0.08$ & $0.05 \pm 0.01$ \\
\hline & $\mathrm{CE}$ & & $-3.9 \pm 2.7$ & $-0.27 \pm 0.09$ & $0.10 \pm 0.01$ \\
\hline \multirow{5}{*}{ SP 38} & $\mathrm{RF}$ & $2.7 \pm 0.1$ & $12.3 \pm 0.5$ & $0.41 \pm 0.03$ & $0.07 \pm 0.01$ \\
\hline & $\mathrm{TF}$ & $2.7 \pm 0.1$ & $12.9 \pm 0.4$ & $0.55 \pm 0.04$ & $0.75 \pm 0.03$ \\
\hline & NTF & $0.0 \pm 0.2$ & $0.6 \pm 0.6$ & $0.14 \pm 0.05$ & $0.68 \pm 0.03$ \\
\hline & $\mathrm{DD}_{\mathrm{TF}}$ & & $0.0 \pm 0.0$ & $0.0 \pm 0.0$ & $0.0 \pm 0.0$ \\
\hline & $\mathrm{CE}$ & & $0.6 \pm 0.6$ & $0.14 \pm 0.05$ & $0.68 \pm 0.03$ \\
\hline \multirow{5}{*}{ SP 57} & $\mathrm{RF}$ & $2.3 \pm 0.1$ & $10.8 \pm 0.4$ & $0.45 \pm 0.03$ & $0.077 \pm 0.005$ \\
\hline & $\mathrm{TF}$ & $5.0 \pm 0.2$ & $20.7 \pm 0.4$ & $0.60 \pm 0.04$ & $0.70 \pm 0.03$ \\
\hline & NTF & $2.7 \pm 0.3$ & $9.9 \pm 0.6$ & $0.15 \pm 0.05$ & $0.62 \pm 0.03$ \\
\hline & $\mathrm{DD}_{\mathrm{TF}}$ & & $12.9 \pm 1.5$ & $0.54 \pm 0.07$ & $0.09 \pm 0.01$ \\
\hline & $\mathrm{CE}$ & & $-3.0 \pm 1.6$ & $-0.39 \pm 0.08$ & $0.53 \pm 0.03$ \\
\hline \multirow{5}{*}{ SP 68} & $\mathrm{RF}$ & $2.0 \pm 0.1$ & $8.0 \pm 0.3$ & $0.29 \pm 0.02$ & $0.12 \pm 0.01$ \\
\hline & $\mathrm{TF}$ & $2.4 \pm 0.1$ & $8.1 \pm 0.3$ & $0.23 \pm 0.02$ & $0.64 \pm 0.03$ \\
\hline & NTF & $0.4 \pm 0.2$ & $0.2 \pm 0.4$ & $-0.06 \pm 0.03$ & $0.52 \pm 0.03$ \\
\hline & $\mathrm{DD}_{\mathrm{TF}}$ & & $1.5 \pm 0.6$ & $0.05 \pm 0.02$ & $0.02 \pm 0.01$ \\
\hline & $\mathrm{CE}$ & & $-1.3 \pm 0.7$ & $-0.12 \pm 0.04$ & $0.50 \pm 0.03$ \\
\hline
\end{tabular}




\subsubsection{Modification of iodine and selenium composition of atmospheric inputs}

AVWM concentrations of I (SI Table S3; range and median $=1.37-4.97$ and $2.85 \mu \mathrm{g} \mathrm{L}^{-}$ ${ }^{1}$ ) and $\mathrm{Se}$ (range and median $=31-149$ and $90 \mathrm{ng} \mathrm{L^{-1 }}$ ) in throughfall were higher than in corresponding rainfall (range and median $=0.85-2.18$ and $1.23 \mu \mathrm{g} \mathrm{L}^{-1}$, and $23-85$ and $41 \mathrm{ng} \mathrm{L^{- }}$ 1; for I and Se, respectively). The concentration ratios were in the same order of magnitude for both elements (SI Table S3; range and median $=0.9-4.0$ and 2.0, and 0.8-3.3 and 1.8; for I and Se, respectively). Only the beech site HET30 presented CR below one for both elements. Focusing on functional types, no difference was detected between functional tree types for both $\mathrm{CR}(\mathrm{I})$ or $\mathrm{CR}(\mathrm{Se})$ (Wilcoxon test, $p=0.298$ and 0.438 , respectively). $\mathrm{CR}(\mathrm{I})$ values were in the same range as those found in the literature in European and Japanese forests (Neal et al., 2007; Roulier et al., 2018; Xu et al., 2016). Annual rainfall and throughfall fluxes of I varied respectively from 7.6 to 51.8 and from 8.1 to $38.1 \mathrm{~g} \mathrm{ha}^{-1} \mathrm{yr}^{-1}$ (Table 1). Annual throughfall fluxes of I were not different to rainfall ones considering uncertainties in the sites SP05, SP38 and SP68 (Table 1), and inferior to rainfall ones only in the site HET30 with net throughfall of $-13.7 \pm 1.9 \mathrm{~g} \mathrm{ha}^{-1} \mathrm{yr}^{-1}$. An iodine enrichment in throughfall compared to rainfall occurred for all other sites (Figure 2 (b); EF(I) mean $=1.56$ ), involving positive NTF(I). For selenium, annual rainfall and throughfall fluxes varied respectively from 0.24 to 2.01 and from 0.20 to $1.45 \mathrm{~g} \mathrm{ha}^{-1} \mathrm{yr}^{-1}$ (Table 1). Selenium enrichment of throughfall was observed for seven sites considering uncertainties (Figure $2(\mathrm{c}) ; \mathrm{EF}(\mathrm{Se})$ mean $=1.60$ ), resulting in positive $\mathrm{NTF}(\mathrm{Se})$ for these sites; while for the remaining sites, throughfall fluxes were not different to rainfall, excepted HET30 with negative net throughfall. No significant difference was found for the annual NTF(I) or NTF(Se) neither between functional tree types (Wilcoxon test, $p>0.05$ ), nor according to annual RF and TF amounts (Spearman's correlation, $p>0.05$ ). Regarding monthly fluxes, TF fluxes of iodine and selenium were predominantly higher or equal to those of RF consistent with results obtained at annual scale for sites showing positive annual NTF (SI Figure 
S5 and Figure S6 for I; SI Figure S7 and Figure S8 for Se). Moreover, no seasonal or phenological stages dependence was clearly observed for both elements. The site HET30 presented the lower (negative) annual $\mathrm{NTF}(\mathrm{I})$ and $\mathrm{NTF}(\mathrm{Se})$ due mainly to two months with high precipitations $(>400 \mathrm{~mm})$ and maximum negative monthly NTF fluxes. Hence, iodine and selenium showed similar behaviour as highlighted by significant positive correlations between NTF of I, Se and Na (Figure 3 (a)(b)(d); Spearman's correlation, $p<0.05$ ), and a strong positive correlation between concentration ratios of Se and I (SI Figure S9; Pearson's correlation, $p<$ $0.001)$.
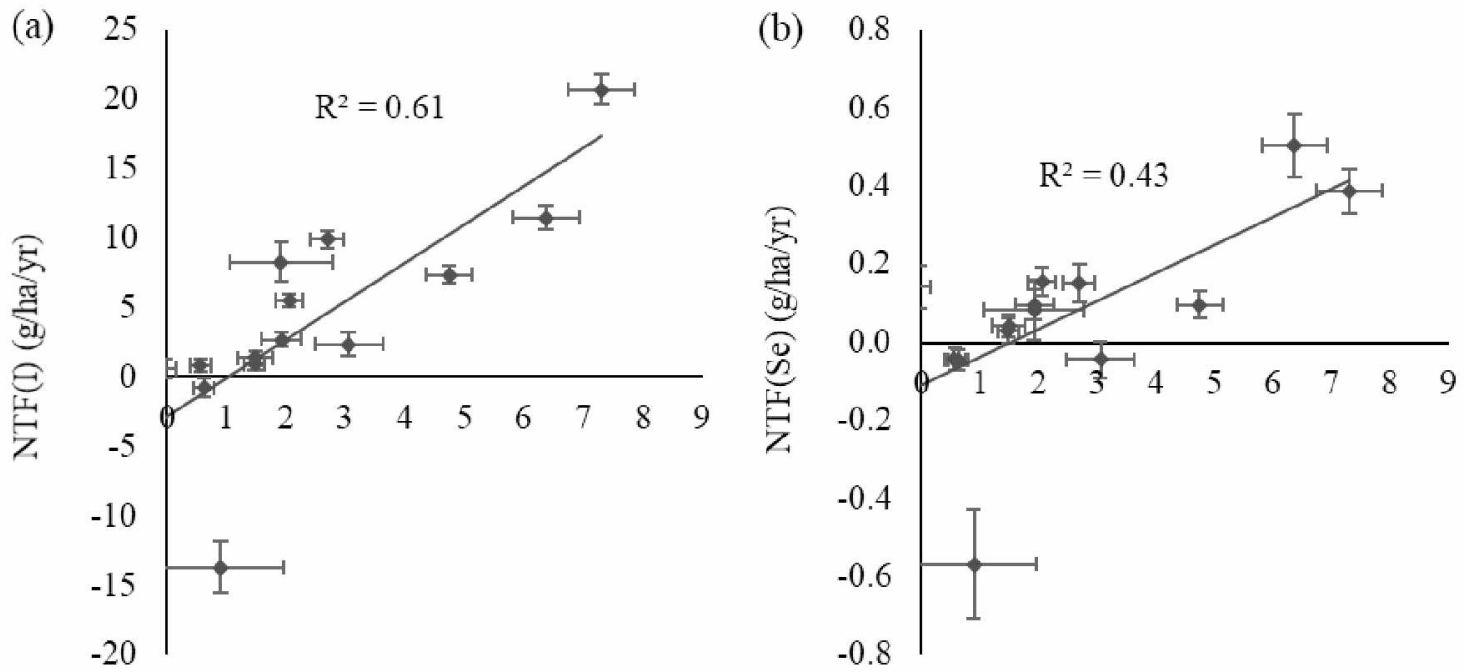

$\operatorname{NTF}(\mathrm{Na})(\mathrm{kg} / \mathrm{ha} / \mathrm{yr})$
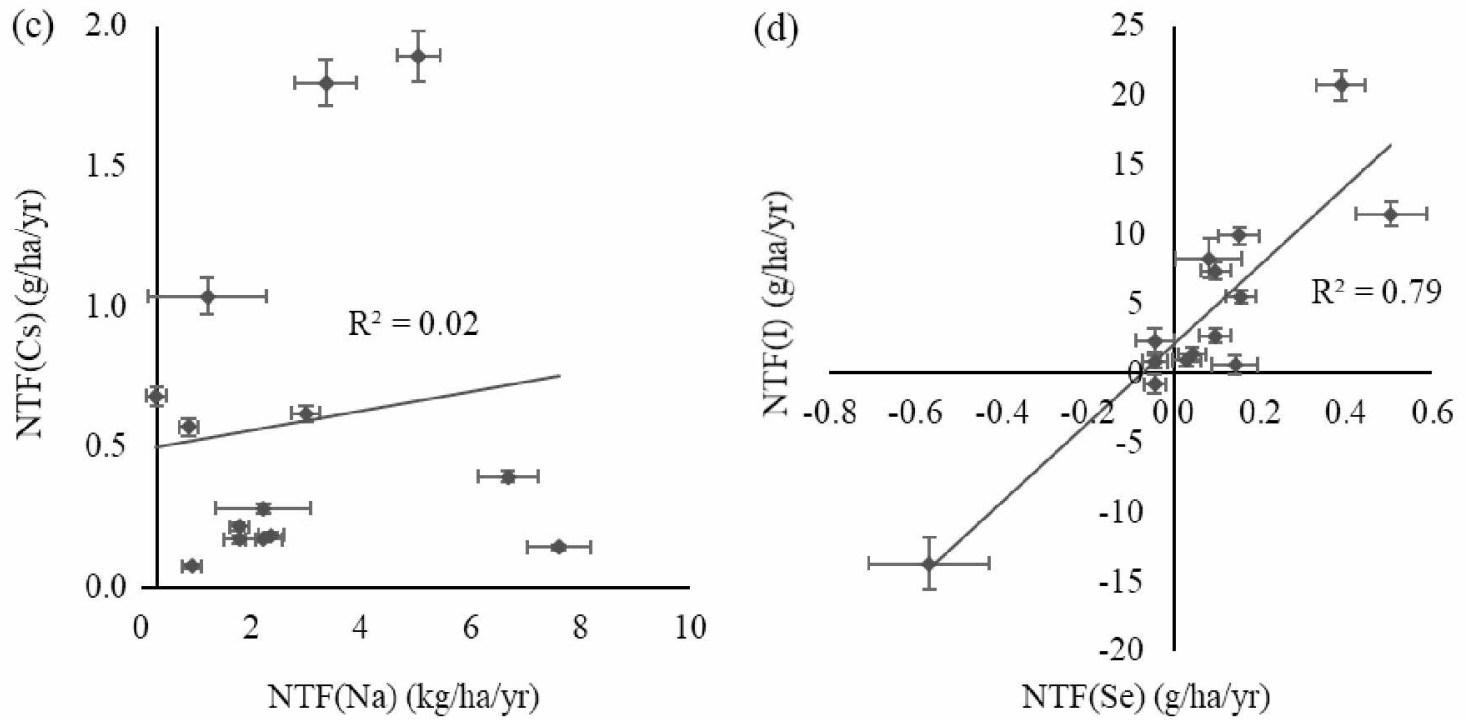

Figure 3. Correlations between net throughfall (NTF) of Na and those of (a) I, (b) Se and (c) Cs. (d) Correlation between NTF(I) and those of Se. Error bars correspond to standard errors. 
Estimated DDTF fluxes of I and Se were of 6.23 and $0.20 \mathrm{~g} \mathrm{ha}^{-1} \mathrm{yr}^{-1}$ (median values) (Table 1) and accounted respectively for $47 \pm 32$ and $55 \pm 38 \%$ of TF. The sites EPC08, EPC63, SP11 and SP57 presented higher $\mathrm{DD}_{\mathrm{TF}}(\mathrm{I})$ and $\mathrm{DD}_{\mathrm{TF}}(\mathrm{Se})$ fluxes $\left(>12.9\right.$ and $>0.51 \mathrm{~g} \mathrm{ha}^{-1} \mathrm{yr}^{-1}$, respectively) compared to overall other sites $\left(4.6 \pm 2.7\right.$ and $0.14 \pm 0.09 \mathrm{~g} \mathrm{ha}^{-1} \mathrm{yr}^{-1}$, respectively). No significant difference was found for $\mathrm{DD}_{\mathrm{TF}}(\mathrm{I})$ or $\mathrm{DD}_{\mathrm{TF}}(\mathrm{Se})$ neither between functional tree types (Wilcoxon test, $p>0.05$ ), nor according to annual RF and TF amounts (Spearman's correlation, $p>0.05$ ). Importance of the canopy exchange (CE) varied greatly from one stand to another (Table 1), but it did not seem to depend on (i) functional tree types (Wilcoxon test, $p>0.05$ ), and (ii) RF amount or interception (Spearman's correlation, $p>0.05$ ). Iodine canopy exchange was positive only for the site HET64 (3.6 $\left.\pm 2.5 \mathrm{~g} \mathrm{ha}^{-1} \mathrm{yr}^{-1}\right)$, involving leaching of I by trees of this stand; whereas it was negative for other sites involving iodine (ab)sorption by tree canopy (excepted for the site SP38 with CE equal to zero considering uncertainty). In case of Se, only the site SP38, for which $\mathrm{DD}_{\mathrm{TF}}$ flux was equal to zero, shown positive CE. Such results indicated that leaves or needles (ab)sorbed selenium in the majority of stands. Although iodine and selenium (ab)sorption could be overestimated, it seems that uptake of these elements occurred by foliar surface and/or related living organism. Indeed, in our previous study on those sites (Roulier et al., 2019), we found a strong correlation between forest litters and rainfall iodine concentrations, involving a potential iodine sorption by leaves and needles returned to soil after their senescence. Some other studies highlighted the foliar sorption of iodine by vegetables after spraying the leaves with radioiodine or following atmospheric radioiodine inputs (e.g. Collins et al., 2004; Hasegawa et al., 2014; Hurtevent et al., 2013; Ota et al., 2020; Tschiersch et al., 2009). In our previous study (Roulier et al., 2018), the washing of beech leaves suggested that the majority of I was incorporated inside the leaves. Same, several studies showed that foliar sorption of selenium was possible for some species following foliar 
application of Se solutions (Se(IV) or Se(VI)) (Haygarth et al., 1994; Hu et al., 2002; Hurtevent et al., 2013; Kápolna et al., 2009).

\subsubsection{Modification of caesium composition of atmospheric inputs}

AVWM Cs concentrations in throughfall showed a greater variability (range $=17-310$ ng $\mathrm{L}^{-1}$ ) between sites than I and Se (SI Table S3; median $=61 \mathrm{ng} \mathrm{L}^{-1}$ ). As for I and Se, caesium concentrations in throughfall were higher than in corresponding rainfall (range and median = 2.3-13.2 and 5.4 $\mathrm{ng} \mathrm{L}^{-1}$ ) with the greatest concentration ratios from 4.2 to 48.9 (SI Table S3; mean $=16.2)$, especially for the spruce sites EPC63 and EPC87 $(\mathrm{CR}=48.9$ and 43.3, respectively). Annual throughfall $\mathrm{Cs}$ fluxes varied greatly from one site to another by a factor $16\left(\right.$ Table 1 ; median $\left.=0.39 \mathrm{~g} \mathrm{ha}^{-1} \mathrm{yr}^{-1}\right)$, and comparison with $\mathrm{RF}$ at the annual scale (median $=$ $0.05 \mathrm{~g} \mathrm{ha}^{-1} \mathrm{yr}^{-1}$ ) confirmed large enrichment for Cs (Figure $2(\mathrm{~d})$; EF range and mean $=2.7$ 31.1 and 10.2) compared to I and Se. Therefore, net throughfall of Cs was always positive, values ranging between +0.1 to $+1.9 \mathrm{~g} \mathrm{ha}^{-1} \mathrm{yr}^{-1}$ (median $=0.3 \mathrm{~g} \mathrm{ha}^{-1} \mathrm{yr}^{-1}$ ). Highest net throughfall fluxes were quantified at beech HET30 and spruce EPC63 and EPC87 sites. This throughfall enrichment occurred in all seasons and sites comparing monthly RF and TF fluxes of Cs (SI Figure S10 and Figure S11). Caesium behaviour differed from that of $\mathrm{Na}$, I and Se, as highlighted by the lack of correlation between annual NTF(Cs) and NTF(Na) (Figure 3 (c); Spearman's correlation, $p=0.892$ ).

Indeed, fluxes of $\mathrm{DD}_{\mathrm{TF}}(\mathrm{Cs})$ accounted to only $9 \pm 8 \%$ of $\mathrm{Cs}$ in TF (Table 1) and they therefore did not explain the $\mathrm{Cs}$ enrichment in throughfall. Once $\mathrm{DD}_{\mathrm{TF}}$ was subtracted from NTF, Cs canopy exchange was always positive. Hence, throughfall enrichment in Cs would be linked to its leaching from leaves/needles internal tissues. That assumption is supported by significant and positive correlations between monthly NTF(Cs) and NTF(K) (SI Figure S12 and Figure S13, $0.44<\mathrm{R}^{2}<0.98$, expected for the sites HET64, PS67a and SP11). Indeed, the 
contribution of $\mathrm{K}^{+}$foliar leaching in forest is well known (e.g. Adriaenssens et al., 2012; Kopacek et al., 2009), and caesium is considered as a biological analogue of K (e.g. Thiry et al., 2009; Yoshihara et al., 2019).

\subsubsection{Focus on iodine and selenium speciation modification}

As no Se-containing peak was detected in throughfall chromatograms, only iodine speciation results will be discussed. However, since rainfall was composed of $26-54 \%$ of inorganic Se compounds (SI Table S3), Se speciation was thus strongly modified in throughfall compared to rainfall with complete loss of inorganic species.

An important modification of iodine speciation from rainfall to throughfall was also detected. In throughfall, proportions of $\mathrm{I}^{-}, \mathrm{IO}_{3}{ }^{-}$and "other" iodine were respectively: $3-25,1-$ 13 and $65-92 \%$ (SI Table S3; mean $=14,4$ and $82 \%$, respectively), reflecting a consequent increase of "other" iodine proportion and a drastic decrease of inorganic iodine species proportion for most sites (in rainfall, range and mean $=19-44$ and 29, 16-32 and 23, 39-60 and $49 \%$, for $\mathrm{I}^{-}, \mathrm{IO}_{3}{ }^{-}$and $\mathrm{I}_{\text {other }}$ respectively). Furthermore, unknown iodine fraction in throughfall was at least in part different from the one in rainfall as no I-containing peak was detected in throughfall samples contrariwise to rainfall (SI Figure S14). Concomitantly, DOC concentrations in throughfall dramatically increased compared to rainfall ones (cf. §3.1.; SI Table S2). Actually, the delta of the "other" iodine concentration (i.e. corresponds to throughfall Iother concentration - rainfall Iother concentration) was overall positively correlated to those of DOC (SI Figure S15 and Figure S16; $0.43<\mathrm{R}^{2}<0.83$ ). DOC in throughfall could come from (i) foliar or needles leaching and microbiological activities in the phyllosphere and/or (ii) from soluble organic deposits washed off from the canopy surface (Mellec et al., 2010; Michalzik et al., 2001). Considering the significant dry deposition of iodine estimated above, these correlations could support the assumption that the amount of iodine and its speciation in rainfall 
were highly modified after crossing the canopy by washing-off of dry deposition. Alongside that, inorganic iodine fluxes decreased clearly, especially those of iodate (Figure 4; $\mathrm{EF}\left(\mathrm{IO}_{3}{ }^{-}\right.$) range and median $=0.1-0.6$ and $0.2 ; \mathrm{EF}\left(\mathrm{I}^{-}\right)$range and median $=0.1-1.5$ and 0.7$)$, according to modification of iodine speciation due to rainfall composition change and/or absorption by leaves and needles of these iodine species. No difference was found in the enrichment factors of $\mathrm{I}^{-}$or $\mathrm{IO}_{3}{ }^{-}$between functional tree types (Wilcoxon's test, $p=0.190$ and 0.147 , respectively). Furthermore, no relationship was found between negatives CE(I) (involving iodine (ab)sorption by canopies) and the decrease of inorganic iodine fluxes (Spearman's test, $p=0.868$ and 0.892 for $\mathrm{EF}\left(\mathrm{I}^{-}\right)$and $\mathrm{EF}\left(\mathrm{IO}_{3}{ }^{-}\right)$, respectively), probably due to dry deposition contribution whose exact role in iodine speciation modification is unknown. To date and to our knowledge, only Xu et al. (2016) provided information about iodine speciation in throughfall which was collected in March 2014 under deciduous and coniferous forest in Fukushima (Japan). They also found a modification of throughfall iodine speciation for both forests, exclusively composed of "other" iodine (iodine unidentified $=100 \%$ ) contrary to rainfall with an "other" iodine fraction of $71.5 \%$ 
(a) 60 Deciduous trees Iodide \& Iodate 目 "Other"

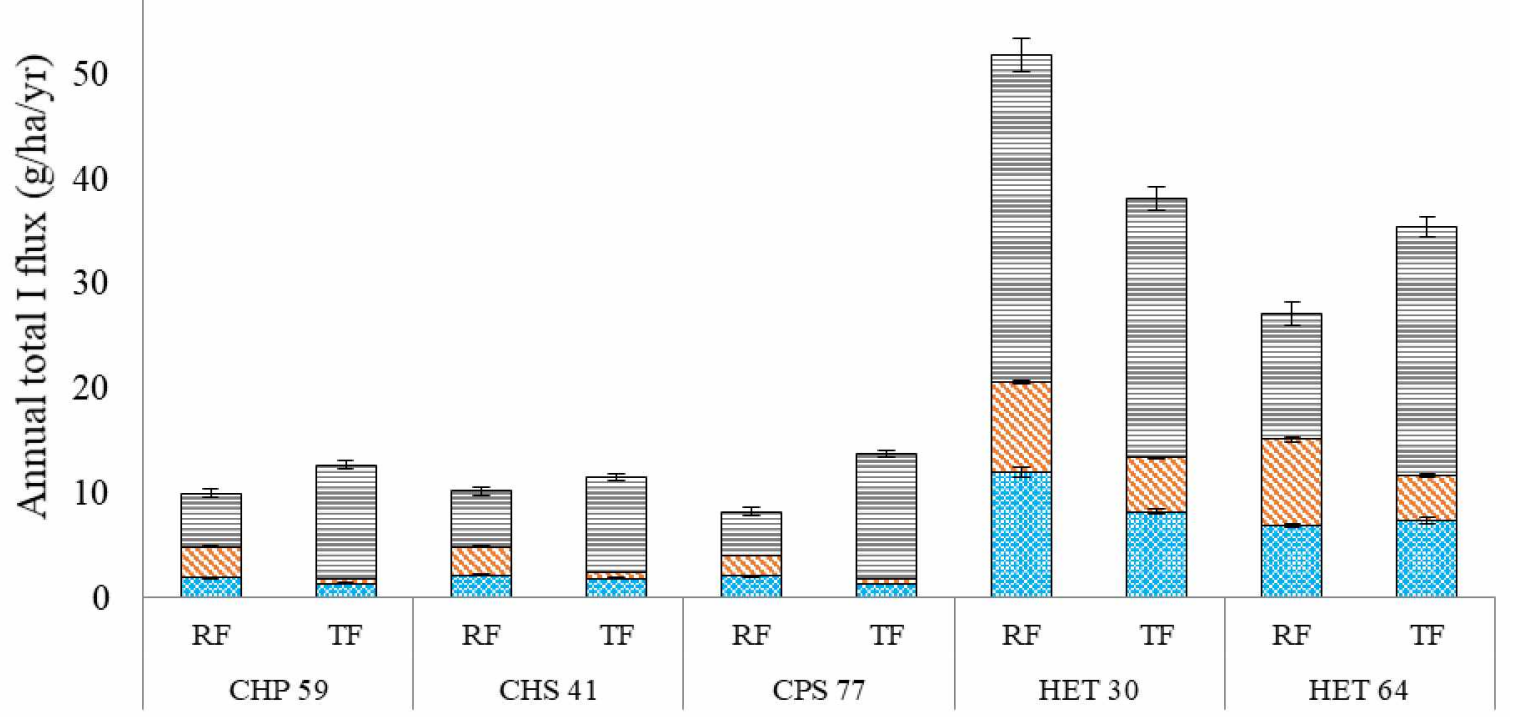

(b) $40 \quad$ Coniferous trees

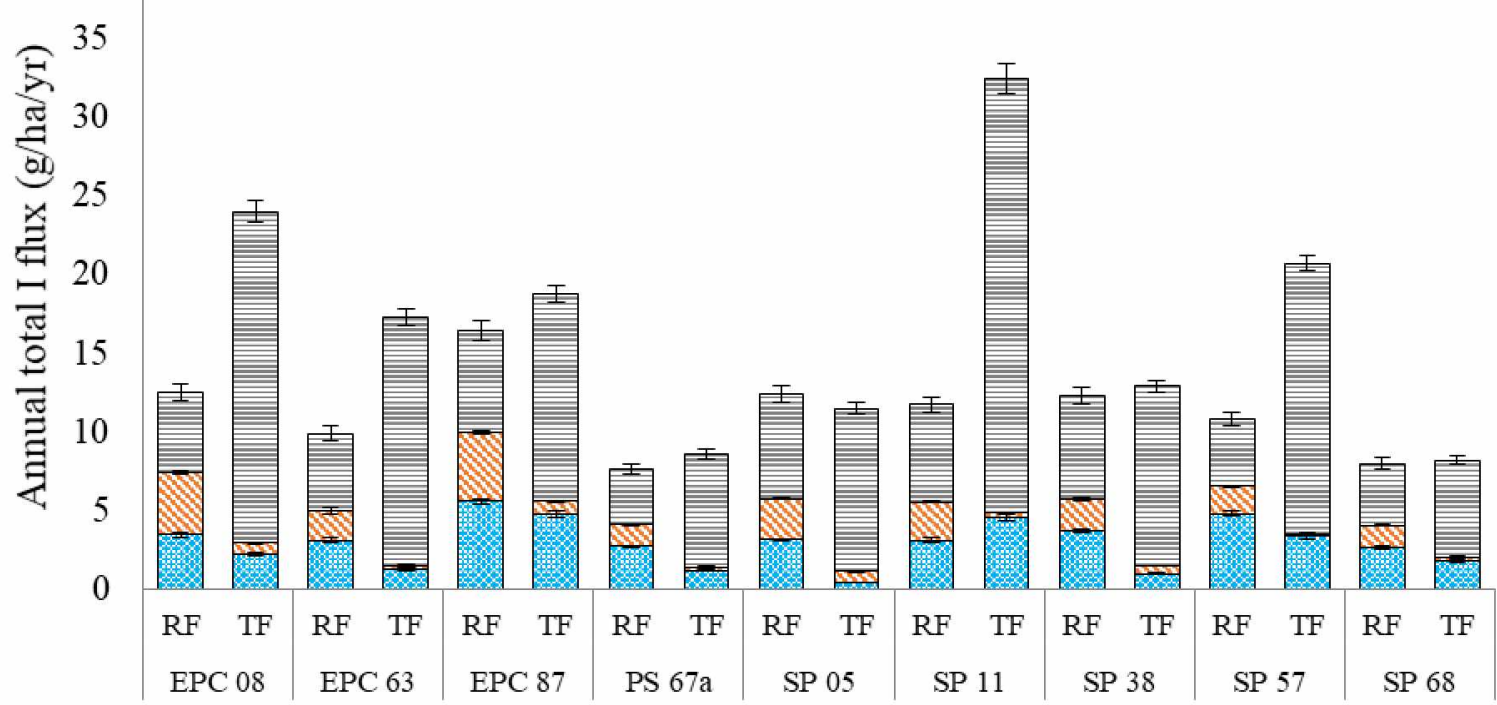

Figure 4. Proportions of iodide, iodate and "other" iodine in annual total I flux from rainfall (RF) and throughfall (TF) for (a) deciduous and (b) coniferous trees. CHP: Pedunculate Oak; CHS: Sessile Oak; CPS: Pedunculate/Sessile Oak; HET: Beech; EPC: Spruce; PS: Scots Pines; SP: Silver Fir. Error bars correspond to standard errors. 


\section{Conclusion}

In the current study, dry deposition and canopy exchange fluxes of I, Se and Cs were estimated for fourteen forest sites representative of five tree species. Iodine and selenium speciation modifications in throughfall compared to rainfall were also studied. The results of one year monitoring showed that: (i) the three elements were enriched in throughfall compared to corresponding rainfall (mean concentration ratios $=2.2,2.0$ and 16.2 for $\mathrm{I}$, Se and $\mathrm{Cs}$ respectively); (ii) the increase of throughfall elemental fluxes were estimated to be mostly due to dry deposition for I and Se, and to leaching from foliage for Cs; (iii) application of the canopy exchange budget model indicated that I and Se were sorbed within canopy in most cases; (iv) important modifications of I and Se speciation from rainfall to throughfall resulted in increased proportion of unidentified species (from $39-60$ to $65-92 \%$ for iodine; from $46-74 \%$ to almost $100 \%$ for selenium), inorganic species were thus either minor compounds or undetectable. This study provides a better understanding of the processes acting within tree canopy and affecting atmospheric inputs of I, Se and Cs towards forest soils and their recycling by forest, and should thus help improving long-term predictions of the behaviour of these elements in forest ecosystems. 


\section{Credit author statement}

Roulier Marine: Conceptualization, Investigation, Validation, Formal analysis, Writing - original draft, Writing - review \& editing; Maïté Bueno: Conceptualization, Investigation, Validation, Funding acquisition, Writing - review \& editing, Supervision; Frédéric Coppin: Conceptualization, Validation, Funding acquisition, Writing - review \& editing, Supervision; Manuel Nicolas: Resources, Writing - review \& editing; Yves Thiry: Conceptualization, Funding acquisition, Writing - review \& editing; François Rigal: Formal analysis, Validation, Writing - review \& editing; Isabelle Le Hécho: Conceptualization, Writing - review \& editing, Supervision; Florence Pannier: Conceptualization, Writing - review \& editing, Supervision.

\section{Declaration of competing interest}

The authors declare that they have no known competing financial interests or personal relationships that could have appeared to influence the work reported in this paper.

\section{Acknowledgments}

We would like to acknowledge the technical staff of RENECOFOR-ONF for providing samples for this study as well datasets, apart from those for iodine, selenium and caesium. This work was financed by the Région Nouvelle Aquitaine and the Agence Nationale de la Recherche with funds allocated in the 'Investissements d'Avenir' framework program under reference ANR11-RSNR-0002.

\section{Appendix A. Supplementary data}

Supplementary data to this article can be found online at https://doi.org/10.1016/j.chemosphere.2020.128952. 


\section{References}

Adriaenssens, S., Hansen, K., Staelens, J., Wuyts, K., De Schrijver, A., Baeten, L., Boeckx, P., Samson, R., Verheyen, K., 2012. Throughfall deposition and canopy exchange processes along a vertical gradient within the canopy of beech (Fagus sylvatica L.) and Norway spruce (Picea abies (L.) Karst). Sci. Total Environ. 420, 168-182. https://doi. org/10.1016/j.scitotenv.2011.12.029

Alfthan, G., Wang, D., Aro, A., Soveri, J., 1995. The Geochemistry of Selenium in Groundwaters in Finland. Sci. Total Environ. 162, 93-103. https://doi.org/10.1016/0048-9697(95)04436-5

Aussenac, G., 1968. Interception des précipitations par le couvert forestier. Annales des Sciences Forestières 25, 135-156. https://doi.org/10.1051/forest/19680302

Bergkvist, B., Folkeson, L., Berggren, D., 1989. Fluxes of $\mathrm{Cu}, \mathrm{Zn}, \mathrm{Pb}, \mathrm{Cd}, \mathrm{Cr}$, and $\mathrm{Ni}$ in Temperate Forest Ecosystems - a Literature-Review. Water Air Soil Pollut. 47, $217-$ 286. https://doi.org/10.1007/BF00279328

Collins, C.D., Gravett, A.E., Bell, J.N.B., 2004. The deposition and translocation of methyl iodide by crops. Health Phys. 87, 512-516. https://doi.org/10.1097/01.HP.0000137177.99193.8f

Cutter, G.A., Church, T.M., 1986. Selenium in western Atlantic precipitation. Nature 322, 720. https://doi.org/10.1038/322720a0

Di Tullo, P., 2015. Dynamique du cycle biogéochimique du sélénium en écosystèmes terrestres: rétention et réactivité dans le sol, rôle de la végétation. $\mathrm{PhD}$. Université de Pau et des Pays de l'Adour.

Epp, T., Neidhardt, H., Pagano, N., Marks, M.A.W., Markl, G., Oelmann, Y., 2020. Vegetation canopy effects on total and dissolved $\mathrm{Cl}, \mathrm{Br}, \mathrm{F}$ and I concentrations in soil and their fate along the hydrological flow path. Sci. Total Environ. 712, 135473. https://doi.org/10.1016/j.scitotenv.2019.135473

Floor, G.H., Iglesias, M., Roman-Ross, G., Corvini, P.F.X., Lenz, M., 2011. Selenium speciation in acidic environmental samples: Application to acid rain-soil interaction at Mount Etna volcano. Chemosphere 84, 1664-1670. https://doi.org/10.1016/j.chemosphere.2011.05.006

Fuge, R., Johnson, C.C., 2015. Iodine and human health, the role of environmental geochemistry and diet, a review. J. Appl. Geochem. 63, 282-302. https://doi.org/10.1016/j.apgeochem.2015.09.013

Gandois, L., Tipping, E., Dumat, C., Probst, A., 2010. Canopy influence on trace metal atmospheric inputs on forest ecosystems: speciation in throughfall. Atmos. Environ. 44, 824833.

Goor, F., Thiry, Y., 2004. Processes, Dynamics and Modelling of Radiocaesium Cycling in a Chronosequence of Chernobyl-Contaminated Scots Pine (Pinus Sylvestris L.) $\begin{array}{llll}\text { Plantations. } & \text { Sci. } & \text { Total } & \text { Environ. }\end{array}$ https://doi.org/10.1016/j.scitotenv.2003.10.037.

Hasegawa, H., Tsukada, H., Kawabata, H., Takaku, Y., Hisamatsu, S., 2014. Foliar uptake and translocation of stable Cs and I in radish plants. J. Radioanal. Nucl. Chem. 303, 14091412. https://doi.org/10.1007/s10967-014-3496-0

Haygarth, P.M., Fowler, D., Stürup, S., Davison, B.M., Tones, K.C., 1994. Determination of gaseous and particulate selenium over a rural grassland in the U.K. Atmos. Environ. 28, 3655-3663. https://doi.org/10.1016/1352-2310(94)00196-R

Hu, Q., Chen, L., Xu, J., Zhang, Y., Pan, G., 2002. Determination of selenium concentration in rice and the effect of foliar application of Se-enriched fertiliser or sodium selenite on 
the selenium content of rice. J. Sci. Food Agr. 82, 869-872. https://doi.org/10.1002/jsfa.1115

Hurtevent, P., Thiry, Y., Levchuk, S., Yoschenko, V., Henner, P., Madoz-Escande, C., Leclerc, E., Colle, C., Kashparov, V., 2013. Translocation of ${ }^{125} \mathrm{I},{ }^{75} \mathrm{Se}$ and ${ }^{36} \mathrm{Cl}$ to Wheat edible parts following wet foliar contamination under field conditions. J. Environ. Radioact. Special Issue: 2011 ICRER meeting 121, 43-54. https://doi.org/10.1016/j.jenvrad.2012.04.013

Kápolna, E., Hillestrøm, P.R., Laursen, K.H., Husted, S., Larsen, E.H., 2009. Effect of foliar application of selenium on its uptake and speciation in carrot. Food Chem. 115, 13571363. https://doi.org/10.1016/j.foodchem.2009.01.054

Karavoltsos, S., Fotiadis, F., Michopoulos, P., Sakellari, A., Plavšić, M., Bourletsikas, A., Kaoukis, K., Thomaidis, N.S., Dassenakis, M., Scoullos, M., 2017. Organic complexation of copper in throughfall and open field bulk deposition: Influence of the tree canopy of Mediterranean forest ecosystems. Chemosphere 167, 28-35. https://doi.org/10.1016/j.chemosphere.2016.09.131

Kato, H., Onda, Y., Hisadome, K., Loffredo, N., Kawamori, A., 2017. Temporal changes in radiocesium deposition in various forest stands following the Fukushima Dai-ichi Nuclear Power Plant accident. J. Environ. Radioact. 166, 449-457. https://doi.org/10.1016/j.jenvrad.2015.04.016

Kopacek, J., Turek, J., Hejzlar, J., Santruckova, H., 2009. Canopy leaching of nutrients and metals in a mountain spruce forest. Atmos. Environ. 43, 5443-5453. https://doi.org/10.1016/j.atmosenv.2009.07.031

Lindberg, S., Lovett, G.M., Richter, D.D., Johnson, D.W., 1986. Atmospheric Deposition and Canopy Interactions of Major Ions in a Forest. Science 231, 141-45. https://doi.org/10.1126/science.231.4734.141

Loffredo, N., Onda, Y., Hurtevent, P., Coppin, F., 2015. Equation to predict the ${ }^{137} \mathrm{Cs}$ leaching dynamic from evergreen canopies after a radio-cesium deposit. J. Environ. Radioact. 147, 100-107. https://doi.org/10.1016/j.jenvrad.2015.05.018

Lovett, G.M., Lindberg, S.E., 1984. Dry Deposition and Canopy Exchange in a Mixed Oak Forest as Determined by Analysis of Throughfall. J. Appl. Ecol. 21, 1013-1027. https://doi.org/10.2307/2405064

Mellec, A., Meesenburg, H., Michalzik, B., 2010. The importance of canopy-derived dissolved and particulate organic matter (DOM and POM) - comparing throughfall solution from broad-leaved and coniferous forests. Ann. For. Sci. 67, 411-411. https://doi.org/10.1051/forest/2009130

Michalzik, B., Kalbitz, K., Park, J.H., Solinger, S., Matzner, E., 2001. Fluxes and concentrations of dissolved organic carbon and nitrogen - a synthesis for temperate forests. Biogeochemistry 52, 173-205. https://doi.org/10.1023/A:1006441620810

Neal, C., Neal, M., Wickham, H., Hill, L., Harman, S., 2007. Dissolved iodine in rainfall, cloud, stream and groundwater in the Plynlimon area of mid-Wales. Hydrol. Earth Syst. Sci. 11, 283-293. https://doi.org/10.5194/hess-11-283-2007

Neary, A., Gizyn, W., 1994. Throughfall and Stemflow Chemistry Under Deciduous and Coniferous Forest Canopies in South-Central Ontario. Can. J. For. Res. 24, 1089-1100. https://doi.org/10.1139/x94-145.

Ota, M., Terada, H., Hasegawa, H., Kakiuchi, H., 2020. Processes affecting land-surface dynamics of ${ }^{129} \mathrm{I}$ impacted by atmospheric ${ }^{129} \mathrm{I}$ releases from a spent nuclear fuel reprocessing plant. Sci. Total Environ. 704, 135319. https://doi.org/10.1016/j.scitotenv.2019.135319

R Core Team, 2013. R: A language and Environment for Statistical Computing. R Foundation for Statistical Computing, Vienna, Austria. 
Robberecht, H., Vangrieken, R., Vansprundel, M., Vandenberghe, D., Deelstra, H., 1983. Selenium in Environmental and Drinking Waters of Belgium. Sci. Total Environ. 26, 163-172. https://doi.org/10.1016/0048-9697(83)90109-2

Roulier, M., Bueno, M., Coppin, F., Nicolas, M., Thiry, Y., Rigal, F., Le Hécho, I., Pannier, F., 2020. Atmospheric iodine, selenium and caesium deposition in France: I. Spatial and seasonal variations.

Chemosphere. https://doi.org/10.1016/j.chemosphere.2020.128971

Roulier, M., Bueno, M., Thiry, Y., Coppin, F., Redon, P.-O., Le Hécho, I., Pannier, F., 2018. Iodine distribution and cycling in a beech (Fagus sylvatica) temperate forest. Sci. Total Environ. 645, 431-440. https://doi.org/10.1016/j.scitotenv.2018.07.039

Roulier, M., Coppin, F., Bueno, M., Nicolas, M., Thiry, Y., Della Vedova, C., Février, L., Pannier, F., Le Hécho, I., 2019. Iodine budget in forest soils: Influence of environmental conditions and soil physicochemical properties. Chemosphere 224, 20-28. https://doi. org/10.1016/j.chemosphere.2019.02.060

Sombré, L., Vanhouche, M., de Brouwer, S., Ronneau, C., Lambotte, J.M., Myttenaere, C., 1994. Long-term radiocesium behaviour in spruce and oak forests. Sci. Total Environ., 157, 59-71. https://doi.org/10.1016/0048-9697(94)90565-7

Staelens, J., Schrijver, A.D., Verheyen, K., 2007. Seasonal Variation in Throughfall and Stemflow Chemistry beneath a European Beech (Fagus Sylvatica) Tree in Relation to Canopy Phenology. Can. J. For. Res. 37, 1359-72. https://doi.org/10.1139/X07-003.

Staelens, J., Houle, D., De Schrijver, A., Neirynck, J., Verheyen, K., 2008. Calculating Dry Deposition and Canopy Exchange with the Canopy Budget Model: Review of Assumptions and Application to Two Deciduous Forests. Water, Air, and Soil Pollut. 191, 149-169. https://doi.org/10.1007/s11270-008-9614-2

Suess, E., Aemisegger, F., Sonke, J.E., Sprenger, M., Wernli, H., Winkel, L.H.E., 2019. Marine versus Continental Sources of Iodine and Selenium in Rainfall at Two European HighAltitude Locations. Environ. Sci. Technol. 53, 1905-1917. https://doi.org/10.1021/acs.est.8b05533

Takeda, A., Tsukada, H., Takaku, Y., Satta, N., Baba, M., Shibata, T., Hasegawa, H., Unno, Y., Hisamatsu, S., 2016. Determination of Iodide, Iodate and Total Iodine in Natural Water Samples by HPLC with Amperometric and Spectrophotometric Detection, and Off-line UV Irradiation. Anal. Sci. 32, 839-845. https://doi.org/10.2116/analsci.32.839

Talkner, U., Krämer, I., Hölscher, D., Beese, F.O., 2010. Deposition and canopy exchange processes in central-German beech forests differing in tree species diversity. Plant Soil 336, 405-420. https://doi.org/10.1007/s11104-010-0491-2

Thiry, Y., Colle, C., Yoschenko, V., Levchuk, S., Van Hees, M., Hurtevent, P., Kashparov, V., 2009. Impact of Scots pine (Pinus sylvestris L.) plantings on long term Cs-137 and Sr90 recycling from a waste burial site in the Chernobyl Red Forest. J. Environ. Radioact. 100, 1062-1068. https://doi.org/10.1016/j.jenvrad.2009.05.003

Thimonier, A., Schmitt, M., Waldner, P., Schleppi, P., 2008. Seasonality of the $\mathrm{Na} / \mathrm{Cl}$ Ratio in Precipitation and Implications of Canopy Leaching in Validating Chemical Analyses of Throughfall Samples. Atmos. Environ. 42, 9106-17. https://doi.org/10.1016/j.atmosenv.2008.09.007.

Tschiersch, J., Shinonaga, T., Heuberger, H., 2009. Dry deposition of gaseous radioiodine and particulate radiocaesium onto leafy vegetables. Sci. Total Environ. 407, 5685-5693. https://doi.org/10.1016/j.scitotenv.2009.06.025

Tyler, G., Olsson, T., 2006. The importance of atmospheric deposition, charge and atomic mass to the dynamics of minor and rare elements in developing, ageing, and wilted leaves of beech (Fagus sylvatica L.). Chemosphere 65, 250-260. https://doi.org/10.1016/j.chemosphere.2006.02.051 
Ulrich, B., 1983. Interaction of forest canopies with atmospheric constituents: $\mathrm{SO}_{2}$, alkali and earth alkali cations and chloride. In: Pankrath J (Ed.), B Ulrich. Effects of accumulation of air pollutants in forest ecosystems. D Reidel Publishing Company, Dordrecht, pp 3345

Ulrich, E., Lelong, N., Lanier, M., Schneider, A., 1995. Interception des pluies en forêt: facteurs déterminants. Interprétation des mesures réalisées dans le sous-réseau CATAENAT de RENECOFOR. ONF - Bulletin technique 30, 33-44

Varga, B., Leclerc, E., Zagyvai, P., 2009. The Role of Analogues in Radioecology. J. Environ. Radioact. 100, 802-5. https://doi.org/10.1016/j.jenvrad.2008.10.004.

Xu, C., Zhang, S., Sugiyama, Y., Ohte, N., Ho, Y.-F., Fujitake, N., Kaplan, D.I., Yeager, C.M., Schwehr, K., Santschi, P.H., 2016. Role of natural organic matter on iodine and ${ }^{239,240} \mathrm{Pu}$ distribution and mobility in environmental samples from the northwestern Fukushima Prefecture, Japan. J. Environ. Radioact. 153, 156-166. https://doi.org/10.1016/j.jenvrad.2015.12.022

Yoschenko, V., Takase, T., Hinton, T.G., Nanba, K., Onda, Y., Konoplev, A., Goto, A., Yokoyama, A., Keitoku, K., 2018. Radioactive and stable cesium isotope distributions and dynamics in Japanese cedar forests. J. Environ. Radioact. 186, 34-44. https://doi.org/10.1016/j.jenvrad.2017.09.026

Yoshihara, T., Yoschenko, V., Watanabe, K., Keitoku, K., 2019. A through year behavior of ${ }^{137} \mathrm{Cs}$ in a Japanese flowering cherry tree in relation to that of potassium. J. Environ. Radioact. 202, 32-40. https://doi.org/10.1016/j.jenvrad.2019.01.013 


\section{Supporting Information}

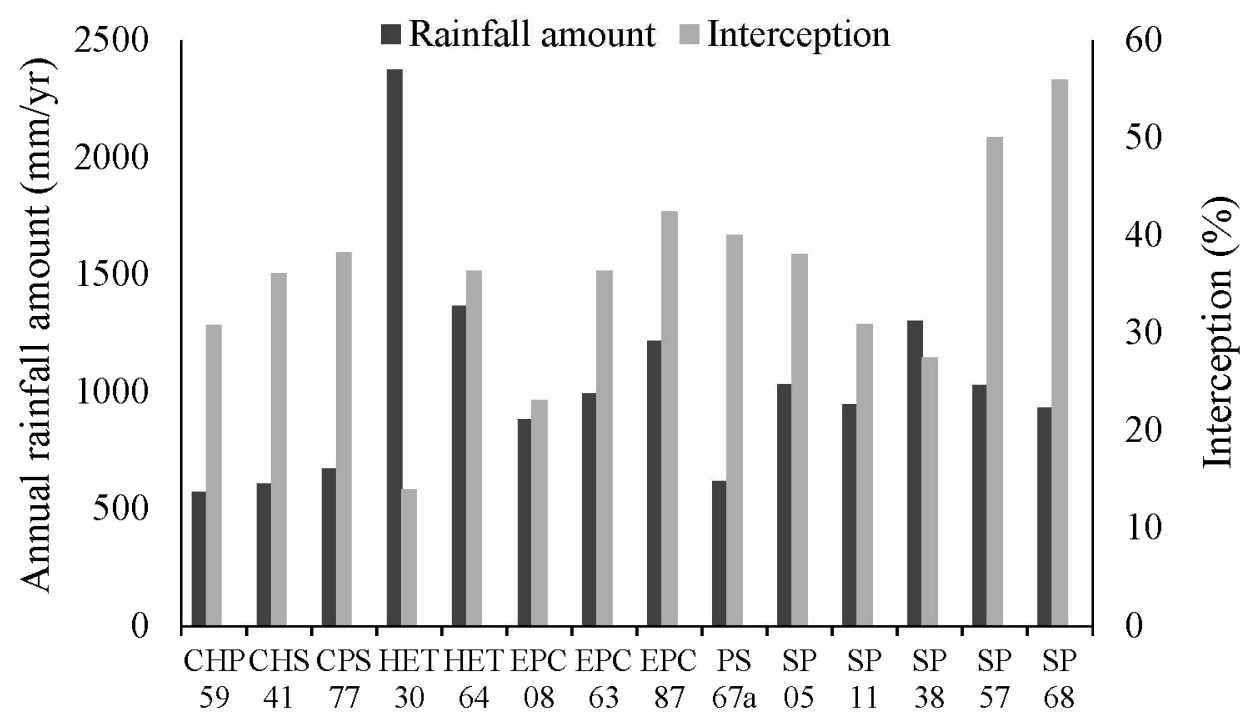

Figure S1. Annual rainfall amount and its interception by canopy $(\mathrm{n}=14$ sites). CHP: Pedunculate Oak; CHS: Sessile Oak; CPS: Pedunculate/Sessile Oak; HET: Beech; EPC: Spruce; PS: Scots Pines; SP: Silver Fir. 

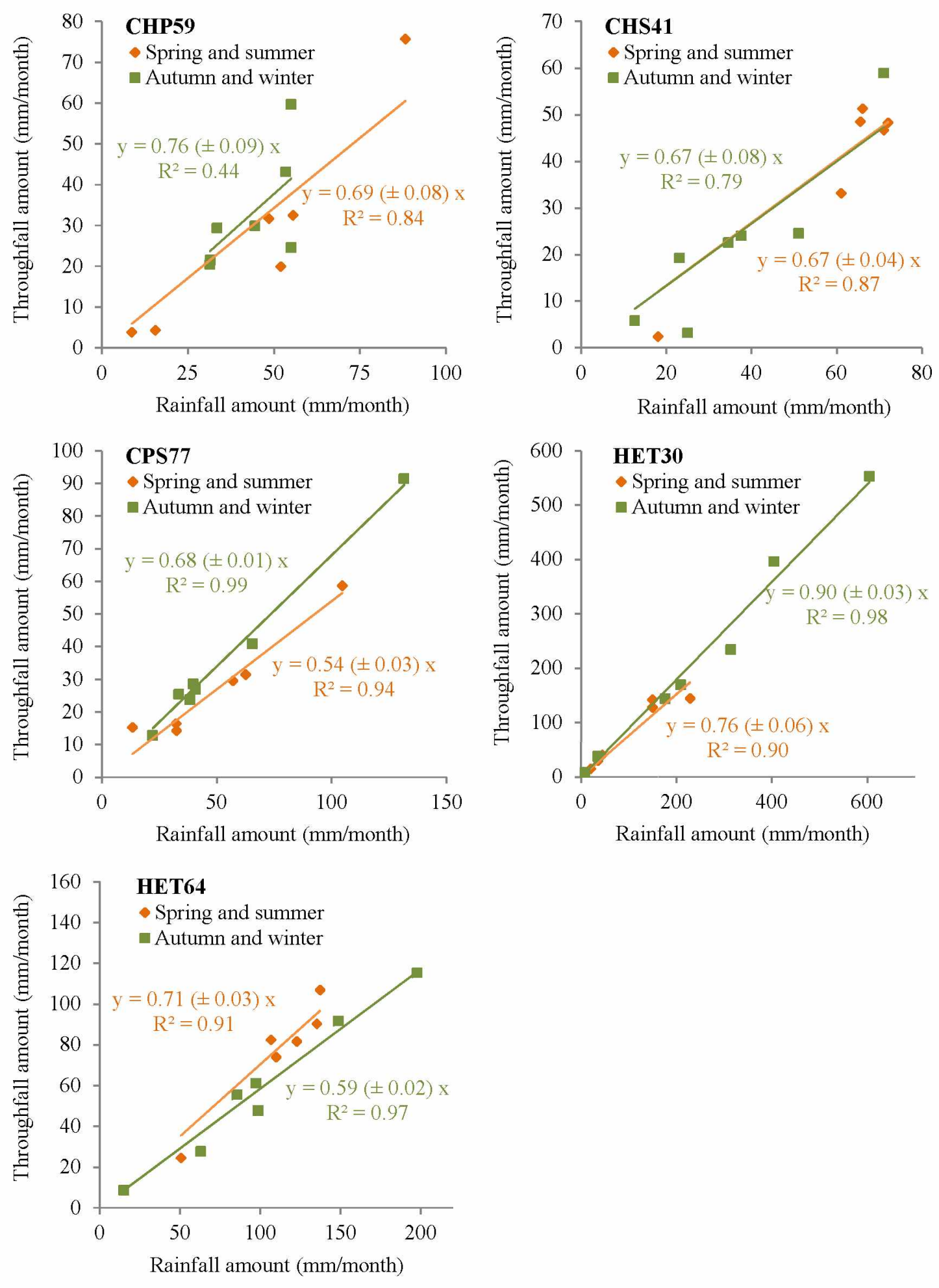

Figure S2. Monthly throughfall amount as function of those of rainfall for each deciduous trees stand and according to season. HET: Beech; CHP: Pedunculate Oak; CHS: Sessile Oak; CPS: Pedunculate/Sessile Oak. The four seasons were defined as follows: September 2016 to November 2016 and September 2017 (Autumn), December 2016 to February 2017 (Winter), March 2017 to May 2017 (Spring), and June 2017 to August 2017 (Summer). 


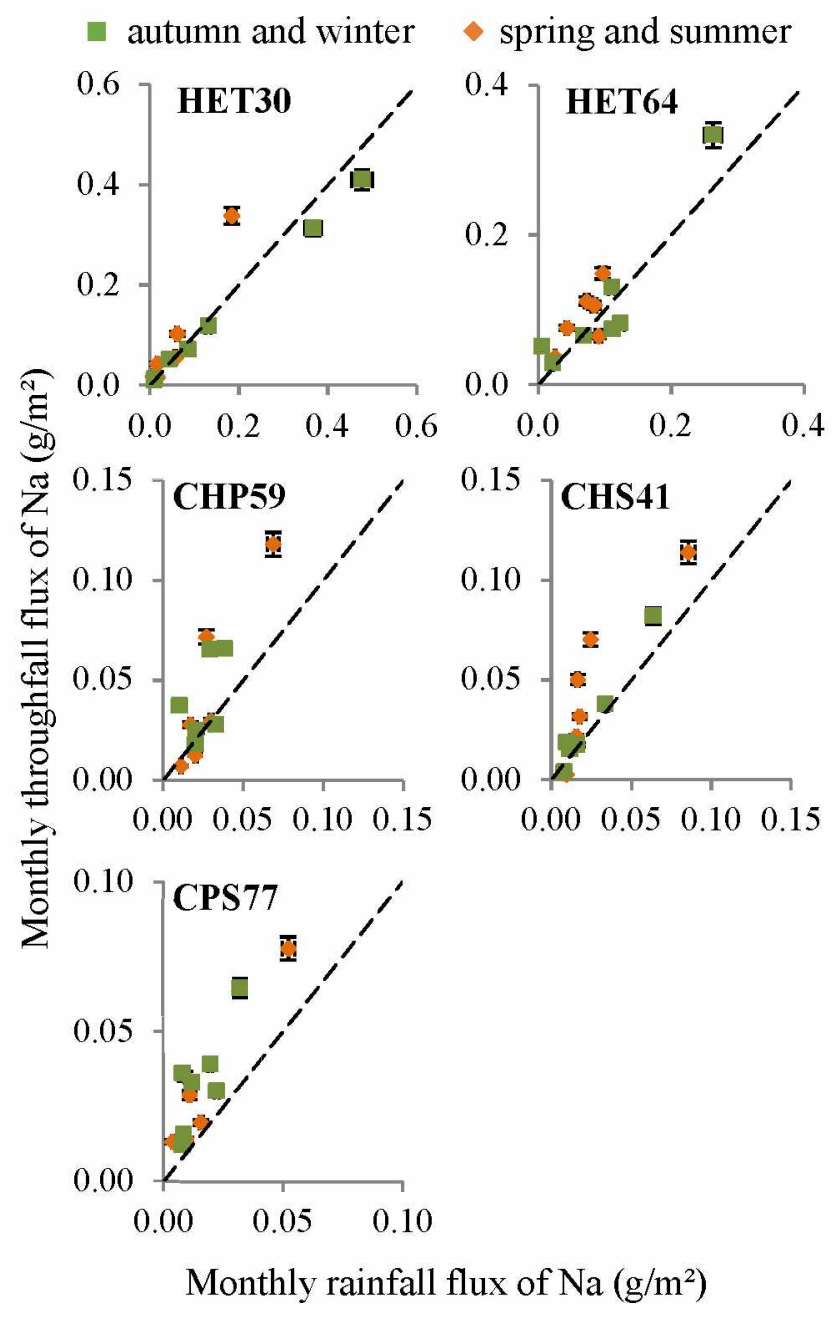

Figure S3. Monthly throughfall flux of $\mathrm{Na}$ as function of those of rainfall according to season. Error bars correspond to standard errors. The dotted line corresponds to a 1:1 ratio. HET=Beech; $\mathrm{CHP}=$ Pedunculate Oak; $\mathrm{CHS}=$ Sessile Oak; $\mathrm{CPS}=$ Sessile/Ped. Oak. The four seasons were defined as follows: September 2016 to November 2016 and September 2017 (Autumn), December 2016 to February 2017 (Winter), March 2017 to May 2017 (Spring), and June 2017 to August 2017 (Summer). 
autumn and winter spring and summer
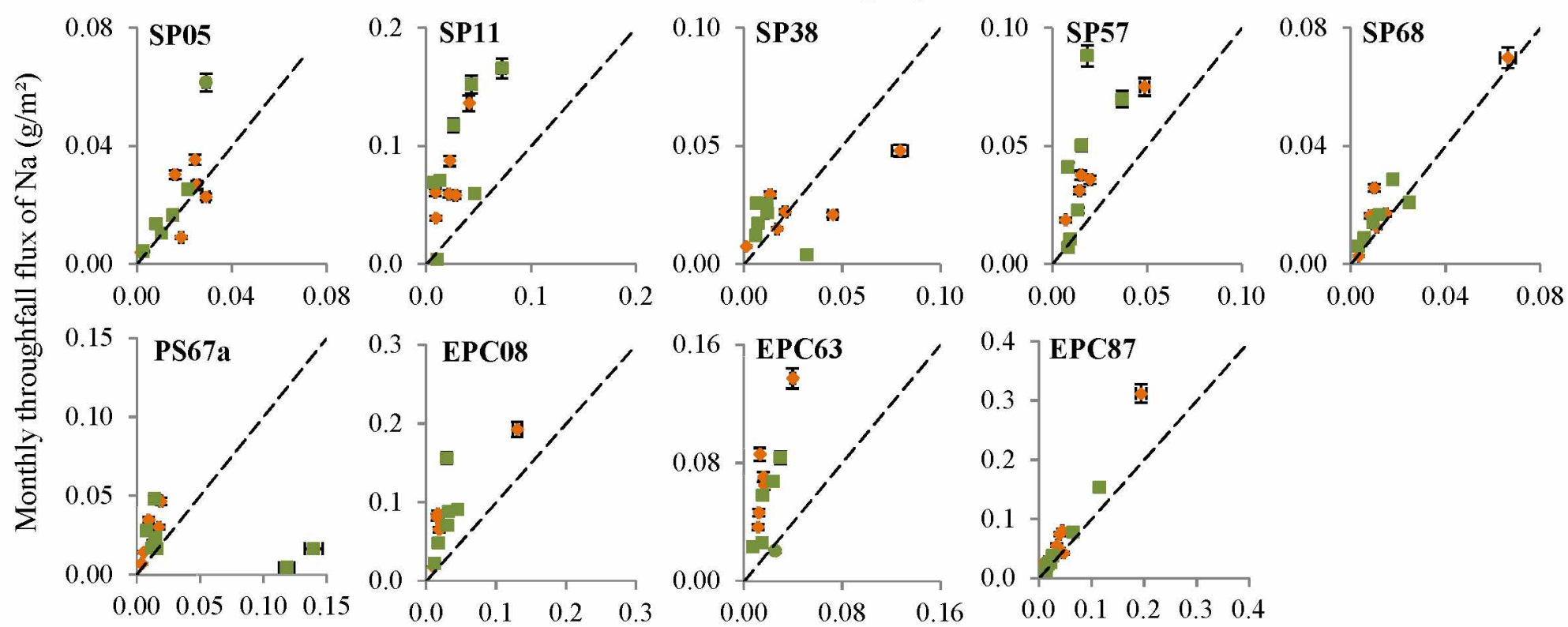

Monthly rainfall flux of $\mathrm{Na}\left(\mathrm{g} / \mathrm{m}^{2}\right)$

Figure S4. Monthly throughfall flux of $\mathrm{Na}$ as function of those of rainfall according to season. Error bars correspond to standard errors. The dotted line corresponds to a 1:1 ratio. SP=Silver fir; PS=Scots Pine; EPC=Spruce. The four seasons were defined as follows: September 2016 to November 2016 and September 2017 (Autumn), December 2016 to February 2017

(Winter), March 2017 to May 2017 (Spring), and June 2017 to August 2017 (Summer). 


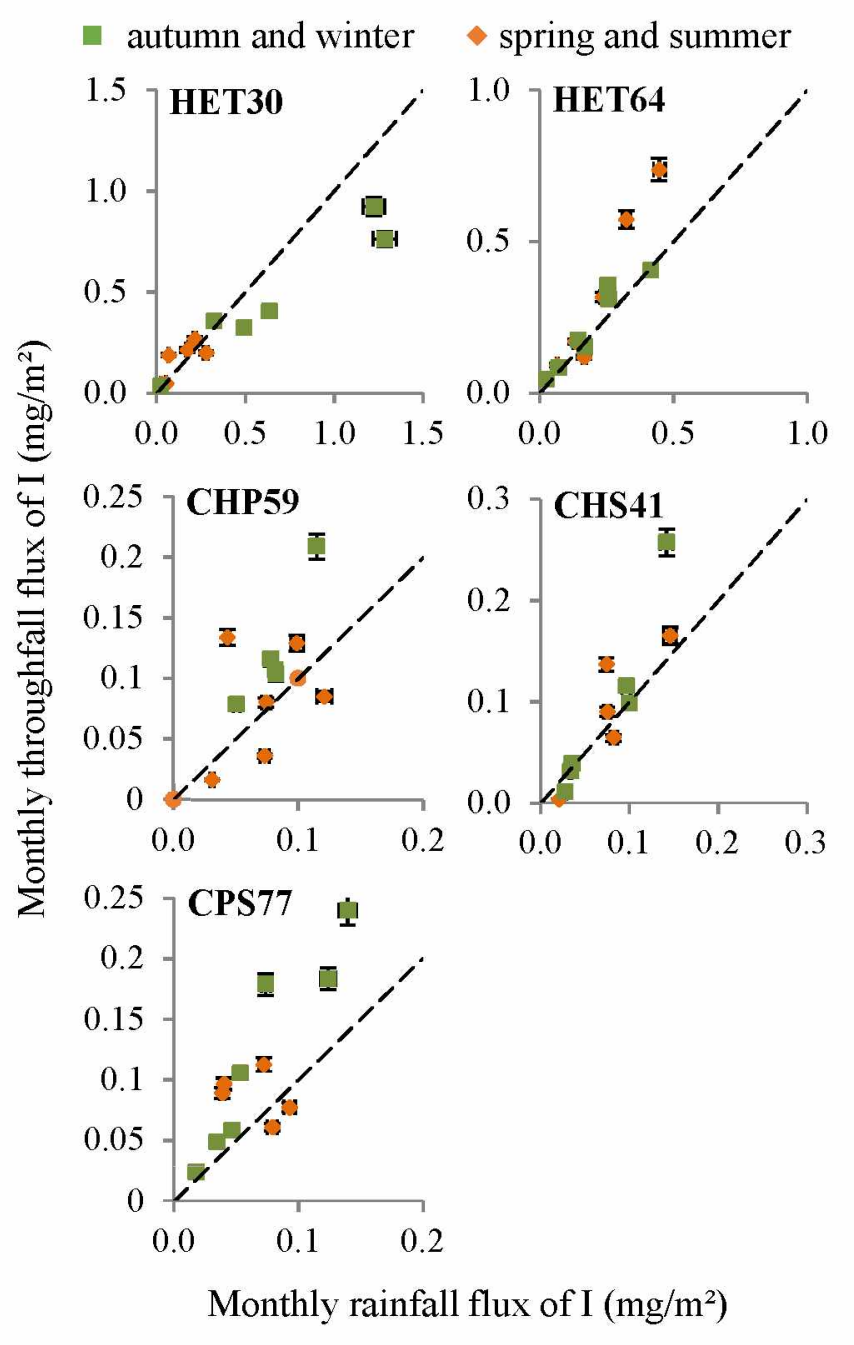

Figure S5. Monthly throughfall flux of I as function of those of rainfall according to season. Error bars correspond to standard errors. The dotted line corresponds to a 1:1 ratio. HET=Beech; $\mathrm{CHP}=$ Pedunculate Oak; $\mathrm{CHS}=$ Sessile Oak; $\mathrm{CPS}=$ Sessile/Ped. Oak. The four seasons were defined as follows: September 2016 to November 2016 and September 2017 (Autumn), December 2016 to February 2017 (Winter), March 2017 to May 2017 (Spring), and June 2017 to August 2017 (Summer). 


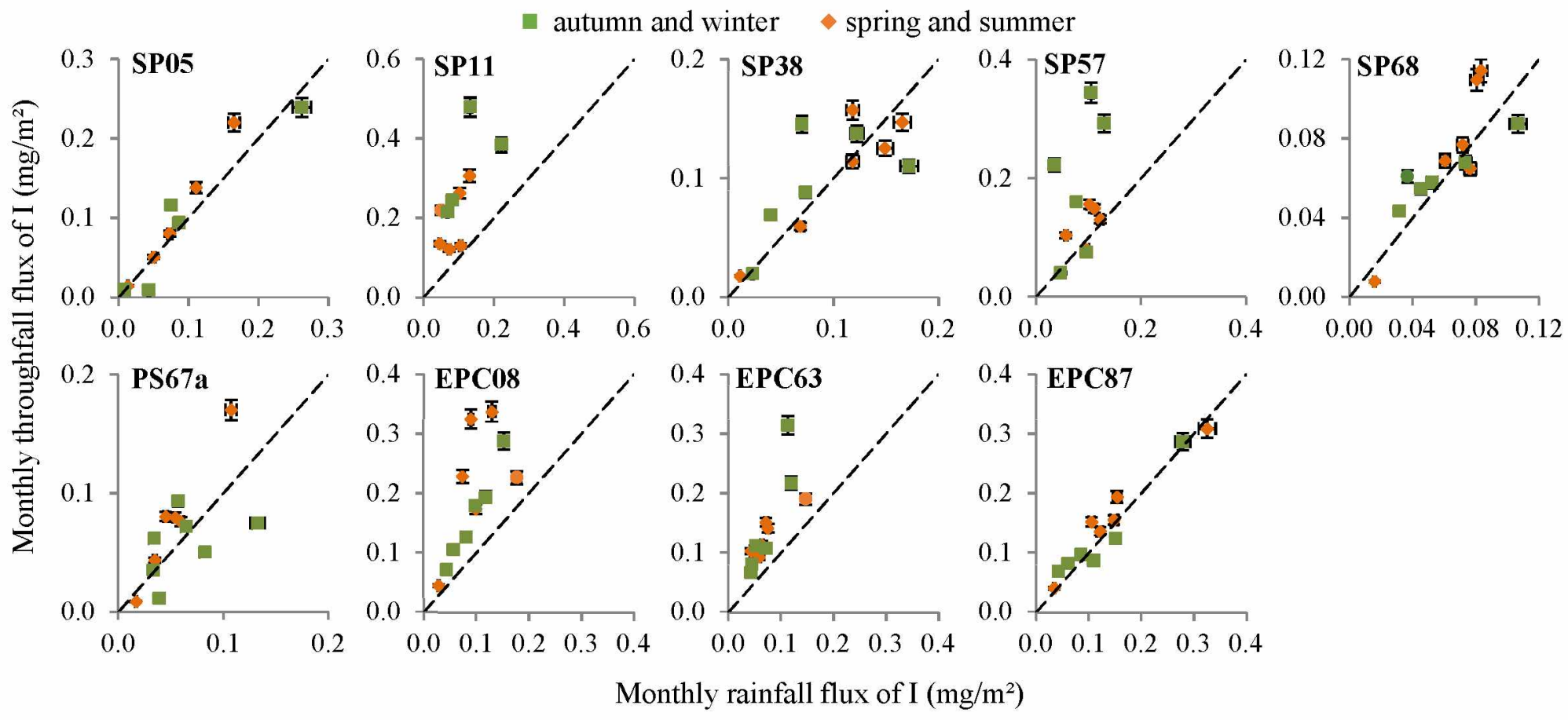

Figure S6. Monthly throughfall flux of I as function of those of rainfall according to season. Error bars correspond to standard errors. The dotted line corresponds to a 1:1 ratio. $\mathrm{SP}=$ Silver fir; PS=Scots Pine; $\mathrm{EPC}=$ Spruce. The four seasons were defined as follows: September 2016 to November 2016 and September 2017 (Autumn), December 2016 to February 2017 (Winter), March 2017 to May 2017 (Spring), and June 2017 to August 2017 (Summer). 


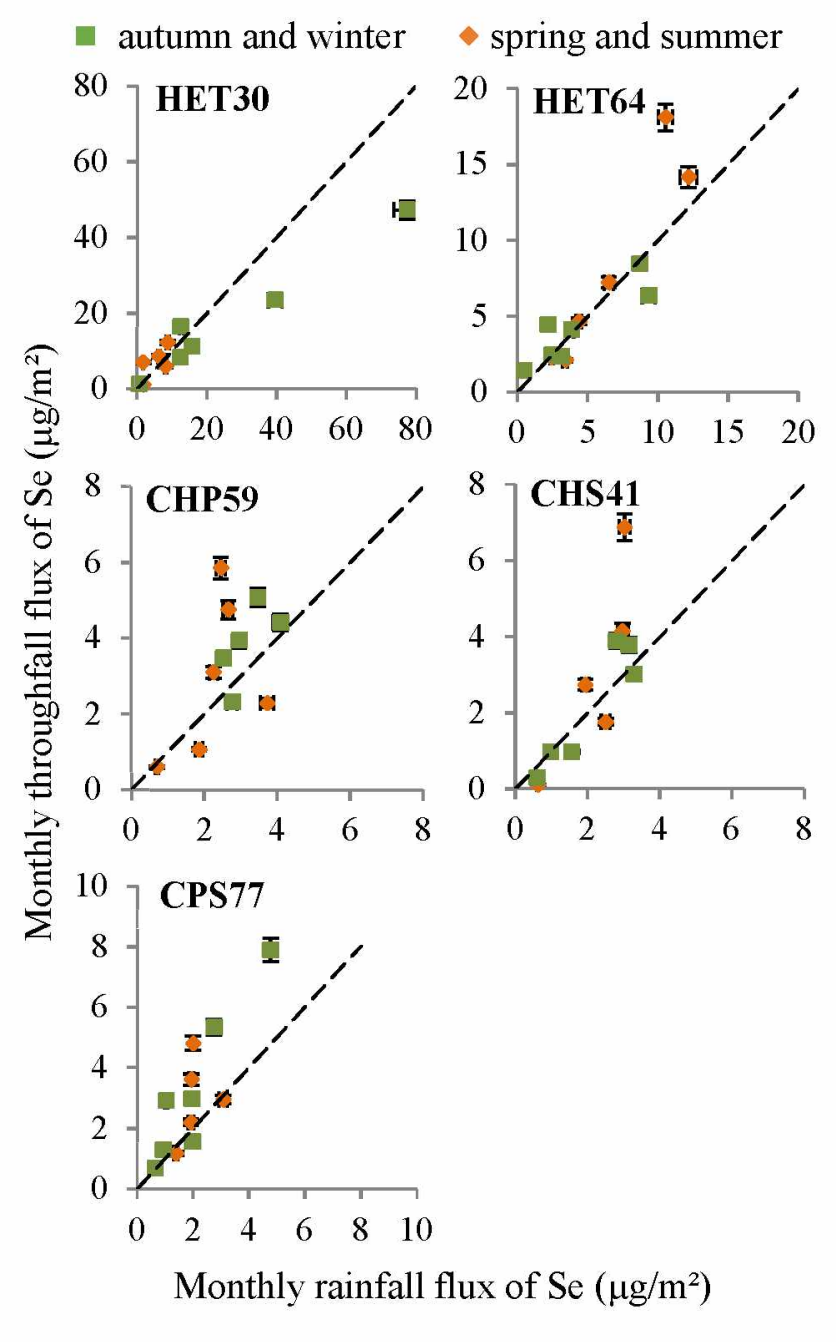

Figure S7. Monthly throughfall flux of Se as function of those of rainfall according to season. Error bars correspond to standard errors. The dotted line corresponds to a 1:1 ratio. $\mathrm{HET}=$ Beech; $\mathrm{CHP}=$ Pedunculate Oak; $\mathrm{CHS}=$ Sessile Oak; $\mathrm{CPS}=$ Sessile/Ped. Oak. The four seasons were defined as follows: September 2016 to November 2016 and September 2017 (Autumn), December 2016 to February 2017 (Winter), March 2017 to May 2017 (Spring), and June 2017 to August 2017 (Summer). 


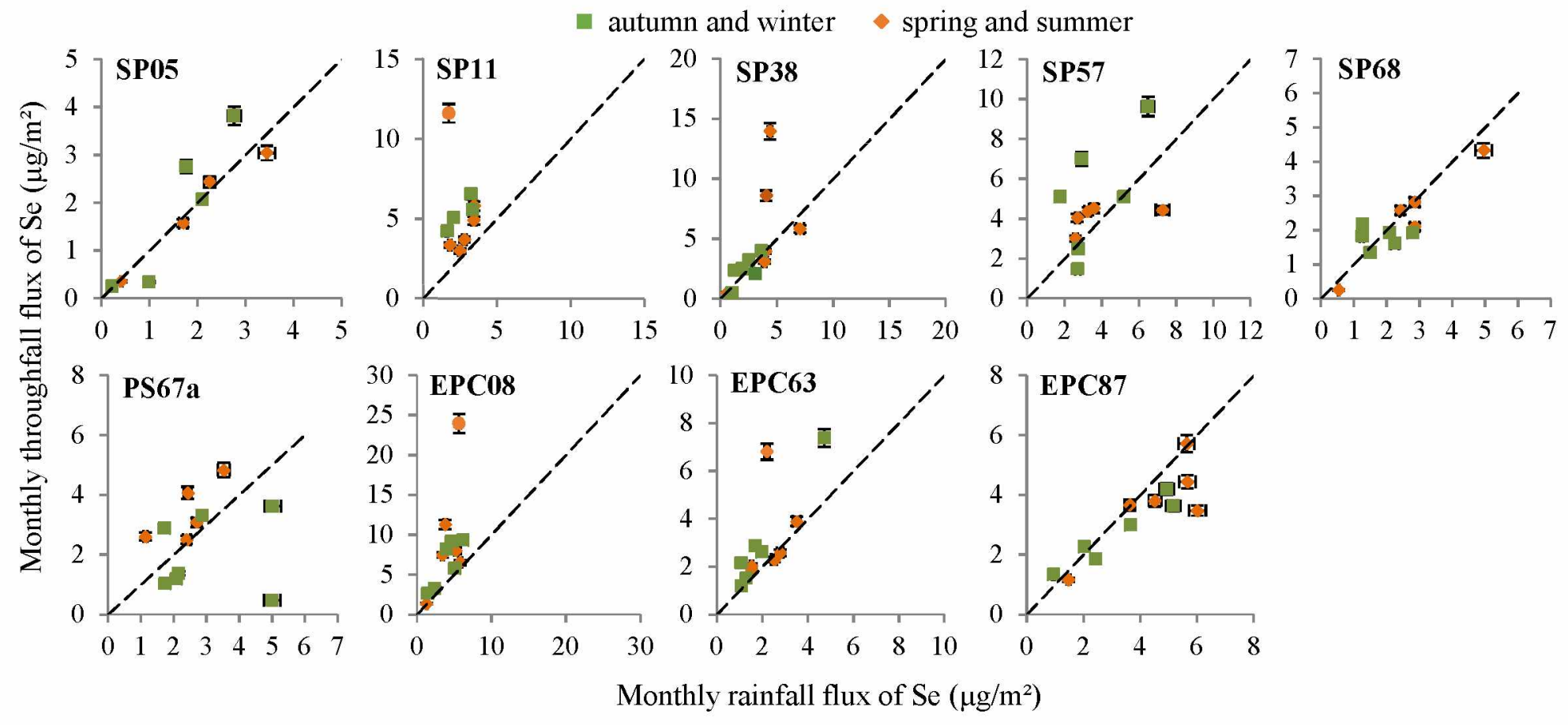

Figure S8. Monthly throughfall flux of Se as function of those of rainfall according to season. Error bars correspond to standard errors. The dotted line corresponds to a 1:1 ratio. SP=Silver fir; PS=Scots Pine; EPC=Spruce. The four seasons were defined as follows: September 2016 to November 2016 and September 2017 (Autumn), December 2016 to February 2017 (Winter), March 2017 to May 2017 (Spring), and June 2017 to August 2017

(Summer). 


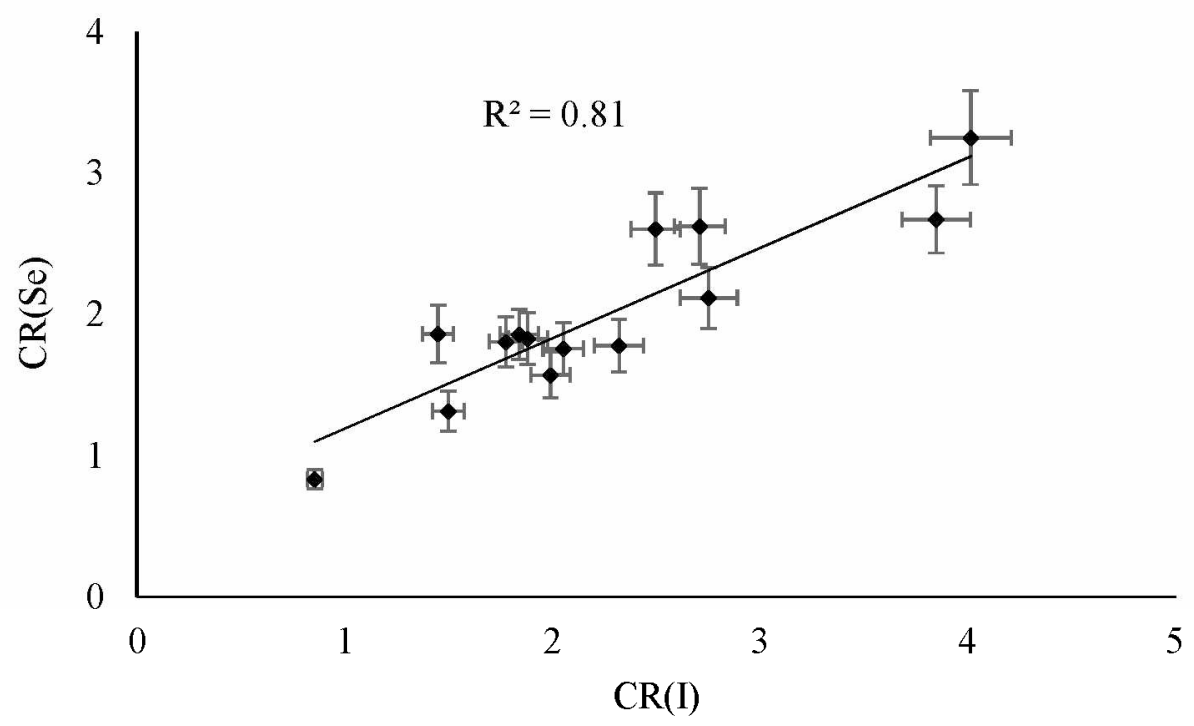

Figure S9. Concentration Ratios (CR) from AVWM concentrations of Se as function of those of $I(n=14$ sites $)$. Error bars correspond to standard errors. 


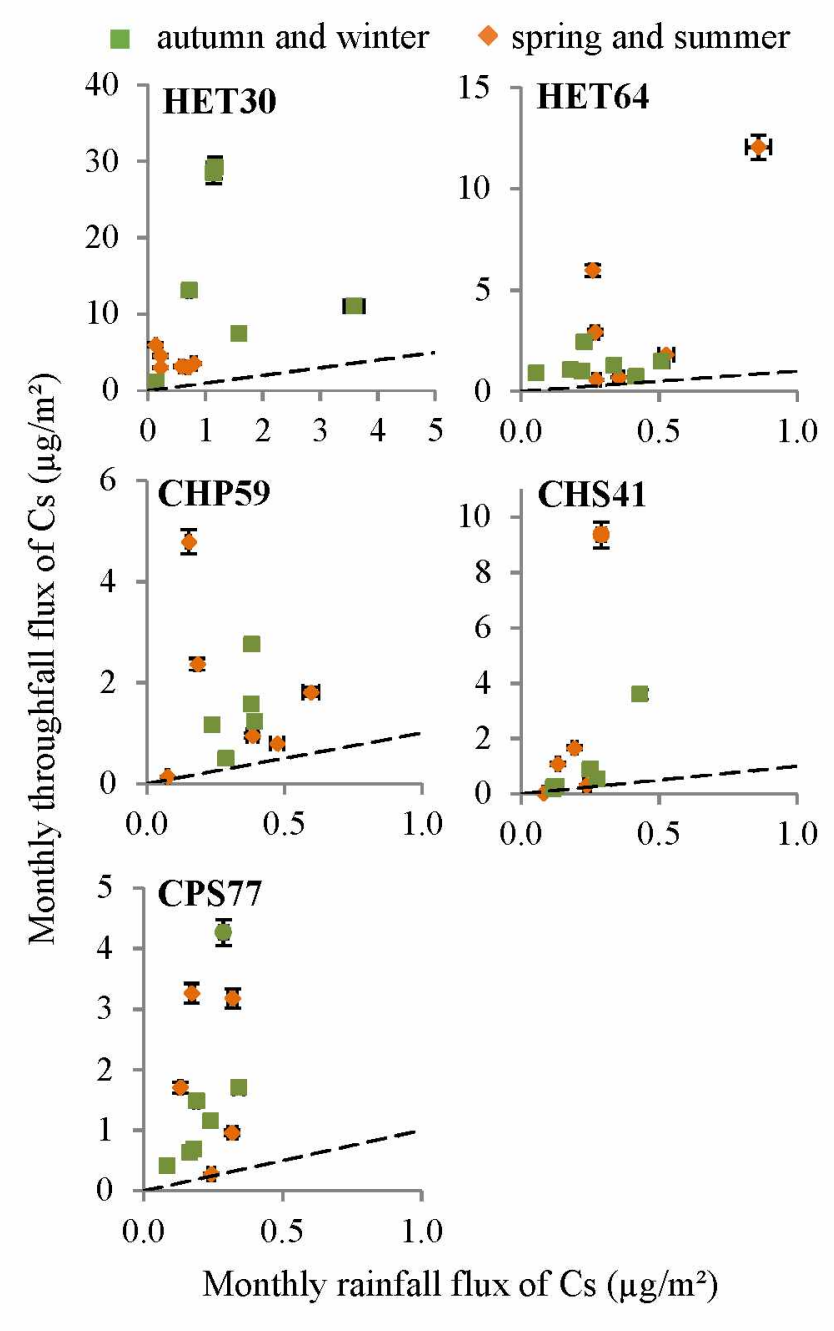

Figure S10. Monthly throughfall flux of Cs as function of those of rainfall according to season. Error bars correspond to standard errors. The dotted line corresponds to a 1:1 ratio. $\mathrm{HET}=\mathrm{Beech}$; $\mathrm{CHP}=$ Pedunculate Oak; $\mathrm{CHS}=$ Sessile Oak; $\mathrm{CPS}=$ Sessile/Ped. Oak. The four seasons were defined as follows: September 2016 to November 2016 and September 2017 (Autumn), December 2016 to February 2017 (Winter), March 2017 to May 2017 (Spring), and June 2017 to August 2017 (Summer). 


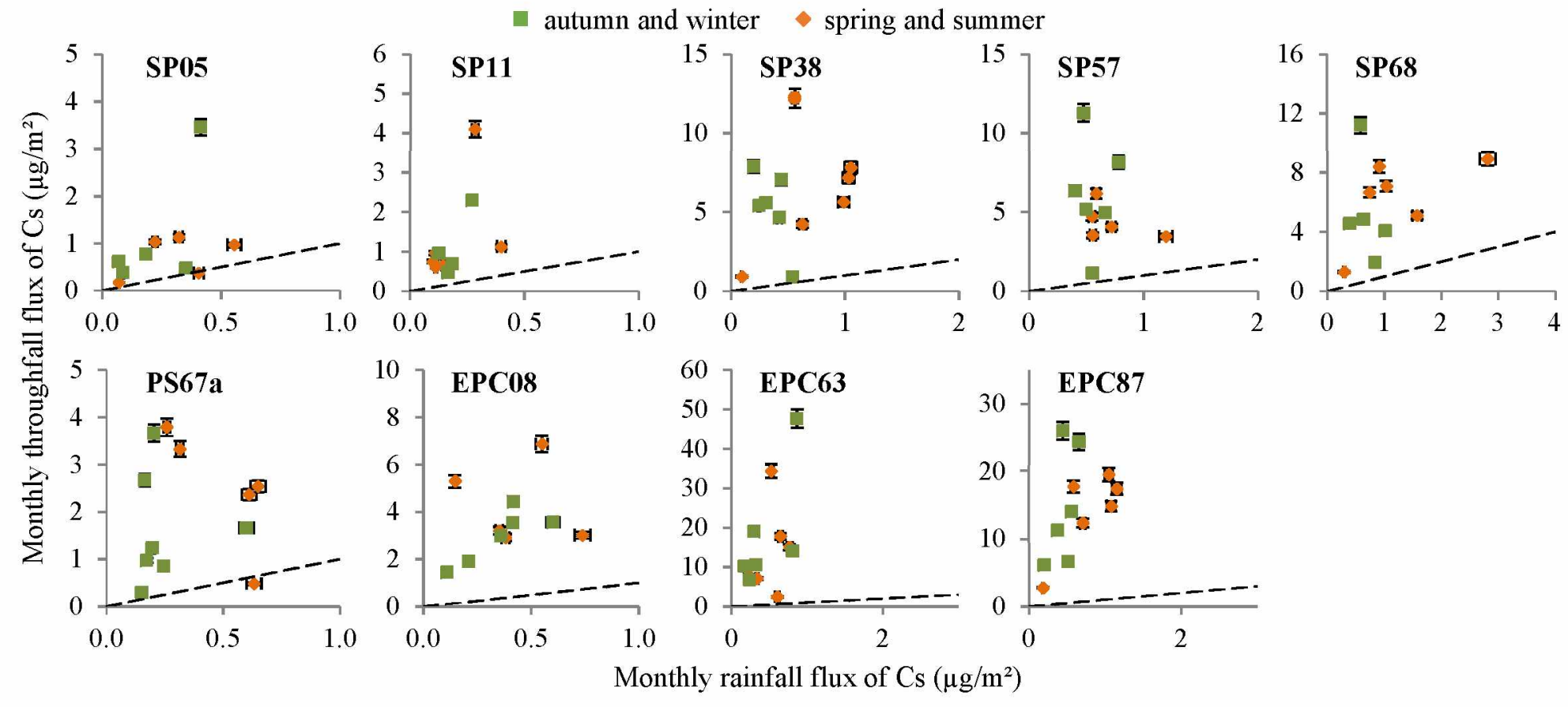

Figure S11. Monthly throughfall flux of $\mathrm{Cs}$ as function of those of rainfall according to season. Error bars correspond to standard errors. The dotted line corresponds to a 1:1 ratio. SP=Silver fir; PS=Scots Pine; EPC=Spruce. The four seasons were defined as follows: September 2016 to November 2016 and September 2017 (Autumn), December 2016 to February 2017 (Winter), March 2017 to May 2017 (Spring), and June 2017 to August 2017 (Summer). 


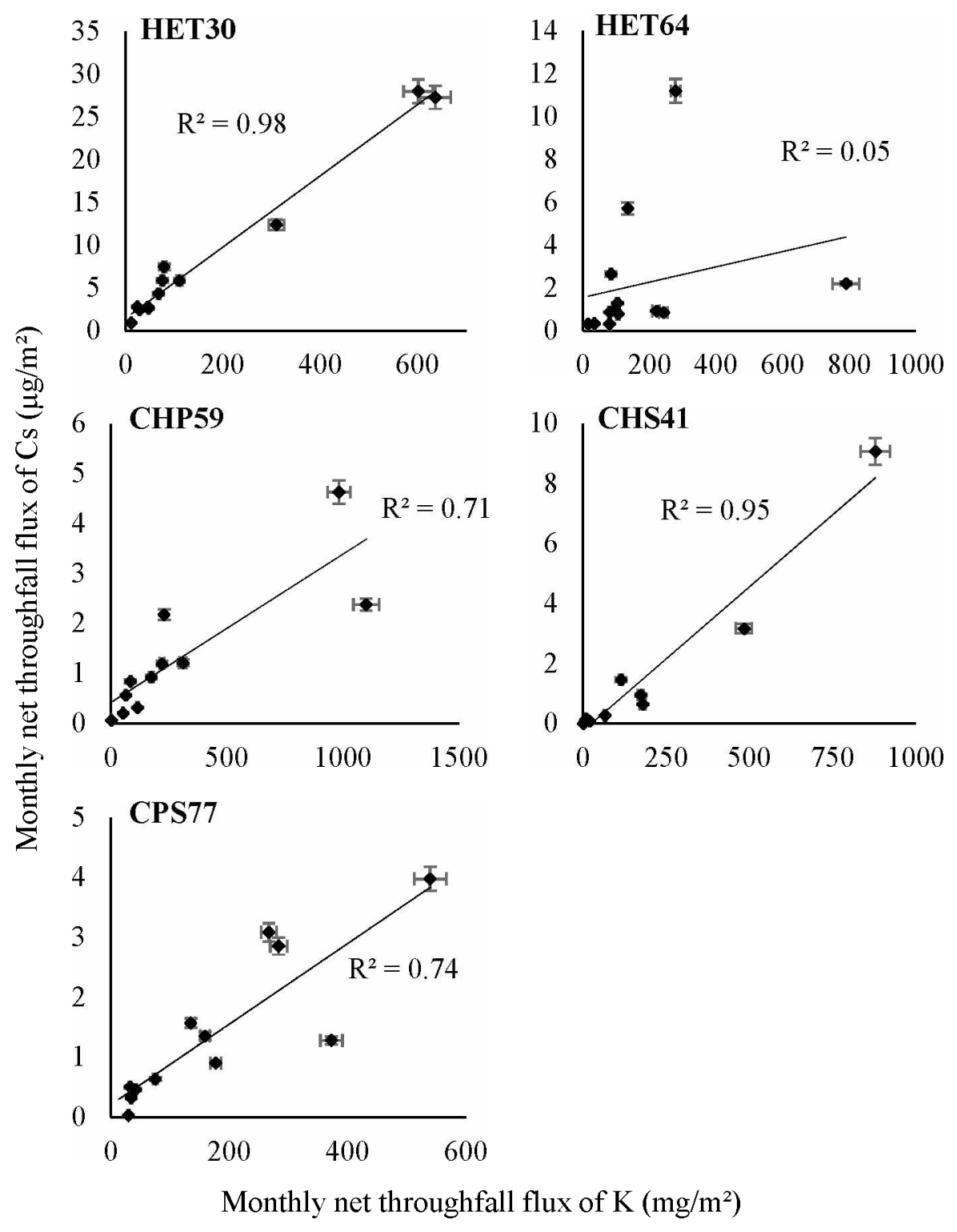

Figure S12. Monthly net throughfall flux of $\mathrm{Cs}$ as function of those of $\mathrm{K}$ for deciduous trees. Error bars correspond to standard errors. $\mathrm{HET}=\mathrm{Beech}$; $\mathrm{CHP}=$ Pedunculate Oak; $\mathrm{CHS}=$ Sessile Oak; CPS $=$ Sessile/Ped. 

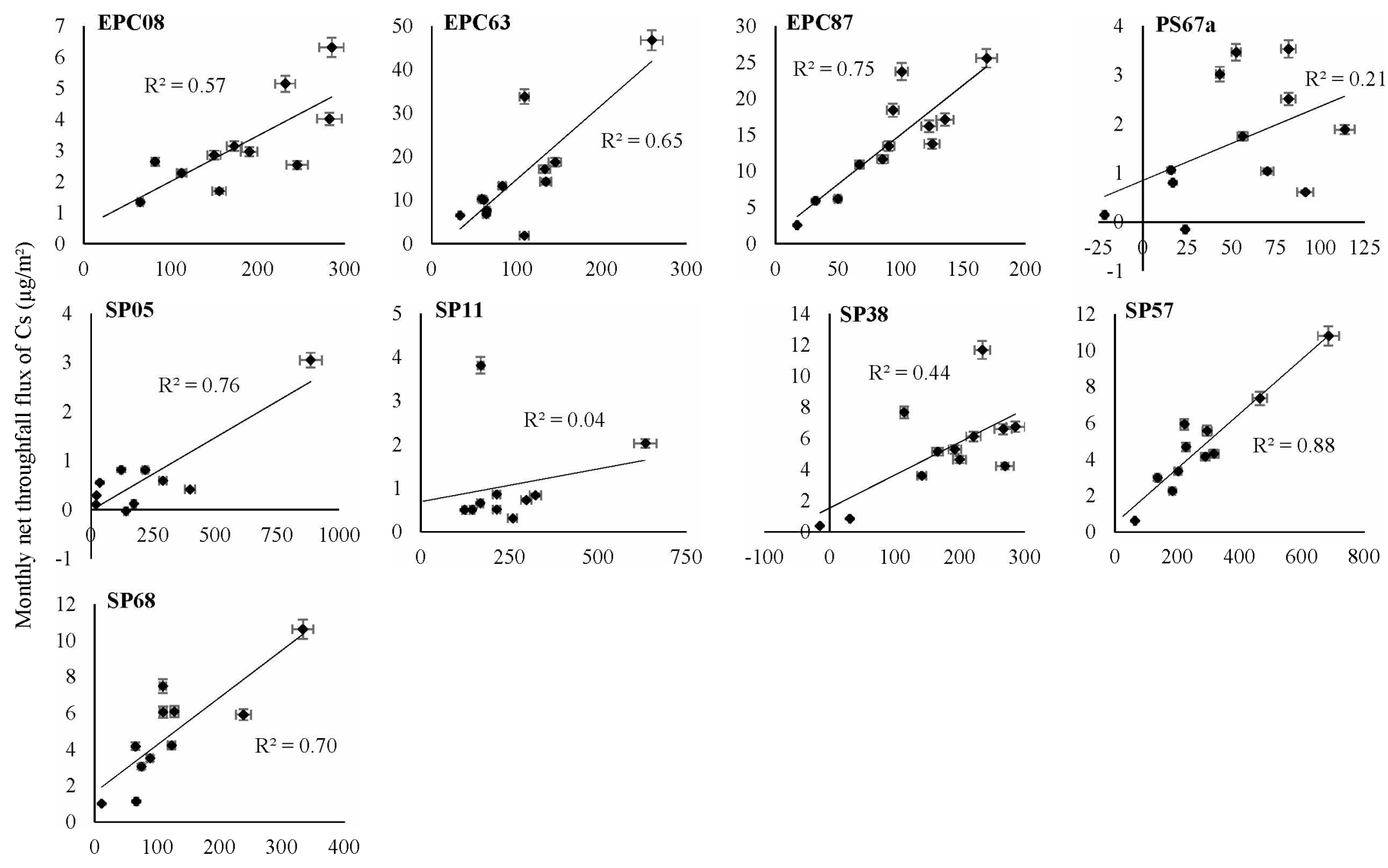

Monthly net throughfall flux of K (mg/m²)

Figure S13. Monthly net throughfall flux of $\mathrm{Cs}$ as function of those of $\mathrm{K}$ for coniferous trees. Error bars correspond to standard errors. $\mathrm{EPC}=\mathrm{Spruce} ; \mathrm{PS}=\mathrm{Scots}$ Pine; $\mathrm{SP}=$ Silver fir. 


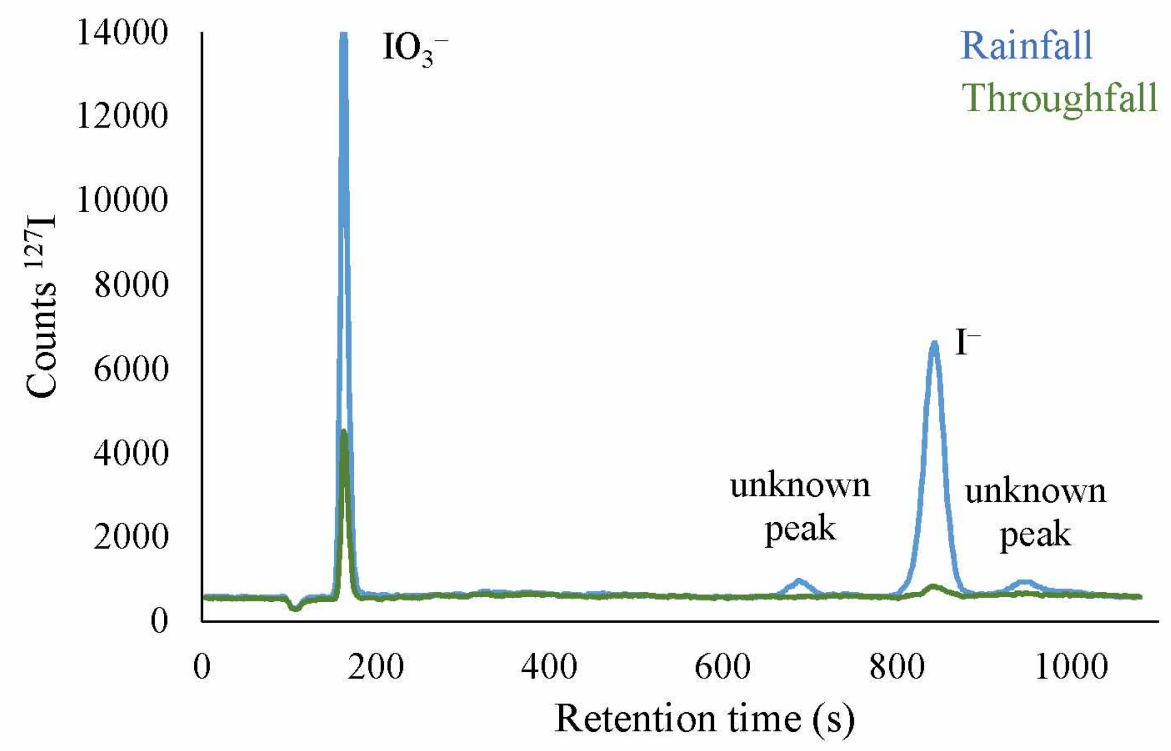

Figure S14. Example of IC-ICP-MS chromatograms of inorganic iodine species in rainfall and throughfall (sample EPC08, February 2017). 


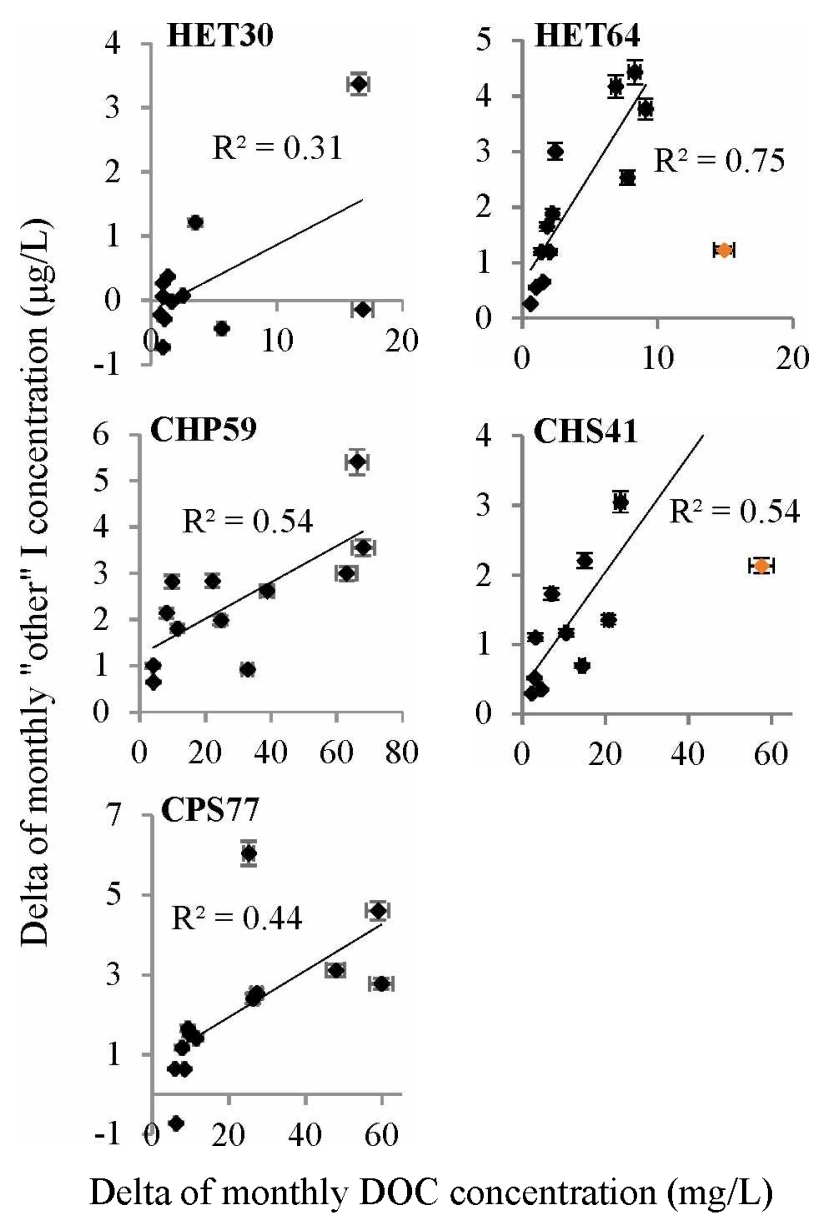

Figure S15. Delta of monthly "other" iodine concentration (= throughfall I concentration - rainfall I concentration) as function of those of DOC for deciduous trees. Orange dots correspond to excluded data. Error bars correspond to standard errors. $\mathrm{HET}=\mathrm{Beech}$; $\mathrm{CHP}=$ Pedunculate Oak; $\mathrm{CHS}=$ Sessile Oak; CPS=Sessile/Ped. 

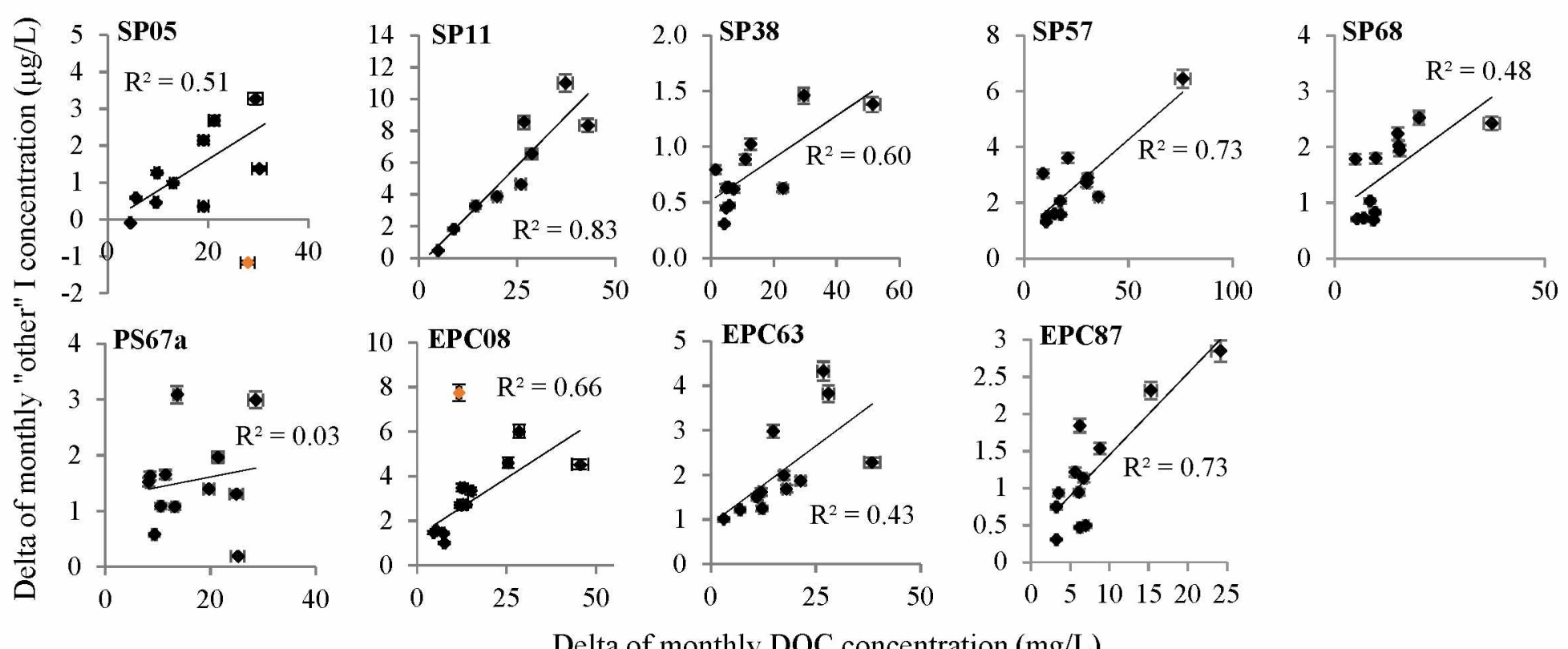

Delta of monthly DOC concentration $(\mathrm{mg} / \mathrm{L})$

Figure S16. Delta of monthly "other" iodine concentration (= throughfall I concentration - rainfall I concentration) as function of those of DOC for coniferous trees. Orange dots correspond to excluded data. Error bars correspond to standard errors. EPC=Spruce; PS=Scots Pine; SP=Silver fir. 
Table S1. Environmental conditions characteristics of studied sites ( $\mathrm{n}=14$ sites).

\begin{tabular}{cccccc}
\hline Forest site* & $\begin{array}{c}\text { Dominant tree } \\
\text { species* }\end{array}$ & $\begin{array}{c}\text { Functional tree } \\
\text { types }\end{array}$ & Climate* & $\begin{array}{c}\text { Tree height } \\
(\mathrm{m}) * *\end{array}$ & $\begin{array}{c}\text { Tree diameter } \\
(\mathrm{cm})^{* *}\end{array}$ \\
\hline CHP59 & Pedunculate Oak & Deciduous & Oceanic & 26.0 & 45.1 \\
CHS41 & Sessile Oak & Deciduous & Transition & 26.6 & 42.2 \\
CPS77 & Sessile/Ped. Oak & Deciduous & Transition & 30.0 & 49.2 \\
EPC08 & Spruce & Coniferous & Transition & 27.6 & 38.4 \\
EPC63 & Spruce & Coniferous & Mountainous & 27.5 & 35.5 \\
EPC87 & Spruce & Coniferous & Transition & 23.9 & 31.1 \\
HET30 & Beech & Deciduous & Mountainous & 18.7 & 32.7 \\
HET64 & Beech & Deciduous & Mountainous & 29.0 & 29.8 \\
PS67a & Scots Pine & Coniferous & Continental & 25.9 & 32.1 \\
SP05 & Silver fir & Coniferous & Mountainous & 30.9 & 36.9 \\
SP11 & Silver fir & Coniferous & Mountainous & 32.4 & 47.1 \\
SP38 & Silver fir & Coniferous & Mountainous & 29.9 & 41.5 \\
SP57 & Silver fir & Coniferous & Continental & 28.4 & 40.8 \\
SP68 & Silver fir & Coniferous & Continental & 32.6 & 51.5 \\
\hline
\end{tabular}

*: published in Redon et al. 2011; **measured in 2014 


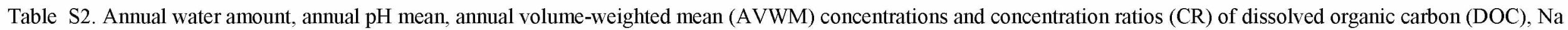
and $\mathrm{K}$ in rainfall and throughfall of studied sites $(\mathrm{n}=14$ sites $)$. Uncertainties correspond to standard errors.

\begin{tabular}{|c|c|c|c|c|c|c|c|c|c|c|c|c|c|c|c|c|c|c|c|c|c|c|}
\hline \multirow{3}{*}{$\begin{array}{l}\text { Forest site } \\
\text { CHP59 }\end{array}$} & \multicolumn{2}{|c|}{ Water amount $\left(\mathrm{mm} \mathrm{yr}^{-1}\right)$} & \multicolumn{2}{|c|}{$\mathrm{pH}$} & \multicolumn{2}{|c|}{$\begin{array}{c}\text { AVWM DOC conc. } \\
\left(\mathrm{mg} \mathrm{L}^{-1}\right)\end{array}$} & \multirow{2}{*}{\multicolumn{3}{|c|}{$\mathrm{CR}(\mathrm{DOC})$}} & \multicolumn{2}{|c|}{$\begin{array}{c}\text { AVWM Na } \\
\left(\mathrm{mg} \mathrm{L}^{-1}\right)\end{array}$} & \multirow{2}{*}{\multicolumn{2}{|c|}{$\mathrm{CR}(\mathrm{Na})$}} & \multicolumn{6}{|c|}{$\begin{array}{c}\text { AVWM K }{ }^{+} \text {conc. } \\
\left(\mathrm{mg} \mathrm{L}^{-1}\right)\end{array}$} & \multirow{2}{*}{\multicolumn{3}{|c|}{$\mathrm{CR}(\mathrm{K})$}} \\
\hline & Rainfall* & Throughfall & Rainfall* & Throughfall & Rainfall* & Throughfall & & & & Rainfall* & Throughfall & & & \multicolumn{3}{|c|}{ Rainfall* } & \multicolumn{3}{|c|}{ Throughfall } & & & \\
\hline & 573 & 396 & $6.1 \pm 0.6$ & $66.5 \pm 0.5$ & $0.68 \pm 0.03$ & $25.8 \pm 1.3$ & 38 & \pm & 3 & $0.62 \pm 0.03$ & $1.39 \pm 0.07$ & $2.2 \pm$ & 0.2 & 0.35 & $5 \pm 1$ & 0.02 & 9.86 & \pm 0 & 0.49 & 28 & \pm & 2 \\
\hline CHS41 & 608 & 388 & $6.1 \pm 0.3$ & $6.3 \pm 0.4$ & $0.58 \pm 0.03$ & $20.4 \pm 1.0$ & 35 & \pm & 3 & $0.53 \pm 0.03$ & $1.21 \pm 0.06$ & $2.3 \pm$ & 0.2 & 0.12 & $2 \pm 1$ & 0.01 & 5.96 & \pm 0 & 0.30 & 49 & \pm & 3 \\
\hline CPS77 & 673 & 416 & $6.0 \pm 0.3$ & $6.1 \pm 0.5$ & $0.50 \pm 0.03$ & $21.8 \pm 1.1$ & 44 & \pm & 3 & $0.31 \pm 0.02$ & $1.00 \pm 0.05$ & $3.2 \pm$ & 0.2 & 0.13 & \pm & 0.01 & 5.42 & \pm 0 & 0.27 & 41 & \pm & 3 \\
\hline $\mathrm{EPC} 08$ & 882 & 678 & $6.0 \pm 0.5$ & $6.2 \pm 0.4$ & $0.37 \pm 0.02$ & $14.2 \pm 0.7$ & 38 & \pm & 3 & $0.44 \pm 0.02$ & $1.51 \pm 0.08$ & $3.4 \pm$ & 0.2 & 0.08 & $3 \pm 1$ & 0.00 & 3.21 & \pm 0 & 0.16 & 41 & \pm & 3 \\
\hline EPC63 & 993 & 631 & $6.2 \pm 0.4$ & $+5.9 \pm 0.4$ & $0.25 \pm 0.01$ & $17.6 \pm 0.9$ & 70 & \pm & 4 & $0.26 \pm 0.01$ & $1.16 \pm 0.06$ & $4.4 \pm$ & 0.3 & 0.16 & $5 \pm$ & 0.01 & 2.22 & \pm 0 & 0.11 & 14 & \pm & 1 \\
\hline EPC87 & 1218 & 701 & $5.8 \pm 0.2$ & $5.8 \pm 0.3$ & $0.40 \pm 0.02$ & $7.9 \pm 0.4$ & 20 & \pm & 1 & $0.53 \pm 0.03$ & $1.35 \pm 0.07$ & $2.6 \pm$ & 0.2 & 0.10 & \pm & 0.01 & 1.77 & \pm 0 & 0.09 & 17 & \pm & 1 \\
\hline HET30 & 2372 & 2041 & $5.9 \pm 0.6$ & $6.1 \pm 0.7$ & $0.12 \pm 0.01$ & $2.0 \pm 0.1$ & 17 & \pm & 2 & $0.62 \pm 0.03$ & $0.76 \pm 0.04$ & $1.2 \pm$ & 0.1 & 0.07 & $7 \pm 1$ & 0.00 & 1.10 & \pm 0 & 0.05 & 15 & \pm & 1 \\
\hline HET64 & 1365 & 868 & $6.2 \pm 0.3$ & $6.6 \pm 0.5$ & $0.30 \pm 0.02$ & $3.6 \pm 0.2$ & 12 & \pm & 1 & $0.82 \pm 0.04$ & $1.50 \pm 0.08$ & $1.8 \pm$ & 0.1 & 0.11 & \pm & 0.01 & 2.78 & \pm 0 & 0.14 & 25 & \pm & 2 \\
\hline PS67a & 619 & 371 & $6.2 \pm 0.7$ & $76.0 \pm 0.5$ & $0.61 \pm 0.03$ & $17.0 \pm 0.8$ & 28 & \pm & 2 & $0.26 \pm 0.01$ & $0.83 \pm 0.04$ & $3.2 \pm$ & 0.2 & 0.24 & $t \pm$ & 0.01 & 2.09 & \pm 0 & 0.10 & 9 & \pm & 1 \\
\hline SP05 & 1032 & 639 & $6.4 \pm 0.5$ & $56.7 \pm 0.4$ & $0.55 \pm 0.03$ & $17.2 \pm 0.9$ & 31 & \pm & 2 & $0.20 \pm 0.01$ & $0.41 \pm 0.02$ & $2.1 \pm$ & 0.2 & 0.15 & $5 \pm$ & 0.01 & 5.65 & \pm 0 & 0.28 & 37 & \pm & 3 \\
\hline SP11 & 945 & 653 & $5.9 \pm 0.3$ & $6.2 \pm 0.3$ & $0.55 \pm 0.03$ & $14.8 \pm 0.7$ & 27 & \pm & 2 & $0.37 \pm 0.02$ & $1.65 \pm 0.08$ & $4.5 \pm$ & 0.3 & 0.08 & $3 \pm$ & 0.00 & 4.71 & \pm 0 & 0.24 & 57 & \pm & 4 \\
\hline SP38 & 1301 & 943 & $6.0 \pm 0.5$ & $6.1 \pm 0.7$ & $0.32 \pm 0.02$ & $11.7 \pm 0.6$ & 37 & \pm & 3 & $0.21 \pm 0.01$ & $0.29 \pm 0.01$ & $1.4 \pm$ & 0.1 & 0.17 & $7 \pm$ & 0.01 & 2.66 & \pm 0 & 0.13 & 15 & \pm & 1 \\
\hline SP57 & 1029 & 514 & $5.6 \pm 0.5$ & $5.8 \pm 0.6$ & $0.41 \pm 0.02$ & $22.0 \pm 1.1$ & 54 & \pm & 4 & $0.22 \pm 0.01$ & $0.97 \pm 0.05$ & $4.4 \pm$ & 0.3 & 0.09 & \pm & 0.00 & 6.29 & \pm 0 & 0.31 & 72 & \pm & 5 \\
\hline SP68 & 931 & 411 & $5.7 \pm 0.4$ & $6.3 \pm 0.3$ & $0.27 \pm 0.01$ & $10.1 \pm 0.5$ & 37 & \pm & 2 & $0.22 \pm 0.01$ & $0.58 \pm 0.03$ & $2.7 \pm$ & 0.2 & 0.07 & $7 \pm 1$ & 0.00 & 4.10 & \pm 0 & 0.21 & 56 & \pm & 4 \\
\hline Mean & 1039 & 689 & 6.0 & 6.2 & 0.42 & 15 & & 35 & & 0.40 & 1.04 & 2.8 & & & 0.14 & & & 4.13 & & & 34 & \\
\hline Median & 969 & 635 & 6.0 & 6.2 & 0.40 & 16 & & 36 & & 0.34 & 1.08 & 2.6 & & & 0.12 & & & 3.66 & & & 32 & \\
\hline Min & 573 & 371 & 5.6 & 5.8 & 0.12 & 2 & & 12 & & 0.20 & 0.29 & 1.2 & & & 0.07 & & & 1.10 & & & 9 & \\
\hline $\operatorname{Max}$ & 2372 & 2041 & 6.4 & 6.7 & 0.68 & 26 & & 70 & & 0.82 & 1.65 & 4.5 & & & 0.35 & & & 9.86 & & & 72 & \\
\hline
\end{tabular}

*published in Roulier et al. submitted 
Table S3. Annual volume-weighted mean (AVWM) concentrations and concentration ratios (CR) of total iodine, selenium and caesium, and proportions of $I$ and Se species in rainfall and throughfall of studied sites $(\mathbf{n}=14$ sites $)$. Uncertainties correspond to standard errors.

\begin{tabular}{|c|c|c|c|c|c|c|c|c|c|c|c|c|c|c|c|c|c|c|c|c|c|c|c|c|c|}
\hline \multirow{4}{*}{$\begin{array}{c}\begin{array}{c}\text { Forest } \\
\text { site }\end{array} \\
\text { CHP59 }\end{array}$} & \multicolumn{22}{|c|}{ AVWM I conc. $\left(\mu \mathrm{g} \mathrm{L}^{-1}\right)$} & \multirow{3}{*}{\multicolumn{3}{|c|}{$\mathrm{CR}(\mathrm{I})$}} \\
\hline & \multicolumn{12}{|c|}{ Rainfall* } & \multicolumn{10}{|c|}{ Throughfall } & & & \\
\hline & & $\mathrm{I}$ & & & $(\%)$ & & & $3^{-}(\%$ & & & er $(\%$ & & & $\mathrm{I}$ & & $\mathrm{I}^{-}(\%)$ & & $3^{-}(\%)$ & & $\mathrm{I}_{\mathrm{othe}}$ & $(\%$ & & & & \\
\hline & 1.74 & \pm 0 & 0.07 & 19 & \pm & 1 & 30 & \pm & 2 & 51 & \pm & 4 & 3.19 & \pm 0 & 0.10 & $11 \pm 1$ & 3.0 & \pm 0 & 0.1 & 86 & \pm & 4 & 1.8 & \pm 0 & \\
\hline CHS41 & 1.68 & \pm 0 & 0.06 & 21 & \pm & 1 & 27 & \pm & 1 & 52 & \pm & 4 & 2.98 & \pm 0 & 0.07 & $16 \pm 1$ & 4.9 & \pm 0 & 0.2 & 79 & \pm & 3 & 1.8 & \pm 0 & 0.1 \\
\hline CPS77 & 1.23 & \pm( & 0.05 & 25 & \pm & 1 & 24 & \pm & 1 & 51 & \pm & 4 & 3.32 & \pm 0 & 0.08 & $10 \pm 1$ & 3.1 & \pm 0 & 0.1 & 87 & \pm & 3 & 2.7 & \pm 0 & 0.1 \\
\hline ЕРC08 & 1.42 & \pm 1 & 0.05 & 27 & \pm & 1 & 32 & \pm & 2 & 41 & \pm & 4 & 3.54 & \pm 0 & 0.10 & $9.2 \pm 0.5$ & 2.8 & \pm 0 & 0.1 & 88 & \pm & 4 & 2.5 & \pm 0 & 0.1 \\
\hline EPC63 & 0.99 & \pm & 0.04 & 31 & \pm & 2 & 19 & \pm & 2 & 50 & \pm & 5 & 2.73 & \pm 0 & 0.08 & $7 \pm 1$ & 1 & \pm & 1 & 92 & \pm & 4 & 2.8 & \pm 0 & 0.1 \\
\hline EPC87 & 1.35 & \pm 0 & 0.05 & 34 & \pm & 2 & 27 & \pm & 1 & 39 & \pm & 4 & 2.68 & \pm 0 & 0.07 & $25 \pm 1$ & 4.4 & \pm 0 & 0.2 & 71 & \pm & 3 & 2.0 & \pm 0 & 0.1 \\
\hline HET30 & 2.18 & \pm 0 & 0.06 & 23 & \pm & 1 & 17 & \pm & 1 & 60 & \pm & 4 & 1.87 & \pm 0 & 0.05 & $22 \pm 1$ & 13 & \pm & 1 & 65 & \pm & 4 & 0.9 & \pm 0 & 0.0 \\
\hline HET64 & 1.99 & \pm( & 0.08 & 25 & \pm & 1 & 30 & \pm & 1 & 44 & \pm & 5 & 4.07 & \pm 0 & 0.10 & $21 \pm 1$ & 12 & \pm & 1 & 67 & \pm & 3 & 2.1 & \pm 0 & 0.1 \\
\hline PS67a & 1.23 & \pm( & 0.05 & 35 & \pm & 2 & 19 & \pm & 1 & 46 & \pm & 4 & 2.31 & \pm 0 & 0.07 & $14 \pm 1$ & 2.4 & \pm 0 & 0.1 & 84 & \pm & 4 & 1.9 & \pm 0 & 0.1 \\
\hline SP05 & 1.20 & \pm 0 & 0.05 & 25 & \pm & 1 & 21 & \pm & 1 & 54 & \pm & 5 & 1.79 & & 0.05 & $3.2 \pm 0.3$ & 6.2 & \pm 0 & 0.3 & 91 & \pm & 4 & 1.5 & \pm 0 & 0.1 \\
\hline SP11 & 1.24 & \pm & 0.05 & 26 & \pm & 1 & 21 & \pm & 1 & 53 & \pm & 5 & 4.97 & \pm 0 & 0.14 & $14 \pm 1$ & 0.98 & \pm 0 & .04 & 85 & \pm & 4 & 4.0 & \pm 0 & 0.2 \\
\hline SP38 & 0.94 & \pm( & 0.04 & 30 & \pm & 2 & 17 & \pm & 1 & 53 & \pm & 5 & 1.37 & \pm 0 & 0.04 & $7.3 \pm 0.4$ & 3.7 & \pm 0 & 0.2 & 89 & \pm & 4 & 1.4 & \pm 0 & 0.1 \\
\hline SP57 & 1.05 & \pm( & 0.04 & 44 & \pm & 2 & 16 & \pm & 1 & 40 & \pm & 4 & 4.03 & & 0.08 & $16 \pm 1$ & 0.59 & \pm 0 & .03 & 83 & \pm & 3 & 3.8 & \pm 0 & 0.2 \\
\hline SP68 & 0.85 & \pm & 0.03 & 33 & \pm & 2 & 18 & \pm & 1 & 49 & \pm & 5 & 1.98 & \pm 0 & 0.06 & $21 \pm 1$ & 3.5 & \pm 0 & 0.2 & 75 & \pm & 4 & 2.3 & \pm 0 & 0.1 \\
\hline Mean & & 1.36 & & & 29 & & & 23 & & & 49 & & & 2.92 & & 14 & & 4 & & & 82 & & & 2.2 & \\
\hline Median & & 1.23 & & & 27 & & & 21 & & & 50 & & & 2.85 & & 14 & & 3 & & & 85 & & & 2.0 & \\
\hline $\operatorname{Min}$ & & 0.85 & & & 19 & & & 16 & & & 39 & & & 1.37 & & 3 & & 1 & & & 65 & & & 0.9 & \\
\hline $\operatorname{Max}$ & & 2.18 & & & 44 & & & 32 & & & 60 & & & 4.97 & & 25 & & 13 & & & 92 & & & 4.0 & \\
\hline \multirow{3}{*}{$\begin{array}{l}\text { Forest } \\
\text { site }\end{array}$} & \multicolumn{15}{|c|}{ AVWM Se conc. $\left(\mathrm{ng} \mathrm{L}^{-1}\right)$} & \multicolumn{7}{|c|}{ AVWM Cs conc. $\left(\right.$ ng L $\left.^{-1}\right)$} & \multirow{3}{*}{\multicolumn{3}{|c|}{$\mathrm{CR}(\mathrm{Cs})$}} \\
\hline & \multicolumn{12}{|c|}{ Rainfall* } & \multirow{2}{*}{\multicolumn{3}{|c|}{$\begin{array}{c}\text { Throughfall } \\
\mathrm{Se}\end{array}$}} & \multirow[t]{2}{*}{$\mathrm{CR}(\mathrm{Se})$} & \multirow{2}{*}{\multicolumn{3}{|c|}{ Rainfall* }} & \multirow{2}{*}{\multicolumn{3}{|c|}{ Throughfall }} & & & \\
\hline & & $\mathrm{Se}$ & & $\mathrm{SeO}$ & $3^{2-}(0$ & $\%)$ & $\mathrm{SeO}$ & 4 & & $\mathrm{Se}_{\mathrm{ot}}$ & her ( & & & & & & & & & & & & & & \\
\hline CHP59 & 59 & \pm & 4 & 13 & \pm & 1 & 14 & \pm & 1 & 74 & \pm & 8 & 109 & \pm & 8 & $1.9 \pm 0.2$ & 7.3 & \pm 0 & 0.5 & 54 & \pm & 2 & 7 & \pm & 1 \\
\hline CHS41 & 46 & \pm & 3 & 8 & \pm & 1 & 21 & \pm & 2 & 72 & \pm & 8 & 83 & \pm & 6 & $1.8 \pm 0.2$ & 5.0 & \pm 0 & 0.4 & 52 & \pm & 3 & 10 & \pm & 1 \\
\hline CPS77 & 37 & \pm & 3 & 9 & \pm & 1 & 17 & \pm & 2 & 74 & \pm & 9 & 97 & \pm & 7 & $2.6 \pm 0.3$ & 4.1 & \pm 0 & 0.3 & 51 & \pm & 2 & 13 & \pm & 1 \\
\hline EPC08 & 57 & \pm & 4 & 10 & \pm & 1 & 18 & \pm & 2 & 72 & \pm & 8 & 149 & \pm & 11 & $2.6 \pm 0.3$ & 5.4 & \pm 0 & 0.4 & 65 & \pm & 3 & 12 & \pm & 1 \\
\hline EPC63 & 28 & \pm & 2 & 11 & \pm & 1 & 16 & \pm & 1 & 73 & \pm & 8 & 60 & \pm & 5 & $2.1 \pm 0.2$ & 6.3 & \pm 0 & 0.4 & 310 & \pm & 14 & 49 & \pm & 4 \\
\hline EPC87 & 38 & \pm & 2 & 10 & \pm & 1 & 33 & \pm & 3 & 57 & \pm & 8 & 60 & \pm & 5 & $1.6 \pm 0.2$ & 6.2 & \pm 0 & 0.4 & 268 & \pm & 12 & 43 & \pm & 3 \\
\hline HET30 & 85 & \pm & 4 & 20 & \pm & 2 & 34 & \pm & 3 & 46 & \pm & 6 & 71 & \pm & 5 & $0.8 \pm 0.1$ & 5.0 & \pm 0 & 0.4 & 57 & \pm & 3 & 11 & \pm & 1 \\
\hline HET64 & 51 & \pm & 3 & 6.9 & \pm 0 & 0.5 & 31 & \pm & 2 & 62 & \pm & 8 & 90 & \pm & 7 & $1.8 \pm 0.2$ & 3.3 & \pm 0 & 0.2 & 38 & \pm & 2 & 11 & \pm & 1 \\
\hline PS67a & 49 & \pm & 3 & 8 & \pm & 1 & 37 & \pm & 3 & 55 & \pm & 8 & 90 & \pm & 6 & $1.8 \pm 0.2$ & 6.9 & \pm 0 & 0.4 & 70 & \pm & 3 & 10 & \pm & 1 \\
\hline SP05 & 23 & \pm & 2 & 10 & \pm & 1 & 20 & \pm & 2 & 70 & \pm & 9 & 31 & \pm & 2 & $1.3 \pm 0.1$ & 4.1 & \pm 0 & 0.3 & 17 & \pm & 1 & 4 & \pm & 0 \\
\hline SP11 & 33 & \pm & 2 & 8 & \pm & 1 & 30 & \pm & 3 & 62 & \pm & 9 & 107 & \pm & 8 & $3.3 \pm 0.3$ & 2.3 & \pm 0 & 0.3 & 25 & \pm & 1 & 11 & \pm & 1 \\
\hline SP38 & 31 & \pm & 2 & 10 & \pm & 1 & 26 & \pm & 2 & 64 & \pm & 9 & 58 & \pm & 5 & $1.9 \pm 0.2$ & 5.4 & \pm 0 & 0.4 & 80 & \pm & 3 & 15 & \pm & 1 \\
\hline SP57 & 44 & \pm & 3 & 8 & \pm & 1 & 21 & \pm & 2 & 72 & \pm & 7 & 118 & \pm & 8 & $2.7 \pm 0.2$ & 7.5 & \pm 0 & 0.5 & 136 & \pm & 5 & 18 & \pm & 1 \\
\hline SP68 & 31 & \pm & 2 & 11 & \pm & 1 & 31 & \pm & 3 & 58 & \pm & 9 & 56 & \pm & 4 & $1.8 \pm 0.2$ & 13.2 & \pm 0 & 0.8 & 156 & \pm & 7 & 12 & \pm & 1 \\
\hline Mean & & 44 & & & 16 & & & 25 & & & 59 & & & 84 & & 2.0 & & 5.9 & & & 98 & & & 16 & \\
\hline Median & & 41 & & & 16 & & & 24 & & & 61 & & & 90 & & 1.8 & & 5.4 & & & 61 & & & 12 & \\
\hline Min & & 23 & & & 10 & & & 14 & & & 45 & & & 31 & & 0.8 & & 2.3 & & & 17 & & & 4 & \\
\hline $\operatorname{Max}$ & & 85 & & & 22 & & & 40 & & & 70 & & & 149 & & 3.3 & & 13.2 & & & 310 & & & 49 & \\
\hline
\end{tabular}

*published in Roulier et al. submitted 
Table S4. Monthly water amount of rainfall and throughfall in study sites $(n=14$ sites $)$.

\begin{tabular}{|c|c|c|c|c|c|c|c|c|c|c|c|c|c|}
\hline \multirow{3}{*}{$\begin{array}{c}\text { Forest } \\
\text { site }\end{array}$} & \multicolumn{13}{|c|}{ Water amount (mm month ${ }^{-1}$ ) } \\
\hline & \multicolumn{13}{|c|}{ Rainfall } \\
\hline & Sept.16 & Oct.16 & Nov. 16 & Dec. 16 & Jan.17 & Febr.17 & March.17 & Apr.17 & May.17 & June. 17 & July.17 & Aug.17 & Sept.17 \\
\hline CHP59 & 45 & 31 & 54 & 32 & 55 & 34 & 88 & 9 & 16 & 49 & 52 & 56 & 55 \\
\hline CHS41 & 35 & 13 & 71 & 25 & 23 & 38 & 72 & 18 & 66 & 66 & 71 & 61 & 51 \\
\hline CPS77 & 38 & 40 & 66 & 22 & 34 & 41 & 105 & 13 & 32 & 57 & 63 & 32 & 132 \\
\hline EPC08 & 15 & 35 & 88 & 30 & 63 & 84 & 134 & 13 & 43 & 96 & 89 & 71 & 122 \\
\hline EPC63 & 84 & 74 & 125 & 46 & 43 & 56 & 86 & 57 & 99 & 72 & 136 & 55 & 60 \\
\hline EPC87 & 107 & 73 & 159 & 18 & 45 & 90 & 157 & 49 & 96 & 135 & 143 & 90 & 58 \\
\hline HET30 & 176 & 314 & 403 & 208 & 35 & 604 & 149 & 149 & 228 & 35 & 44 & 20 & 8 \\
\hline HET64 & 98 & 63 & 198 & 15 & 148 & 85 & 123 & 135 & 51 & 110 & 137 & 107 & 97 \\
\hline PS67a & 47 & 47 & 67 & 11 & 29 & 47 & 69 & 6 & 41 & 53 & 64 & 66 & 74 \\
\hline SP05 & 61 & 117 & 269 & 0 & 17 & 80 & 72 & 23 & 148 & 60 & 68 & 73 & 45 \\
\hline SP11 & 53 & 57 & 151 & 16 & 125 & 80 & 74 & 111 & 61 & 55 & 49 & 59 & 57 \\
\hline SP38 & 70 & 77 & 169 & 11 & 41 & 119 & 137 & 13 & 188 & 99 & 133 & 160 & 85 \\
\hline SP57 & 75 & 64 & 118 & 22 & 43 & 136 & 168 & 19 & 94 & 84 & 87 & 76 & 43 \\
\hline SP68 & 37 & 45 & 130 & 3 & 37 & 89 & 195 & 11 & 124 & 82 & 75 & 61 & 45 \\
\hline \multirow{3}{*}{$\begin{array}{c}\text { Forest } \\
\text { site }\end{array}$} & \multicolumn{13}{|c|}{ Water amount (mm month $\left.{ }^{-1}\right)$} \\
\hline & \multicolumn{13}{|c|}{ Throughfall } \\
\hline & Sept.16 & Oct.16 & Nov. 16 & Dec. 16 & Jan.17 & Febr.17 & March.17 & Apr.17 & May. 17 & June.17 & July.17 & Aug.17 & Sept.17 \\
\hline CHP59 & 30 & 20 & 43 & 21 & 60 & 29 & 76 & 4 & 4 & 32 & 20 & 32 & 25 \\
\hline CHS41 & 23 & 6 & 59 & 3 & 19 & 24 & 48 & 2 & 51 & 49 & 47 & 33 & 25 \\
\hline CPS77 & 24 & 29 & 41 & 13 & 25 & 27 & 59 & 15 & 16 & 30 & 31 & 14 & 91 \\
\hline EPC08 & 9 & 22 & 75 & 22 & 59 & 74 & 107 & 5 & 29 & 59 & 67 & 50 & 100 \\
\hline EPC63 & 57 & 46 & 77 & 12 & 43 & 37 & 66 & 46 & 55 & 41 & 89 & 37 & 27 \\
\hline EPC87 & 30 & 49 & 97 & 7 & 30 & 41 & 99 & 33 & 54 & 80 & 95 & 51 & 35 \\
\hline HET30 & 144 & 234 & 396 & 169 & 38 & 553 & 142 & 128 & 145 & 30 & 40 & 15 & 7 \\
\hline HET64 & 48 & 28 & 115 & 9 & 92 & 56 & 82 & 90 & 25 & 74 & 107 & 82 & 61 \\
\hline PS67a & 33 & 31 & 39 & 3 & 15 & 35 & 39 & 2 & 23 & 33 & 36 & 35 & 47 \\
\hline SP05 & 21 & 76 & 211 & 0 & 8 & 48 & 39 & 14 & 79 & 35 & 42 & 32 & 36 \\
\hline SP11 & 41 & 36 & 117 & 3 & 95 & 65 & 57 & 108 & 35 & 28 & 18 & 23 & 28 \\
\hline SP38 & 63 & 32 & 143 & 9 & 20 & 108 & 89 & 14 & 172 & 65 & 70 & 92 & 67 \\
\hline SP57 & 46 & 21 & 68 & 5 & 40 & 81 & 80 & 6 & 46 & 45 & 25 & 38 & 11 \\
\hline SP68 & 14 & 15 & 61 & 0 & 17 & 42 & 106 & 2 & 57 & 39 & 24 & 16 & 17 \\
\hline
\end{tabular}


Table S5. Monthly iodine concentrations in rainfall and throughfall in study sites $(\mathrm{n}=14$ sites).

\begin{tabular}{|c|c|c|c|c|c|c|c|c|c|c|c|c|c|c|c|c|c|}
\hline \multirow{4}{*}{$\begin{array}{c}\begin{array}{c}\text { Forest } \\
\text { site }\end{array} \\
\text { CHP59 }\end{array}$} & \multicolumn{17}{|c|}{ monthly I conc. $\left(\mu \mathrm{g} \mathrm{L}^{-1}\right)$} \\
\hline & \multicolumn{17}{|c|}{ Rainfall } \\
\hline & \multicolumn{2}{|c|}{ Sept.16 } & \multicolumn{2}{|c|}{ Oct.16 } & \multicolumn{2}{|c|}{ Nov.16 } & \multicolumn{2}{|c|}{ Dec. 16} & Jan.17 & Febr. 17 & March.17 & Apr.17 & May.17 & $\begin{array}{l}\text { June. } 17 \\
\end{array}$ & July.17 & Aug. 17 & Sept.17 \\
\hline & 0.08 & \pm 0.00 & 0.07 & \pm 0.00 & 0.11 & \pm 0.00 & & \pm & $0.08 \pm 0.00$ & $0.05 \pm 0.00$ & $0.10 \pm 0.00$ & $0.03 \pm 0.00$ & $0.07 \pm 0.00$ & $0.04 \pm 0.00$ & $0.07 \pm 0.00$ & $0.12 \pm 0.01$ & $0.08 \pm 0.00$ \\
\hline CHS41 & 0.10 & \pm 0.00 & - & $\pm \quad-$ & 0.14 & \pm 0.00 & 0.03 & \pm 0.00 & $0.04 \pm 0.00$ & $0.03 \pm 0.00$ & $0.08 \pm 0.00$ & $0.02 \pm 0.00$ & $0.07 \pm 0.00$ & $0.07 \pm 0.00$ & $0.15 \pm 0.01$ & $0.11 \pm 0.01$ & $0.10 \pm 0.00$ \\
\hline$\$ 77$ & 0.07 & \pm 0.00 & 0.05 & \pm 0.00 & 0.12 & \pm 0.00 & 0.02 & \pm 0.00 & $0.05 \pm 0.00$ & $0.03 \pm 0.00$ & $0.09 \pm 0.00$ & $0.01 \pm 0.00$ & $0.04 \pm 0.00$ & $0.04 \pm 0.00$ & $0.07 \pm 0.00$ & $0.08 \pm 0.00$ & $0.14 \pm$ \\
\hline $\mathrm{C} 08$ & 04 & \pm 0.00 & - & \pm & 0.15 & \pm 0.00 & 0.06 & \pm 0.00 & $0.08 \pm 0.00$ & $0.10 \pm 0.00$ & $0.18 \pm 0.01$ & $0.03 \pm 0.00$ & $0.10 \pm 0.00$ & $0.07 \pm 0.00$ & $0.13 \pm 0.01$ & $0.09 \pm$ & 0.12 \\
\hline $\mathrm{C} 63$ & 11 & \pm 0.00 & 0.07 & \pm 0.00 & 0.12 & \pm 0.00 & 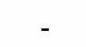 & $\pm \quad-$ & $.04 \pm 0.00$ & $0.05 \pm 0.00$ & $0.04 \pm 0.00$ & $0.06 \pm 0.00$ & $0.08 \pm 0.00$ & $0.06 \pm 0.00$ & $0.15 \pm 0.01$ & $0.07 \pm 0.00$ & $0.05 \pm$ \\
\hline C87 & 15 & \pm 0.00 & 0.11 & \pm 0.01 & 0.28 & \pm 0.01 & 0.02 & \pm 0.00 & $0.04 \pm 0.00$ & $0.06 \pm 0.00$ & $0.15 \pm 0.01$ & $0.03 \pm 0.00$ & $0.11 \pm 0.00$ & $0.12 \pm 0.01$ & $0.32 \pm 0.02$ & $0.15 \pm 0.01$ & $0.09 \pm 0.00$ \\
\hline Г30 & 32 & \pm 0.00 & 0.49 & \pm 0.02 & 1.29 & \pm 0.04 & 0.64 & \pm 0.01 & $0.02 \pm 0.00$ & $1.23 \pm 0.04$ & $0.21 \pm 0.01$ & $0.17 \pm 0.01$ & $0.28 \pm 0.01$ & $0.02 \pm 0.00$ & $0.07 \pm 0.00$ & $0.05 \pm 0.00$ & $-\quad \pm \quad-$ \\
\hline HET64 & 42 & \pm 0.01 & 0.14 & \pm 0.01 & 0.26 & \pm 0.01 & 0.03 & \pm 0.00 & $0.17 \pm 0.01$ & $0.07 \pm 0.00$ & $0.13 \pm 0.01$ & $0.17 \pm 0.01$ & $0.07 \pm 0.00$ & $0.24 \pm 0.01$ & $0.45 \pm 0.02$ & $0.32 \pm 0.02$ & $0.26 \pm 0.01$ \\
\hline PS67a & 0.06 & \pm 0.00 & 0.08 & \pm 0.00 & 0.13 & \pm 0.00 & 0.04 & \pm 0.00 & $0.03 \pm 0.00$ & $0.03 \pm 0.00$ & $0.04 \pm 0.00$ & $0.02 \pm 0.00$ & $0.05 \pm 0.00$ & $0.03 \pm 0.00$ & $0.06 \pm 0.00$ & $0.11 \pm 0.01$ & $0.06 \pm 0.00$ \\
\hline SP05 & 0.09 & \pm 0.00 & 0.24 & \pm 0.01 & 0.26 & \pm 0.01 & - & \pm & $0.01 \pm 0.00$ & $0.04 \pm 0.00$ & $0.07 \pm 0.00$ & $0.01 \pm 0.00$ & $0.17 \pm 0.00$ & $0.05 \pm 0.00$ & $0.11 \pm 0.01$ & $0.11 \pm 0.01$ & $0.08 \pm 0.00$ \\
\hline $\mathrm{s}$ & 13 & \pm 0.00 & 0.07 & \pm 0.00 & 0.22 & \pm 0.01 & 0.02 & \pm 0.00 & $0.08 \pm 0.00$ & $0.06 \pm 0.00$ & $0.05 \pm 0.00$ & $0.11 \pm 0.00$ & $0.05 \pm 0.00$ & $0.07 \pm$ & $0.10 \pm 0.01$ & $0.13 \pm 0.01$ & $0.08 \pm$ \\
\hline SP38 & .07 & \pm 0.00 & 0.17 & \pm 0.01 & 0.12 & \pm 0.00 & - & - & $.02 \pm 0.00$ & $0.04 \pm 0.00$ & $0.12 \pm 0.01$ & $0.01 \pm 0.00$ & $0.12 \pm 0.00$ & $0.07 \pm$ & $0.15 \pm 0.01$ & $0.17 \pm 0.01$ & 0.07 \\
\hline SP57 & 111 & \pm 0.00 & 0.10 & \pm 0.00 & 0.13 & \pm 0.00 & 0.02 & \pm 0.00 & $04 \pm 0.00$ & $0.08 \pm 0.00$ & $0.10 \pm 0.00$ & \pm & $0.11 \pm 0.00$ & $0.06 \pm 0.00$ & $0.10 \pm 0.01$ & $0.12 \pm 0.01$ & $0.05 \pm 0.00$ \\
\hline & 0.03 & \pm 0.00 & 0.07 & \pm 0.00 & 0.11 & \pm 0.00 & - & $\pm \quad-$ & $0.04 \pm 0.00$ & $0.05 \pm 0.00$ & $0.08 \pm 0.00$ & $0.02 \pm 0.00$ & $0.08 \pm$ & $0.06 \pm$ & $0.07 \pm 0.00$ & $0.08 \pm 0.00$ & $0.05 \pm 0.00$ \\
\hline \multirow{3}{*}{$\begin{array}{l}\text { Forest } \\
\text { site }\end{array}$} & \multicolumn{17}{|c|}{ monthly I conc. $\left(\mu \mathrm{g} \mathrm{L}^{-1}\right)$} \\
\hline & \multicolumn{17}{|c|}{ Throughfall } \\
\hline & & ept. 16 & & ct. 16 & & ov. 16 & & ec. 16 & Jan.17 & Febr.17 & March.17 & Apr.17 & May.17 & June.17 & July.17 & Aug. 17 & Sept.17 \\
\hline CHP59 & 0.10 & \pm 0.00 & - & $\pm \quad-$ & 0.21 & \pm 0.00 & 0.07 & \pm 0.00 & $0.12 \pm 0.00$ & $0.08 \pm 0.00$ & $0.13 \pm 0.01$ & $0.02 \pm 0.00$ & $0.04 \pm 0.00$ & $0.13 \pm 0.00$ & $0.08 \pm 0.00$ & $0.09 \pm 0.00$ & $0.11 \pm 0.00$ \\
\hline CHS41 & 0.10 & \pm 0.00 & 0.05 & \pm 0.00 & 0.26 & \pm 0.01 & 0.01 & \pm 0.00 & $0.04 \pm 0.00$ & $0.03 \pm 0.00$ & $0.06 \pm 0.00$ & $0.00 \pm 0.00$ & $0.14 \pm 0.00$ & $0.09 \pm 0.00$ & $0.17 \pm 0.00$ & $-\quad \pm$ & $0.12 \pm 0.00$ \\
\hline & 0.18 & \pm 0.00 & 0.11 & \pm 0.00 & 0.18 & \pm 0.00 & 0.02 & \pm 0.00 & $0.06 \pm 0.00$ & $0.05 \pm 0.00$ & $0.08 \pm 0.00$ & - & $0.09 \pm 0.00$ & $0.10 \pm 0.00$ & $0.11 \pm 0.00$ & $0.06 \pm 0.00$ & 0.24 \\
\hline & 0.07 & \pm 0.00 & 0.10 & \pm 0.00 & 0.29 & \pm 0.01 & 0.11 & \pm 0.00 & $0.13 \pm 0.00$ & $0.18 \pm 0.01$ & $0.23 \pm 0.00$ & $0.04 \pm 0.00$ & $0.17 \pm 0.00$ & $0.23 \pm 0.00$ & $0.34 \pm 0.01$ & $0.32 \pm 0.01$ & 0.19 \\
\hline & 0.31 & \pm 0.01 & 0.11 & \pm 0 & 0.22 & \pm 0. & 0.03 & \pm 0.00 & $7 \pm 0.00$ & $0.08 \pm 0.00$ & $0.10 \pm$ & $0.11 \pm 0.00$ & $0.14 \pm 0$ & $0.09 \pm$ & $0.19 \pm 0.01$ & $0.15 \pm$ & 0.11 \\
\hline 7 & 0.12 & \pm 0.00 & 0.09 & \pm 0.00 & 0.29 & \pm 0.01 & - & $\pm \quad-$ & $77 \pm 0.00$ & $0.08 \pm 0.00$ & $0.16 \pm 0.01$ & $0.04 \pm 0.00$ & $0.15 \pm c$ & $0.14 \pm$ & $0.31 \pm 0.01$ & $0.19 \pm$ & 0.10 \\
\hline 0 & 0.36 & \pm 0.01 & 0.32 & \pm 0.01 & 0.76 & \pm 0.03 & 0.41 & \pm 0.01 & $3 \pm 0.00$ & $0.92 \pm 0$. & $0.27 \pm 0$ & $0.21 \pm 0$ & $0.20 \pm 0$ & $0.05 \pm 0.00$ & $0.19 \pm 0.01$ & $0.05 \pm c$ & $0.05 \pm 0.00$ \\
\hline HET64 & 0.40 & \pm 0.00 & 0.18 & \pm 0.00 & 0.36 & \pm 0.01 & 0.05 & \pm 0.00 & $0.15 \pm 0.00$ & $0.08 \pm 0.00$ & $0.17 \pm 0.01$ & $0.12 \pm 0.00$ & $0.09 \pm 0.00$ & $0.32 \pm 0.01$ & $0.74 \pm 0.02$ & $0.57 \pm 0.02$ & $0.31 \pm 0.01$ \\
\hline PS67a & 0.09 & \pm 0.00 & 0.05 & \pm 0.00 & 0.07 & \pm 0.00 & 0.01 & \pm 0.00 & $0.03 \pm 0.00$ & $0.06 \pm 0.00$ & $0.08 \pm 0.00$ & $0.01 \pm 0.00$ & $0.08 \pm 0.00$ & $0.04 \pm 0.00$ & $0.08 \pm 0.00$ & $0.17 \pm 0.01$ & $0.07 \pm 0.00$ \\
\hline SP05 & 0.09 & \pm 0.00 & - & $\pm \quad-$ & 0.24 & \pm 0.01 & - & $\pm \quad-$ & $0.01 \pm 0.00$ & $0.01 \pm 0.00$ & $0.08 \pm 0.00$ & $0.01 \pm 0.00$ & $0.22 \pm 0.01$ & $0.05 \pm 0.00$ & $0.14 \pm 0.01$ & - \pm & $0.12 \pm 0.00$ \\
\hline SP11 & 0.48 & \pm 0.01 & 0.21 & \pm 0.00 & 0.38 & \pm 0.01 & & \pm & $-\quad \pm \quad-$ & $-\quad \pm \quad-$ & $0.13 \pm 0.00$ & $0.13 \pm 0.00$ & $0.22 \pm 0.01$ & $0.12 \pm 0.00$ & $0.26 \pm 0.01$ & $0.31 \pm 0.01$ & $0.24 \pm 0.01$ \\
\hline & 0.15 & \pm 0.00 & 0.11 & \pm 0.00 & 0.14 & \pm 0.0 & & \pm & $0.02 \pm 0.00$ & $0.07 \pm 0.00$ & $0.11 \pm 0$ & $0.02 \pm 0.00$ & $0.16 \pm 0$ & $0.06 \pm 0.00$ & $0.13 \pm 0.00$ & $0.15 \pm 0.01$ & 0.09 \\
\hline & & \pm 0.00 & 0.08 & \pm 0.00 & 0.29 & \pm 0.0 & - & \pm & $.22 \pm 0.00$ & $0.16 \pm 0.01$ & $0.16 \pm$ & \pm & $0.15 \pm 0.00$ & $0.10 \pm$ & $0.08 \pm 0.00$ & $0.13 \pm 0.00$ & $0.04 \pm 0.00$ \\
\hline SP68 & 0.04 & \pm 0.00 & 0.07 & \pm 0.00 & 0.09 & \pm 0.00 & 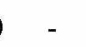 & \pm & $0.06 \pm 0.00$ & $0.06 \pm 0.00$ & $0.11 \pm 0.01$ & $0.01 \pm 0.00$ & $0.11 \pm 0.00$ & $0.07 \pm 0.00$ & $0.08 \pm 0.00$ & $0.06 \pm 0.00$ & $0.05 \pm 0.00$ \\
\hline
\end{tabular}


Table S6. Monthly selenium concentrations in rainfall and throughfall in study sites $(\mathrm{n}=14$ sites).

\begin{tabular}{|c|c|c|c|c|c|c|c|c|c|c|c|c|c|c|c|c|c|c|c|c|}
\hline \multirow{3}{*}{$\begin{array}{c}\text { Forest } \\
\text { site }\end{array}$} & \multicolumn{20}{|c|}{ monthly Se conc. $\left(\mathrm{ng} \mathrm{L}^{-1}\right)$} \\
\hline & \multicolumn{20}{|c|}{ Rainfall } \\
\hline & & pt.16 & & ct. 16 & & v. 16 & & c. 16 & & an.17 & & br.17 & $\mathrm{Mal}$ & rch.17 & Apr.17 & May.17 & June. 17 & July.17 & Aug. 17 & Sept.17 \\
\hline CHP59 & 3.0 & \pm 0.1 & 1.5 & \pm 0.1 & 3.5 & \pm 0.2 & - & \pm & 4.1 & \pm 0.2 & 2.8 & \pm 0.1 & 2.3 & \pm 0.2 & $0.7 \pm 0.1$ & $1.9 \pm 0.1$ & $2.5 \pm 0.2$ & $2.7 \pm 0.2$ & $3.7 \pm 0.3$ & $2.5 \pm 0.2$ \\
\hline CHS41 & 3.2 & \pm 0.1 & - & \pm & 2.8 & \pm 0.2 & 0.6 & \pm 0.0 & 1.0 & & 1.6 & \pm 0.1 & 2.5 & \pm 0.1 & $0.6 \pm 0.0$ & $3.0 \pm 0.1$ & $1.9 \pm 0.2$ & 0.2 & $2.1 \pm 0.2$ & 3.3 \\
\hline CPS77 & 2.8 & \pm 0.1 & 1.0 & \pm 0.1 & 2.0 & \pm 0.1 & 0.7 & \pm 0.0 & 0.9 & \pm 0.1 & 2.0 & \pm 0.1 & 3.1 & \pm 0.2 & $0.4 \pm 0.0$ & $1.9 \pm 0.1$ & $1.9 \pm 0.2$ & $2.0 \pm 0.2$ & $1.4 \pm 0.1$ & $4.8 \pm 0.4$ \\
\hline & 1.5 & \pm 0.0 & - & \pm- & 4.0 & \pm 0.2 & 2.4 & \pm 0.1 & 5.1 & 0.3 & 6.2 & \pm 0.3 & 5.2 & \pm 0.2 & 1 & $5.8 \pm 0.2$ & $3.8 \pm 0.3$ & 5.6 & 3.4 & \\
\hline & 4.7 & 0.2 & 1.1 & \pm 0.1 & 1.7 & \pm 0.2 & 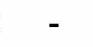 & \pm & 1.1 & \pm 0.1 & 1.3 & \pm 0.1 & 1.5 & \pm 0.1 & \pm 0.2 & $2.8 \pm 0.1$ & $1.5 \pm 0.1$ & 3.5 & $2.2 \pm 0.2$ & 2.0 \\
\hline & 5.2 & 0.2 & 2.0 & \pm 0.1 & 4.9 & \pm 0.4 & 0.2 & \pm 0.0 & 0.9 & \pm 0.1 & 2.4 & \pm 0.2 & 6.0 & \pm 0.3 & \pm 0.1 & $3.6 \pm 0.1$ & $5.7 \pm 0.4$ & $5.6 \pm 0.5$ & $4.5 \pm 0.3$ & $3.7=$ \\
\hline & 2.7 & \pm 0.4 & .5 & \pm 0.8 & 39.6 & \pm 1.6 & 15.9 & \pm 0.9 & 0.6 & \pm 0.0 & 77.4 & \pm 3.6 & 8.8 & \pm 0.4 & \pm 0.5 & $8.1 \pm 0.4$ & $0.4 \pm 0.0$ & $1.8 \pm 0.2$ & $1.7 \pm 0.1$ & -+ \\
\hline & 1 & \pm 0.4 & 8 & \pm 0.3 & 2.2 & \pm 0.2 & 05 & \pm 0.0 & 2.5 & \pm 0.2 & 3.1 & \pm 0.2 & 4.4 & \pm 0.2 & .3 & $2.4 \pm 0.1$ & $6.5 \pm 0.6$ & $10.5 \pm 0.8$ & $12.2 \pm 0.9$ & $8.7 \pm 0.6$ \\
\hline & 2.9 & \pm 0.1 & 2.2 & \pm 0.1 & 2.1 & \pm 0.1 & .0 & \pm 0.3 & 1 & \pm 0.1 & 1.7 & \pm 0.1 & 1.1 & \pm 0.1 & & $2.7 \pm 0.1$ & $2.4 \pm 0.2$ & 2.4 & $3.5 \pm 0.3$ & $5.0 \pm 0.4$ \\
\hline & 2.1 & \pm 0.1 & 2.4 & \pm 0.1 & 2.8 & +003 & - & \pm & 2 & \pm 0.0 & 1.0 & \pm 0.1 & 2.3 & \pm 0.2 & 0 & $3.7 \pm 0.2$ & $1.7 \pm 0.1$ & $3.4=$ & $2.3 \pm 0.2$ & 1.8 \\
\hline & 3.2 & $=0.1$ & 1.6 & \pm 0.1 & & - & 9 & \pm 0.1 & & \pm 0.2 & 1.8 & \pm 0.1 & 1.7 & \pm 0.1 & .2 & $1.8 \pm 0.1$ & $2.5 \pm 0.2$ & 2.8 & 3.5 & 2.1 \\
\hline & 2.5 & $=0.1$ & 3.1 & \pm 0.2 & & \pm & - & $\pm \quad-$ & 1.0 & \pm & 1.3 & \pm 0.1 & 4.0 & \pm 0.2 & $0.6 \pm 0.1$ & $4.1 \pm 0.3$ & $3.9 \pm 0.3$ & $4.4 \pm$ & $7.0 \pm$ & 3.6 \\
\hline & 6.5 & 0.2 & 8 & \pm 0.2 & & \pm & 0.6 & \pm 0.0 & 2.9 & \pm 0 & 5.2 & \pm 0.3 & 2.7 & \pm 0.1 & - \pm & $7.3 \pm 0.3$ & $3.6 \pm 0.3$ & 2.6 & $3.2 \pm$ & 2.7 \\
\hline & 1. & $=0.1$ & 1.5 & \pm 0.1 & 1.3 & \pm & & + & 2.2 & \pm 0 & 2.8 & \pm 0.3 & 2.2 & \pm 0.2 & $0.5 \pm 0.0$ & $5.0 \pm$ & $2.4 \pm 0.2$ & 2.9 & $2.9 \pm$ & 2.1 \\
\hline \multirow{3}{*}{$\begin{array}{l}\text { Forest } \\
\text { site }\end{array}$} & \multicolumn{20}{|c|}{ monthly Se conc. $\left(\mathrm{ng} \mathrm{L}^{-1}\right)$} \\
\hline & \multicolumn{20}{|c|}{ Throughfall } \\
\hline & & pt.16 & & ct. 16 & & V. 16 & & c. 16 & & an. 17 & & br. 17 & Ma1 & rch.17 & Apr.17 & May.17 & June. 17 & July.17 & Aug.17 & Sept.17 \\
\hline & 3.9 & \pm 0.2 & - & $\pm \quad-$ & 5.1 & \pm 0.3 & 3.0 & \pm 0.2 & 4.4 & \pm 0.3 & 2.3 & \pm 0.2 & 3.1 & \pm 0.2 & $0.6 \pm 0.1$ & $1.1 \pm 0.1$ & $5.9 \pm 0.5$ & $4.8 \pm 0.4$ & $2.3 \pm 0.2$ & $3.5 \pm 0.3$ \\
\hline IS41 & 3.8 & \pm 0.2 & 1.0 & \pm 0.1 & 3.9 & \pm 0.3 & $0=$ & \pm 0.0 & 1.0 & \pm 0.1 & 1.0 & \pm 0.1 & 1.8 & \pm 0.1 & $0.1 \pm 0.0$ & $4.1 \pm 0.3$ & $2.7 \pm 0.3$ & $6.9 \pm 0.6$ & \pm & $3.0 \pm 0.3$ \\
\hline & 5.3 & 0.3 & 2.9 & \pm 0.2 & 3.0 & \pm 0.2 & 07 & \pm 0.0 & 1.3 & \pm 0.1 & 1.6 & \pm 0.1 & 2.9 & \pm 0.2 & 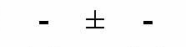 & $2.2 \pm 0.2$ & $3.6 \pm 0.3$ & \pm 0.4 & $1.2 \pm 0.1$ & $7.9 \pm$ \\
\hline & 2. & 0.2 & 3.8 & \pm 0.2 & 8.2 & \pm & & \pm & 5 & \pm 0.4 & 9.3 & \pm 0.6 & 8.0 & \pm & $1.3 \pm$ & $6.5 \pm 0.5$ & $11.3 \pm 0.9$ & $23.9=$ & $7.5 \pm$ & 9.2 \\
\hline & 7. & 0.4 & 2.2 & \pm 0.2 & 2. & 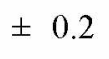 & 0.5 & \pm 0.0 & & \pm & 1.5 & \pm 0.1 & 1.9 & \pm & & $2.6 \pm 0.2$ & $2.0 \pm 0.2$ & $3.9 \pm$ & $6.8 \pm$ & 2.6 \\
\hline & 3.6 & 0.2 & 2.3 & \pm 0.2 & 4.2 & \pm 1 & - & \pm & 1.3 & \pm 0.1 & 1.9 & \pm 0.1 & 3.5 & \pm 0.3 & $1.2 \pm 0.1$ & $3.7 \pm 0.2$ & $4.4 \pm 0.4$ & $5.7 \pm$ & $3.8 \pm$ & 3.0 \\
\hline & 6.3 & \pm 1.0 & 8.2 & \pm 0.5 & 23.3 & \pm & 11.1 & \pm 0.7 & 1 & \pm 0.1 & 47.1 & \pm 3.0 & 12.2 & \pm & $8.5 \pm 0.7$ & $5.8 \pm 0.5$ & $1.3 \pm 0.1$ & $7.0 \pm 0.6$ & $1.1 \pm 0$ & $1.6 \pm$ \\
\hline & 6.3 & \pm 0.4 & 4.1 & \pm 0.3 & 4.4 & \pm & 1 & \pm 0 & & \pm 0.2 & 2.3 & \pm 0.2 & 4.6 & \pm 0.3 & $2.1 \pm 0.2$ & $2.2 \pm 0.1$ & $7.2 \pm 0.6$ & $18.1 \pm 1.5$ & $14.1 \pm 1.2$ & $8.4 \pm$ \\
\hline PSt & 3.3 & \pm 0.2 & 1.4 & \pm 0.1 & 1.2 & \pm 0.1 & 0.5 & \pm 0.0 & 1.0 & \pm 0.1 & 2.9 & \pm 0.2 & 2.6 & \pm 0.2 & - \pm & $3.1 \pm 0.2$ & $2.5 \pm 0.2$ & $4.1 \pm 0.3$ & $4.8 \pm 0.4$ & $3.6 \pm$ \\
\hline & 2.1 & \pm 0.0 & - & \pm- & & \pm 0.3 & - & \pm & 0.3 & \pm 0.0 & 0.3 & \pm 0.0 & 2.4 & \pm 0.1 & $0.4 \pm 0.0$ & $-\quad \pm \quad-$ & $1.6 \pm 0.1$ & $3.0 \pm 0.3$ & $-\quad \pm \quad-$ & $2.8 \pm$ \\
\hline & 6.5 & \pm 0.4 & 4.2 & \pm 0.3 & 5.6 & \pm 0.4 & - & \pm & & \pm & 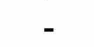 & \pm- & 11.6 & \pm 0.7 & $4.9 \pm 0.4$ & $3.4 \pm 0.3$ & $3.0 \pm 0.3$ & $3.7 \pm 0.3$ & $5.8 \pm 0.5$ & $5.0 \pm$ \\
\hline & 3.2 & 0.2 & 2.1 & \pm 0.1 & 2.5 & \pm & - & \pm & 0.5 & \pm 0.0 & 2.4 & \pm 0.2 & 4.0 & \pm 0.3 & $0.5 \pm 0.1$ & $8.6 \pm 0.6$ & $3.1 \pm 0.3$ & $14.0 \pm 1.2$ & $5.8 \pm 0.5$ & $4.0 \pm$ \\
\hline & 9.6 & 0.3 & 2.5 & \pm 0.2 & & 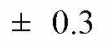 & - & \pm & 7.0 & \pm 0.4 & 5.1 & \pm 0.3 & 4.0 & \pm 0.3 & - \pm & $4.4 \pm 0.4$ & $4.5 \pm 0.4$ & $3.0 \pm 0.3$ & $4.4 \pm 0.4$ & $1.5 \pm$ \\
\hline 08 & 1.8 & \pm 0.1 & 1.4 & \pm 0.1 & 2.2 & \pm 1 & - & \pm & 1.6 & \pm 0.1 & 1.9 & \pm 0.1 & & $\pm \quad-$ & $0.3 \pm 0.0$ & $4.3 \pm 0.3$ & $2.6 \pm 0.2$ & $2.8 \pm 0.2$ & $2.1 \pm 0.2$ & $1.9 \pm$ \\
\hline
\end{tabular}


Table S7. Monthly caesium concentrations in rainfall and throughfall in study sites ( $\mathrm{n}=14$ sites).

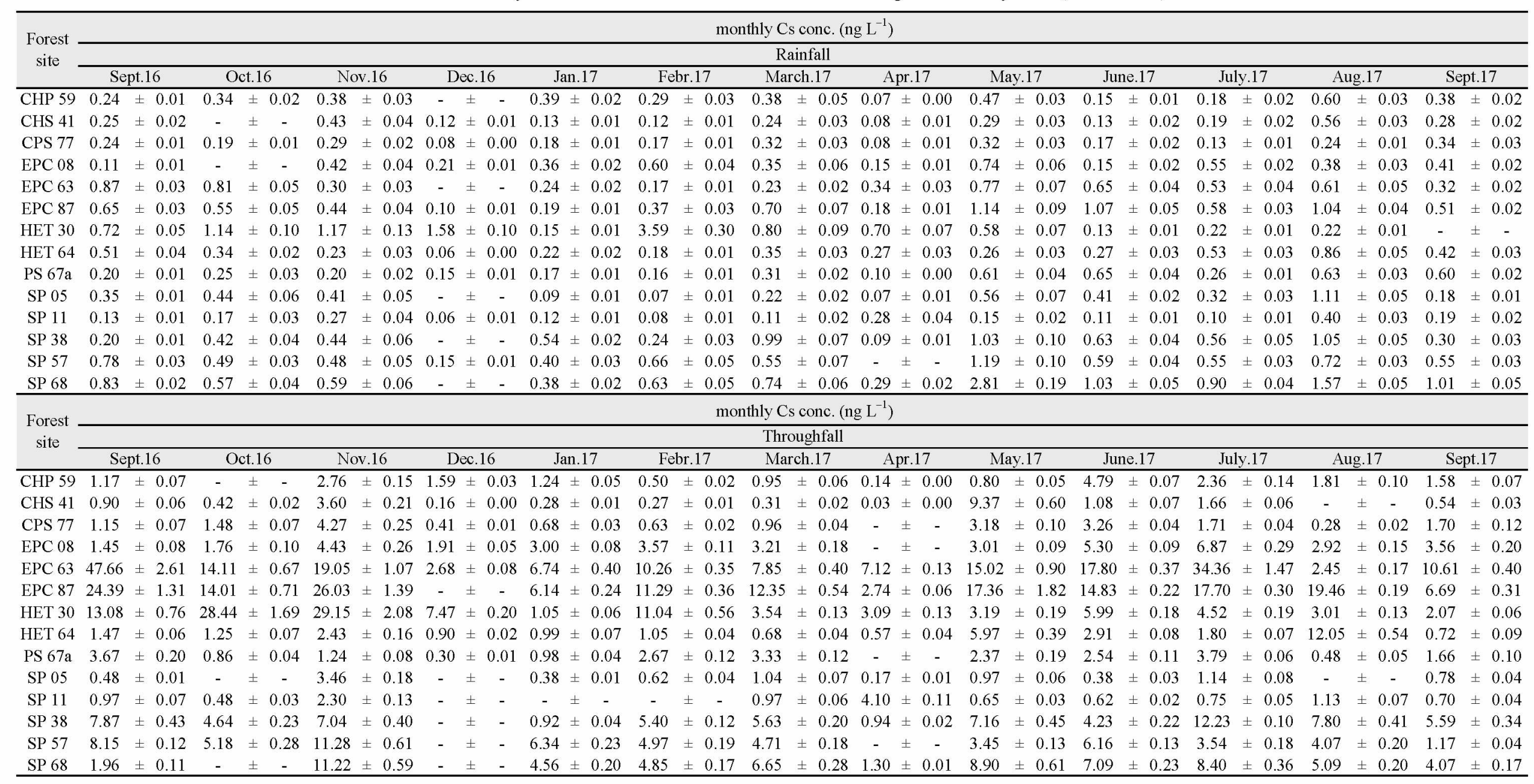


Table S8. Monthly sodium concentrations in rainfall and throughfall in study sites $(n=14$ sites).

\begin{tabular}{|c|c|c|c|c|c|c|c|c|c|c|c|c|c|c|c|c|c|c|c|c|c|c|}
\hline \multirow{3}{*}{$\begin{array}{l}\text { Forest } \\
\text { site }\end{array}$} & \multicolumn{22}{|c|}{ monthly $\mathrm{Na}$ conc. $\left(\mathrm{mg} \mathrm{L}^{-1}\right)$} \\
\hline & \multicolumn{22}{|c|}{ Rainfall } \\
\hline & \multicolumn{2}{|c|}{ Sept.16 } & \multicolumn{2}{|c|}{ Oet.16 } & \multicolumn{2}{|c|}{ Nov.16 } & \multicolumn{3}{|c|}{ Dec.16 } & \multicolumn{2}{|c|}{ Jan. 17} & \multicolumn{2}{|c|}{ Febr.17 } & \multicolumn{2}{|c|}{ March.17 } & \multicolumn{2}{|c|}{ Apr.17 } & May.17 & June. 17 & July. 17 & Aug.17 & Sept.17 \\
\hline CHP59 & 0.46 & \pm 0.02 & 0.66 & \pm 0.03 & 0.55 & \pm 0.03 & 0.93 & \pm & 0.05 & 0.70 & \pm 0.04 & 0.31 & \pm 0.02 & 0.78 & \pm 0.04 & 1.29 & \pm 0.06 & $1.30 \pm 0.07$ & $0.56 \pm 0.03$ & $0.33 \pm 0.02$ & $0.54 \pm 0.03$ & $0.60 \pm 0.03$ \\
\hline CHS41 & 0.47 & \pm 0.02 & 0.69 & \pm 0.03 & 0.90 & \pm 0.05 & 0.32 & & 0.02 & 0.51 & \pm 0.03 & 0.90 & \pm 0.05 & 1.19 & \pm 0.06 & 0.52 & \pm 0.03 & $0.37 \pm 0.02$ & $0.27 \pm 0.01$ & $0.22 \pm 0.01$ & $0.27 \pm 0.01$ & $0.19 \pm 0.01$ \\
\hline CPS77 & 0.22 & \pm 0.01 & 0.20 & \pm 0.01 & 0.49 & \pm 0.02 & 0.36 & \pm & 0.02 & 0.66 & \pm 0.03 & 48 & \pm 0.02 & 0.50 & \pm 0.03 & 0.28 & \pm 0.01 & $0.28 \pm 0.01$ & $0.19 \pm 0.01$ & $0.25 \pm 0.01$ & $0.29 \pm 0.01$ & $0.09 \neq 0.00$ \\
\hline $\mathrm{EPC} 08$ & 0.79 & \pm 0.04 & 0.35 & \pm 0.02 & 0.36 & \pm 0.02 & 1.01 & $=$ & 0.05 & 0.71 & \pm 0.04 & 35 & \pm 0.02 & 0.97 & \pm 0.05 & 0.81 & \pm 0.04 & $0.51 \pm 0.03$ & $0.17 \pm 0.01$ & $0.17 \pm 0.01$ & $0.26 \pm 0.01$ & $0.14 \pm 0.01$ \\
\hline EPC63 & 0.18 & \pm 0.01 & 0.20 & \pm 0.01 & 0.19 & \pm 0.01 & 0.78 & . & 0.04 & 0.59 & \pm 0.03 & 53 & \pm 0.03 & 0.46 & \pm 0.02 & 0.23 & \pm 0.01 & $0.16 \pm 0.01$ & $0.16 \pm 0.01$ & $0.12 \pm 0.01$ & $0.22 \pm 0.01$ & $0.12 \pm 0.01$ \\
\hline EPC87 & .21 & \pm 0.01 & 0.20 & \pm 0.01 & 0.41 & \pm 0.02 & 0.77 & & 0.04 & 0.59 & \pm 0.03 & 28 & \pm 0.06 & 1.24 & \pm 0.06 & 0.20 & \pm 0.01 & $0.41 \pm 0.02$ & $0.25 \pm 0.01$ & $0.31 \pm 0.02$ & $0.52 \pm 0.03$ & $0.30 \pm 0.02$ \\
\hline Т 30 & 24 & \pm 0.01 & 0.27 & \pm 0.01 & 91 & \pm 0.05 & 0.63 & & 0.03 & 0.31 & \pm 0.02 & 79 & \pm 0.04 & 1.23 & \pm 0.06 & 0.41 & \pm 0.02 & $0.25 \pm 0.01$ & $0.18 \pm 0.01$ & $0.37 \pm 0.02$ & $0.75 \pm 0.04$ & $1.17 \pm 0.06$ \\
\hline HET64 & .25 & \pm 0.06 & 0.34 & \pm 0.02 & 0.56 & \pm 0.03 & 0.33 & \pm & 0.02 & 0.75 & \pm 0.04 & 3.09 & \pm 0.15 & 0.79 & \pm 0.04 & 0.67 & \pm 0.03 & $0.49 \pm 0.02$ & $0.39 \pm 0.02$ & $0.61 \pm 0.03$ & $0.68 \pm 0.03$ & $0.70 \pm 0.04$ \\
\hline PS67a & 0.17 & \pm 0.01 & 0.32 & \pm 0.02 & 2.10 & \pm 0.11 & 11.18 & \pm & 0.56 & 0.43 & \pm 0.02 & 0.31 & \pm 0.02 & 0.28 & \pm 0.01 & 0.67 & \pm 0.03 & $0.31 \pm 0.02$ & $0.11 \pm 0.01$ & $0.15 \pm 0.01$ & $0.27 \pm 0.01$ & $0.22 \pm 0.01$ \\
\hline SP05 & 0.25 & \pm 0.01 & 0.25 & \pm 0.01 & 0.08 & \pm 0.00 & - & \pm & 0.00 & 0.16 & \pm 0.01 & 0.13 & \pm 0.01 & 0.40 & \pm 0.02 & 0.07 & \pm 0.00 & $0.17 \pm 0.01$ & $0.31 \pm 0.02$ & $0.36 \pm 0.02$ & $0.22 \pm 0.01$ & $0.18 \pm 0.01$ \\
\hline SP11 & 0.49 & \pm 0.02 & 0.13 & \pm 0.01 & 0.48 & \pm 0.02 & 0.63 & \pm & 0.03 & 0.37 & \pm 0.02 & 0.54 & \pm 0.03 & 0.55 & \pm 0.03 & 0.25 & \pm 0.01 & $0.14 \pm 0.01$ & $0.17 \pm 0.01$ & $0.44 \pm 0.02$ & $0.38 \pm 0.02$ & $0.23 \pm 0.01$ \\
\hline SP38 & 0.09 & \pm 0.00 & 0.15 & \pm 0.01 & 0.07 & \pm 0.00 & - & + & 0.00 & 0.78 & \pm 0.04 & 0.06 & \pm 0.00 & 0.58 & \pm 0.03 & 0.08 & \pm 0.00 & $0.07 \pm 0.00$ & $0.17 \pm 0.01$ & $0.34 \pm 0.02$ & $0.13 \pm 0.01$ & $0.07 \pm 0.00$ \\
\hline SP57 & 0.11 & \pm 0.01 & 0.21 & \pm 0.01 & 0.13 & \pm 0.01 & 0.38 & 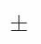 & 0.02 & 0.43 & \pm 0.02 & 0.27 & \pm 0.01 & 0.29 & \pm 0.01 & 0.61 & \pm 0.03 & $0.16 \pm 0.01$ & $0.17 \pm 0.01$ & $0.08 \pm 0.00$ & $0.26 \pm 0.01$ & $0.22 \pm 0.01$ \\
\hline SP68 & 0.09 & \pm 0.00 & 0.21 & \pm 0.01 & 0.19 & \pm 0.01 & - & 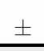 & 0.00 & 0.33 & \pm 0.02 & 0.20 & \pm 0.01 & 0.34 & \pm 0.02 & 0.32 & \pm 0.02 & $0.08 \pm 0.00$ & $0.18 \pm 0.01$ & $0.11 \pm 0.01$ & $0.18 \pm 0.01$ & $0.13 \pm 0.01$ \\
\hline \multirow{3}{*}{$\begin{array}{l}\text { Forest } \\
\text { site }\end{array}$} & \multicolumn{22}{|c|}{ monthly Na conc. $\left(\mathrm{mg} \mathrm{L}^{-1}\right)$} \\
\hline & \multicolumn{22}{|c|}{ Throughfall } \\
\hline & \multicolumn{2}{|c|}{ Sept.16 } & \multicolumn{2}{|c|}{ Oct.16 } & & ov. 16 & & ec. 1 & & & in. 17 & & ebr. 17 & $\mathrm{Ma}$ & irch. 17 & & pr. 17 & May.17 & June. 17 & July.17 & Aug. 17 & Sept.17 \\
\hline CHP59 & 0.60 & \pm 0.03 & 1.21 & \pm 0.06 & 1.52 & \pm 0.08 & 2.06 & \pm & 0.10 & 1.10 & \pm 0.06 & 1.27 & \pm 0.06 & 1.56 & \pm 0.08 & 1.83 & \pm 0.09 & $2.91 \pm 0.15$ & $2.26 \pm 0.11$ & $1.39 \pm 0.07$ & $0.91 \pm 0.05$ & $1.13 \pm 0.06$ \\
\hline CHS41 & 0.77 & \pm 0.04 & 1.17 & \pm 0.06 & 1.39 & \pm 0.07 & 1.19 & \pm & 0.06 & 0.78 & \pm 0.04 & 1.57 & \pm 0.08 & 2.36 & \pm 0.12 & 1.05 & \pm 0.05 & $1.37 \pm 0.07$ & $0.65 \pm 0.03$ & $0.46 \pm 0.02$ & $1.51 \pm 0.08$ & $0.76 \pm 0.04$ \\
\hline CPS77 & 0.65 & \pm 0.03 & 1.26 & \pm 0.06 & 1.57 & \pm 0.08 & 0.93 & \pm & 0.05 & 1.18 & \pm 0.06 & 1.44 & \pm 0.07 & 1.32 & \pm 0.07 & 0.86 & \pm 0.04 & $2.12 \pm 0.11$ & $0.97 \pm 0.05$ & $0.62 \pm 0.03$ & $0.98 \pm 0.05$ & $0.36 \pm 0.02$ \\
\hline $\mathrm{EPC} 08$ & 2.63 & \pm 0.13 & 1.78 & \pm 0.09 & 1.17 & \pm 0.06 & 3.24 & \pm & & 1.54 & \pm 0.08 & 2.10 & \pm 0 & 1.79 & \pm 0.09 & 3.86 & \pm 0 & $2.46 \pm 0$ & $1.45 \pm 0.07$ & $1.20 \pm c$ & $1.30 \pm 0$ & $0.48 \pm 0.02$ \\
\hline & 1.03 & \pm 0.05 & 0.57 & \pm 0.03 & 0.88 & \pm 0.0 & 1.18 & \pm & & 0.48 & \pm 0.02 & 2.25 & \pm 0.11 & 2.07 & \pm 0.10 & 1.86 & \pm 0.09 & $1.29 \pm 0$ & $0.90 \pm 0.05$ & $0.73 \pm 0$ & $1.27 \pm$ & $0.87 \pm$ \\
\hline EPC87 & 0.91 & \pm 0.05 & 0.44 & \pm 0.02 & 0.80 & \pm 0.04 & 2.01 & & 0 & 1.29 & \pm 0.06 & 3.71 & \pm 0.19 & 3.16 & \pm 0.16 & 0.85 & \pm 0.04 & $1.38 \pm 0.07$ & $0.70 \pm 0.04$ & $0.84 \pm 0.04$ & $0.83 \pm 0.04$ & 0.69 \\
\hline 30 & 0.35 & \pm 0.02 & 0.30 & \pm 0.02 & 0.79 & \pm 0.04 & 0.69 & \pm & 3 & 0.33 & \pm 0.02 & 0.74 & \pm 0.04 & 2.38 & \pm 0.12 & 0.80 & \pm 0.04 & $0.38 \pm 0.02$ & $0.56 \pm 0.03$ & $1.06 \pm 0.05$ & $1.00 \pm 0.05$ & $1.27 \pm 0.06$ \\
\hline HET64 & 1.70 & \pm 0.09 & 1.01 & \pm 0.05 & 1.12 & \pm 0.06 & 5.81 & \pm & 29 & 0.81 & \pm 0.04 & 5.99 & \pm 0.30 & 1.82 & \pm 0.09 & 0.72 & \pm 0.04 & $1.49 \pm 0.07$ & $1.02 \pm 0.05$ & $0.99 \pm 0.05$ & $1.35 \pm 0.07$ & $1.07 \pm 0.05$ \\
\hline PS67a & 0.84 & \pm 0.04 & 0.75 & \pm 0.04 & 0.42 & \pm 0.02 & 1.65 & \pm & 0.08 & 1.12 & \pm 0.06 & 1.39 & \pm 0.07 & 1.21 & \pm 0.06 & 3.30 & \pm 0.17 & $0.91 \pm 0.05$ & $0.44 \pm 0.02$ & $0.97 \pm 0.05$ & $0.87 \pm 0.04$ & $0.35 \pm 0.02$ \\
\hline SP05 & 0.80 & \pm 0.04 & 0.81 & \pm 0.04 & 0.12 & \pm 0.01 & - & \pm & 0.00 & 0.57 & \pm 0.03 & 0.22 & \pm 0.01 & 0.58 & \pm 0.03 & 0.29 & \pm 0.01 & $0.34 \pm 0.02$ & $0.26 \pm 0.01$ & $0.84 \pm 0.04$ & $0.94 \pm 0.05$ & $0.38 \pm 0.02$ \\
\hline SP11 & 2.88 & \pm 0.14 & 1.92 & \pm 0.10 & 1.41 & \pm 0.07 & 1.42 & \pm & 0.07 & 0.63 & \pm 0.03 & 2.34 & \pm 0.12 & 2.38 & \pm 0.12 & 0.54 & \pm 0.03 & $1.75 \pm 0.09$ & $1.40 \pm 0.07$ & $3.35 \pm 0.17$ & $3.72 \pm 0.19$ & $2.56 \pm 0.13$ \\
\hline & 0.41 & \pm 0.02 & 0.78 & \pm 0.04 & 0.15 & \pm 0.01 & - & \pm & 0.00 & 0.20 & \pm 0.01 & 0.16 & \pm 0.01 & 0.54 & \pm 0.03 & 0.55 & \pm 0.03 & $0.17 \pm 0.01$ & $0.23 \pm 0.01$ & $0.30 \neq 0.02$ & $0.24 \pm 0.01$ & $0.18 \pm 0.01$ \\
\hline & 0.89 & \pm 0.04 & 1.09 & \pm 0.05 & 0.74 & \pm 0.04 & 1.29 & \pm & 0.06 & 2.20 & \pm 0.11 & 0.86 & \pm 0.04 & 0.94 & \pm 0.05 & 1.49 & \pm 0.07 & $0.81 \pm 0.04$ & $0.69 \pm 0.03$ & $0.74 \pm 0.04$ & $0.93 \pm 0.05$ & $0.92 \pm 0.05$ \\
\hline SP68 & 0.44 & \pm 0.02 & 0.96 & \pm 0.05 & 0.34 & \pm 0.02 & - & \pm & 0.00 & 0.97 & \pm 0.05 & 0.68 & \pm 0.03 & 0.66 & \pm 0.03 & 1.37 & \pm 0.07 & $0.45 \pm 0.02$ & $0.44 \pm 0.02$ & $0.67 \pm 0.03$ & $0.76 \pm 0.04$ & $0.52 \pm 0.03$ \\
\hline
\end{tabular}


Table S9. Monthly potassium concentrations in rainfall and throughfall in study sites ( $\mathrm{n}=14$ sites).

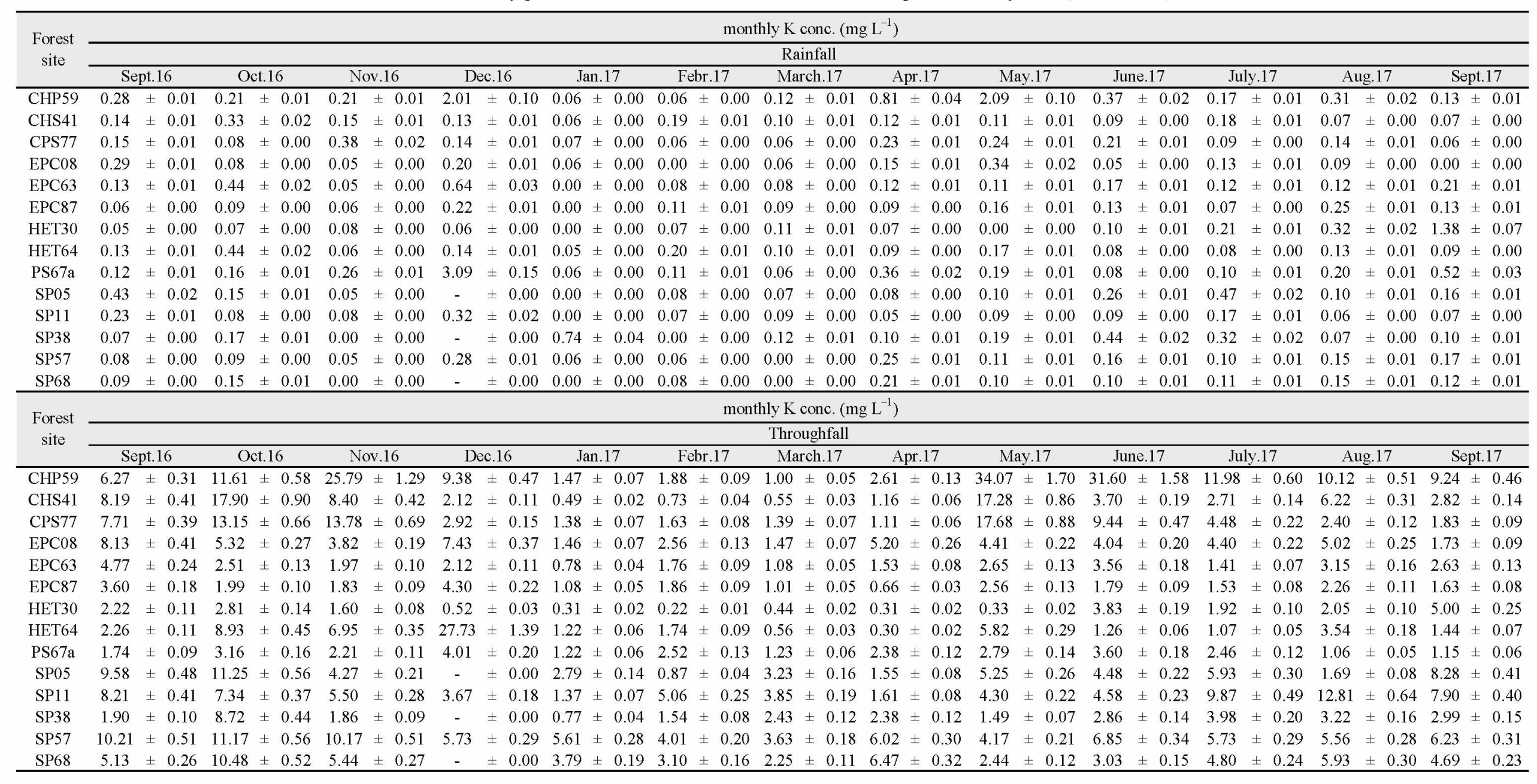

